\title{
Rastreamento de componentes conexas em vídeo $3 D$ para obtenção de estruturas tridimensionais
}

\author{
David da Silva Pires \\ DISSERTAÇÃO APRESENTADA \\ AO \\ INSTITUTO DE MATEMÁTICA E ESTATÍSTICA \\ DA \\ UNIVERSIDADE DE SÃO PAULO \\ PARA \\ OBTENÇÃO DO TÍTULO DE MESTRE \\ EM \\ CIÊNCIAS

\section{Área de Concentração: Computação \\ Orientador: Prof. Dr. Roberto Marcondes Cesar Junior} \\ Durante a elaboração deste trabalho o autor recebeu auxílio financeiro da CAPES
}

- São Paulo, 17 de agosto de 2007 - 



\title{
Rastreamento de componentes conexas em vídeo $3 D$ para obtenção de estruturas tridimensionais
}

\author{
David da Silva Pires
}

\author{
Este exemplar corresponde à redação final \\ da dissertação devidamente corrigida e \\ defendida por David da Silva Pires e \\ aprovada pela Comissão Julgadora.
}

- São Paulo, 17 de agosto de 2007 -

Banca Examinadora:

Prof. Dr. Roberto Marcondes Cesar Junior (orientador)—IME/USP

Prof. Dr. Roberto Hirata Junior-IME/USP

Prof. Dr. Luiz Carlos Pacheco Rodrigues Velho-IMPA 



\title{
RASTREAMENTO DE COMPONENTES CONEXAS EM VÍdeo 3D Para ObTENÇÃo DE ESTRUTURAS TRIDIMENSIONAIS
}

\author{
DISSERTAÇÃO \\ CIÊNCIA DA COMPUTAÇÃO
}

\author{
Aluno: David da Silva Pires \\ davidspevision.ime.usp.br \\ № USP: 2.945.710
}

\author{
ORIENTAdor: Roberto MARCONDES Cesar Junior \\ http://www.vision.ime.usp.br/creativision/ \\ http://www.vision.ime.usp.br/ davidsp/ \\ DCC - Departamento de CiênCIA dA COMPUTAÇÃo \\ IME - INSTITUTO DE MATEMÁtiCA E EstatísticA \\ USP - UNIVERSIDADE DE SÃo PAULO \\ Rua do Matão, 1010 - Cidade Universitária \\ CEP 05508-090 - São Paulo - SP - Brasil \\ Telefone: +55 11 3091-6111 \\ Fax: +55 $113814-4135$
}

17 de agosto de 2007 

A meus queridos pais, Antonio e Dulcinéia, por todo o apoio que deram à minha educação. 



\section{Tabela de Conteúdo}

Lista de Símbolos $\quad$ xi

Lista de Figuras $\quad$ xv

Lista de Tabelas $\quad$ xvii

Resumo $\quad$ xix

$\begin{array}{ll}\text { Abstract } & \mathbf{x x i}\end{array}$

Apresentação $\quad$ xxiii

Agradecimentos $\quad$ xxvii

$\begin{array}{lll}\text { Capítulo } 1 & \text { Introdução } & 1\end{array}$

$\begin{array}{lll}\text { CAPítulo } 2 & \text { Revisão Bibliográfica } & 17\end{array}$

Capítulo 3 Vídeo 3D 44

Capítulo 4 Rastreamento e Registro de CCs 3D 69

$\begin{array}{lll}\text { Capítulo } 5 & \text { Resultados Experimentais } & 85\end{array}$

Capítulo 6 Conclusão $\quad 93$

Capítulo A Código Desenvolvido $\quad 105$

$\begin{array}{ll}\text { Referências Bibliográficas } & 111\end{array}$

$\begin{array}{ll}\text { Índice Remissivo } & 121\end{array}$

$\begin{array}{lr}\text { Notas Finais } & 129\end{array}$ 



\section{Sumário}

Lista de Símbolos $\quad$ xi

Lista de Figuras $\quad$ xv

Lista de Tabelas $\quad$ xvii

Resumo $\quad$ xix

$\begin{array}{ll}\text { Abstract } & \text { xxi }\end{array}$

Apresentação $\quad$ xxiii

$\begin{array}{ll}\text { Agradecimentos } & \text { xxvii }\end{array}$

Capítulo 1 Introdução 1

1.1 Considerações Preliminares: Vídeo Digital . . . . . . . . . . . . . 1

1.1 .1 O Formato Digital . . . . . . . . . . . . . . . 1

1.1.2 A Revolução do Vídeo Digital . . . . . . . . . . . . . . . . . 2

1.2 O Que É Vídeo 3D? . . . . . . . . . . . . . . . . . . . . . 3

1.2.1 A Execução em Tempo Real . . . . . . . . . . . . 6

1.3 Modelagem 3D . . . . . . . . . . . . . . . . 7

1.3.1 Modelagem 3D Passo a Passo . . . . . . . . . . . 7

1.3.2 Aquisição de Dados de Geometria . . . . . . . . . . . . . 7

1.3 .3 Registro . . . . . . . . . . . . . 8

1.3.4 Integração e Aquisição de Dados de Reflexão . . . . . . . 9

1.4 Breve Descrição da Metodologia Introduzida . . . . . . . . . . . 10

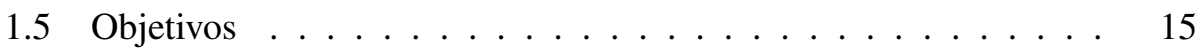

1.6 Organização do Texto . . . . . . . . . . . . . . 15

Capítulo 2 Revisão Bibliográfica $\quad 17$

2.1 Visão Computacional: Dados Tridimensionais a partir de Imagens 18

2.1.1 Reconstrução de Formas . . . . . . . . . . . . . . . . . 19

2.2 Luz Estruturada e o Problema da Correspondência . . . . . . . . . 19

2.2 .1 Visão Estéreo . . . . . . . . . . . . . . . . 20

2.2.2 Luz Estruturada . . . . . . . . . . . . . . . . . . 23

2.2.3 Mensuração de Superfícies . . . . . . . . . . . . . . . . . . 25

2.2.4 Codificação do Padrão Projetado . . . . . . . . . . . . . 28 
2.2.5 Conclusões . . . . . . . . . . . . . . . 30

2.3 O Algoritmo ICP (Iterative Closest Point) . . . . . . . . . . . . . . . 32

$2.3 .1 \quad$ Variantes do ICP . . . . . . . . . . . . . . . . 34

2.3.2 Registro Inicial e Registro Multivisão . . . . . . . . . . . . . 35

2.4 Biblioteca de Malha Dinâmica Adaptativa . . . . . . . . . . . . . . 36

2.4 .1 Visão Geral . . . . . . . . . . . . . . . . 36

Capítulo 3 Vídeo 3D 4

3.1 Introdução . . . . . . . . . . . . . . . . . . 42

3.2 Trabalhos Relacionados . . . . . . . . . . . . . . . 44

3.3 O Método $(\mathrm{b}, \mathrm{s})-\mathrm{BCSL} \ldots \ldots \ldots \ldots$

3.3 .1 Codificação . . . . . . . . . . . . . . . . . . 48

3.3 .2 Decodificação . . . . . . . . . . . . . . . . . . . . 49

3.4 Características do Sistema . . . . . . . . . . . . 52

3.4.1 Geração de padrões de cores $(\mathrm{b}, \mathrm{s})$-BCSL . . . . . . . 52

3.4 .2 Requisitos do Projetor . . . . . . . . . . . . . . 53

3.4 .3 Requisitos da Câmera . . . . . . . . . . . . . . 53

3.4 .4 Calibração de Cores . . . . . . . . . . . . . . . . 54

3.5 Pipeline do Processamento do Fluxo . . . . . . . . . . . . 55

3.5.1 Projeção e Captura dos Padrões de Cores . . . . . . . . . 55

3.5.2 Detecção de Bordas das Faixas e Cores . . . . . . . . . . 57

3.5.3 Correspondência Câmera/Projetor . . . . . . . . . . 60

3.5.4 Reconstrução da Colorimetria e da Geometria . . . . . . . 62

3.5.5 Tradeoffs de Qualidade . . . . . . . . . . . . . . . . 62

3.5.6 Pipeline do Sistema . . . . . . . . . . . . . . 64

3.6 Sumário e Conclusões . . . . . . . . . . . . . . . . . 67

3.7 Formalização Matemática de Vídeo 3D . . . . . . . . . . . . . 68

Capítulo 4 Rastreamento e Registro de CCs 3D 69

4.1 Visão Geral da Abordagem Proposta . . . . . . . . . . . . . . 70

4.2 Detecção de Componentes Conexas . . . . . . . . . . . . . . . 76

4.3 Rastreamento de Componentes Conexas . . . . . . . . . . . . . 77

4.4 Registro de Componentes Conexas . . . . . . . . . . . . . . 80

4.5 Aplicações Desenvolvidas . . . . . . . . . . . . . . 83

Capítulo 5 Resultados Experimentais $\quad 85$

5.1 Rastreamento e Casamento de Componentes Conexas . . . . . . . 85

5.2 Aplicação da Malha e Sistema de Visualização . . . . . . . . . . 89 
Capítulo 6 Conclusão $\quad 93$

6.1 Discussão . . . . . . . . . . . . . . . . . . . . . . . . . . . 94

6.2 Trabalhos Futuros . . . . . . . . . . . . . . 95

6.2 .1 ICP . . . . . . . . . . . . . . . . . 97

6.2 .2 Kalman . . . . . . . . . . . . . . . . 98

6.2.3 A Malha Dinâmica Adaptativa A48 . . . . . . . . . . . 98

6.2.4 Uso da Textura para o Rastreamento de CCs . . . . . . . . 102

6.3 Considerações Finais . . . . . . . . . . . . . . . . 103

\section{Capítulo A Código Desenvolvido 105}

A.1 Rastreamento de CCs . . . . . . . . . . . . . . . . . . . 105

A.2 Limitação do Número de Faces e de Arestas em Relação ao Número de Vértices . . . . . . . . . . . . . . . . . . . . . 108

$\begin{array}{ll}\text { Referências Bibliográficas } & 111\end{array}$

$\begin{array}{ll}\text { Índice Remissivo } & 121\end{array}$

$\begin{array}{lr}\text { Notas Finais } & 129\end{array}$ 



\section{Lista de Símbolos}

\section{Convenções Tipográficas}

As convenções adotadas para a tipografia matemática neste documento seguem as reconhecidas pela Organização Internacional de Padrões (ISO, do inglês International Standards Organization), cujos elementos essenciais foram apresentados em um artigo de Beccari, em 1997, juntamente com a descrição de como a tipografia pode ser obedecida com o uso de $\mathrm{LT}_{\mathrm{E}} \mathrm{X}$. Os pontos mais importantes dos padrões adotados são:

Números possuem tipografia com fonte do tipo romana: 42, 2, 7182, 3, 1415.

Variáveis simples são representadas por letras em itálico: $a, b, c, x, y, z$.

Vetores são escritos em itálico e negrito: $\boldsymbol{v}, \boldsymbol{\nu}, \boldsymbol{\omega}$.

Matrizes aparecem em uma fonte sem serifa: $M, R, T$.

Números especiais (como a unidade imaginária i), constantes numéricas (e.g., e, $\pi$ ), assim como o operador diferencial d, são escritos em uma fonte direita (upright) para enfatizar que não são variáveis.

Uma medida consistindo de um número mais uma dimensão é uma unidade indivisível, com um espaço menor que o normal entre eles, como em $5,3 \mathrm{~km}$ e $62 \mathrm{~kg}$. A dimensão é dada em uma fonte direita.

Quando um número é menor que a unidade em valor absoluto, o fato deve ser indicado explicitamente com um 'zero' precedendo o separador decimal. Assim, é necessário escrever 0.123456 e -0.789 em vez de .123456 e -.789, respectivamente.

\section{Símbolos Usados}

\begin{tabular}{|c|l|}
\hline Símbolo & Descrição \\
\hline$\pi_{i}$ & i-ésimo plano de imagem, $i \in\{1,2\}$. \\
\hline$O$ & Origem do centro de projeção da câmera. \\
\hline$O_{i}$ & $\begin{array}{l}\text { Origem do sistema de coordenadas do plano de } \\
\text { imagem } \pi_{i}, i \in\{1,2\} .\end{array}$ \\
\hline
\end{tabular}

Continua na próxima página. 
Continuação.

\begin{tabular}{|c|c|}
\hline Símbolo & Descrição \\
\hline$\left(x_{i}, y_{i}, z_{i}\right)$ & $\begin{array}{l}\text { Sistema de coordenadas do plano de imagem } \pi_{i} \\
i \in\{1,2\} \text {. }\end{array}$ \\
\hline$x_{i}$ & $\begin{array}{l}\text { Eixo das abscissas do sistema de coordenadas do } \\
\text { plano de imagem } \pi_{i}, i \in\{1,2\} \text {. }\end{array}$ \\
\hline$y_{i}$ & $\begin{array}{l}\text { Eixo das ordenadas do sistema de coordenadas } \\
\text { do plano de imagem } \pi_{i}, i \in\{1,2\} \text {. }\end{array}$ \\
\hline$z_{i}$ & $\begin{array}{l}\text { Eixo das cotas do sistema de coordenadas do } \\
\text { plano de imagem } \pi_{i}, i \in\{1,2\} \text {. Coincide com o } \\
\text { eixo óptico da câmera } i \text {. }\end{array}$ \\
\hline$x_{i} y_{i}$ & $\begin{array}{l}\text { Representação equivalente ao plano } \pi_{i}, i \in \\
\{1,2\} .\end{array}$ \\
\hline$F_{i}$ & Ponto focal da câmera $i, i \in\{1,2\}$. \\
\hline$f_{i}$ & Distância focal da câmera $i, i \in\{1,2\}$. \\
\hline$(x, y, z)$ & Coordenadas de um vetor no espaço 3D. \\
\hline $\mathrm{R}$ & $\begin{array}{l}\text { Matriz ortonormal } 3 \times 3 \text { que representa a rotação } \\
\text { do sistema de coordenadas } O_{2} \text { em relação a } O_{1} \text {. }\end{array}$ \\
\hline $\mathrm{T}$ & $\begin{array}{l}\text { Representação matricial do vetor que descreve } \\
\text { a translação do sistema de coordenadas } O_{2} \text { em } \\
\text { relação a } O_{1} \text {. }\end{array}$ \\
\hline$P_{0}$ & $\begin{array}{l}\text { Ponto de um objeto no espaço } 3 \mathrm{D} \text {, chamado de } \\
\text { ponto objeto. }\end{array}$ \\
\hline$P_{i}$ & $\begin{array}{l}\text { Projeção do ponto } P_{0} \text { no plano de imagem } \pi_{i}, \\
i \in\{1,2\} \text {. }\end{array}$ \\
\hline$\left(x_{P_{0}}, y_{P_{0}}, z_{P_{0}}\right)$ & Coordenadas de $P_{0}$ com relação a $O_{1}$. \\
\hline$\left(x_{P_{0}}^{\prime}, y_{P_{0}}^{\prime}, z_{P_{0}}^{\prime}\right)$ & Coordenadas de $P_{0}$ com relação a $O_{2}$. \\
\hline$\left(x_{P_{i}}, y_{P_{i}}, 0\right)$ & Coordenadas de $P_{i}$ com relação a $O_{i}, i \in\{1,2\}$. \\
\hline$\alpha$ & Escalar usado para obter $P_{1}$ a partir de $P_{0}$ e $F_{1}$. \\
\hline$\beta$ & Escalar usado para obter $P_{2}$ a partir de $P_{0}$ e $F_{2}$. \\
\hline$l$ & Reta definida pelos pontos $F_{1}$ e $P_{0}$. \\
\hline $\mathrm{A}^{T}$ & $\mathrm{O} T$ sobrescrito indica a transposta da matriz $\mathrm{A}$. \\
\hline M & $\begin{array}{l}\text { Matriz que descreve a rotação e a translação do } \\
\text { sistema de coordenadas } \mathrm{O}_{2} \text { em relação a } O \text {. }\end{array}$ \\
\hline
\end{tabular}

Continua na próxima página. 
Continuação.

\begin{tabular}{|c|c|}
\hline Símbolo & Descrição \\
\hline$\overline{P_{2}}$ & $\begin{array}{l}\text { Representação de } P_{2} \text { no sistema de coordenadas } \\
O \text {. }\end{array}$ \\
\hline$O(1)$ & Notação assintótica para uma função constante. \\
\hline$S_{k} \overline{S_{k}}$ & $\begin{array}{l}\text { Par de padrões de faixas coloridas. O padrão } \overline{S_{k}} \\
\text { contém a cor complementar à do padrão } S_{k} .\end{array}$ \\
\hline$S_{1} \overline{S_{1}} S_{2} \overline{S_{2}}$ & $\begin{array}{l}\text { Sequiência de pares de padrões complementares } \\
\text { usada no código }(b, s) \text {-BCSL. }\end{array}$ \\
\hline$S_{i j}$ & $\begin{array}{l}\text { Representação de dois padrões, } S_{i} \text { e } S_{j} \text { que se } \\
\text { casam ao se comparar dois quadros consecuti- } \\
\text { vos. }\end{array}$ \\
\hline $\mathbf{C C}$ & Abreviação usada para componente conexa. \\
\hline$(u, v)$ & $\begin{array}{l}\text { Coordenadas de um pixel na textura, correspon- } \\
\text { dentes a abscissa e ordenada, respectivamente. }\end{array}$ \\
\hline$R(u, v)$ & $\begin{array}{l}\text { Função que fornece o valor da banda vermelha } \\
\text { (red) do pixel na posição }(u, v) \text { da textura. }\end{array}$ \\
\hline$G(u, v)$ & $\begin{array}{l}\text { Mesmo que o anterior, porém fornece o valor da } \\
\text { banda verde (green). }\end{array}$ \\
\hline$B(u, v)$ & $\begin{array}{l}\text { Mesmo que o anterior, porém fornece o valor da } \\
\text { banda azul (blue). }\end{array}$ \\
\hline$c(u, v)$ & $\begin{array}{l}\text { Função de cor. Fornece a cor de um pixel } \\
\text { que se encontra na coordenada }(u, v) \text { na } \\
\text { textura. Uma vez que trabalhamos com o } \\
\text { espaço de cores RGB, temos que } c(u, v)= \\
(R(u, v), G(u, v), B(u, v)) \text {. }\end{array}$ \\
\hline$c(u, v, t)$ & $\begin{array}{l}\text { Semelhante ao anterior, porém refere-se à textura } \\
\text { correspondente ao quadro no tempo } t \text { do vídeo. }\end{array}$ \\
\hline$d(u, v)$ & $\begin{array}{l}\text { Função de profundidade. Fornece o valor da pro- } \\
\text { fundidade do pixel de coordenada }(u, v) \text { na tex- } \\
\text { tura. }\end{array}$ \\
\hline$d(u, v, t)$ & $\begin{array}{l}\text { Semelhante ao anterior, porém refere-se à pro- } \\
\text { fundidade correspondente à do quadro no tempo } \\
t \text { do vídeo. }\end{array}$ \\
\hline$P$ & Ponto amostrado na imagem de profundidade. \\
\hline
\end{tabular}

Continua na próxima página. 
Continuação.

\begin{tabular}{|c|c|}
\hline Símbolo & Descrição \\
\hline$p$ & $\begin{array}{l}\text { Pixel de coordenadas }(u, v) \text { associado ao ponto } \\
P \text { ou índice de uma faixa projetada no padrão } \\
\text { (b, s)-BCSL de luz estruturada. Também é usado } \\
\text { como nome do eixo das abscissas no sistema de } \\
\text { coordenadas da câmera. }\end{array}$ \\
\hline$w_{P}$ & Profundidade do ponto $P$. \\
\hline$v$ & Vetor direção de $P$. \\
\hline$w$ & $\begin{array}{l}\text { Indica a distância até a origem do centro de } \\
\text { projeção. }\end{array}$ \\
\hline$r$ & $\begin{array}{l}\text { Vetor que indica o raio de visão determinado } \\
\text { pelo centro de projeção e pelo ponto } P \text {. }\end{array}$ \\
\hline$j$ & $\begin{array}{l}\text { Coordenada que representa a linha no espaço da } \\
\text { câmera. }\end{array}$ \\
\hline$l_{x}$ & Rótulo de uma componente conexa. \\
\hline$L=\left\{l_{1}, l_{2}, \ldots, l_{|L|}\right\}$ & $\begin{array}{l}\text { Conjunto de rótulos de componentes conexas em } \\
\text { cada quadro de um vídeo. }\end{array}$ \\
\hline$l$ & $\begin{array}{l}\text { Limiar usado para definir se dois pontos em um } \\
\text { grafo estão conexos. }\end{array}$ \\
\hline$M$ & $\begin{array}{l}\text { Função de rastreamento } L \rightarrow L \text { de componentes } \\
\text { conexas. Faz o mapeamento de componentes } \\
\text { conexas entre quadros consecutivos de um vídeo. }\end{array}$ \\
\hline$c$ & Representa uma componente conexa. \\
\hline$c_{1}, c_{2}, \ldots, c_{n}$ & Componentes conexas presentes em um quadro. \\
\hline$m\left(c, c_{i}\right)$ & $\begin{array}{l}\text { Diferença média entre as coordenadas de pro- } \\
\text { fundidade das componentes conexas } c \text { e } c_{i} \text {, para } \\
i=1,2, \ldots, n \text {. }\end{array}$ \\
\hline$d_{\max }$ & $\begin{array}{l}\text { Limiar de distância máximo usado para determi- } \\
\text { nar se uma componente conexa é nova na cena. }\end{array}$ \\
\hline$c\left(u, v, t_{1}\right) \circ c\left(u, v, t_{2}\right)$ & Correlação entre duas porções de textura. \\
\hline
\end{tabular}




\section{Lista de Figuras}

1.1 Representação 3D em superfícies 2D . . . . . . . . . . . . . 3

1.2 Exemplo de um tour into the picture . . . . . . . . . . . . . . 4

1.3 O vídeo interativo . . . . . . . . . . . . . . . . 5

1.4 Etapas que constituíram o trabalho . . . . . . . . . . . . . 10

1.5 Projeto de visão computacional . . . . . . . . . . . . . . . . 11

1.6 Fluxograma das atividades concluídas no mestrado . . . . . . . . 13

1.7 Visão geral do esquema proposto . . . . . . . . . . . . . . . 14

2.1 Sistema estereoscópico . . . . . . . . . . . . . . . . . 21

2.2 Sistema de mensuração usado em luz estruturada . . . . . . . . . 26

2.3 Ilustração do algoritmo ICP . . . . . . . . . . . . . . . . . . 33

2.4 Vantagem do algoritmo de Chen e Medioni . . . . . . . . . . 34

3.1 Hardware usado . . . . . . . . . . . . . . . . . . . . . 45

3.2 Grafo $(3,2)$-BCSL e seu esquema de vizinhança . . . . . . . . . . 49

3.3 (3, 2)-BCSL usando R, G e B como base . . . . . . . . . . . 50

3.4 Exemplo de código de fronteira . . . . . . . . . . . . . 50

3.5 Hardware do vídeo 3D . . . . . . . . . . . . . . . 56

3.6 Padrões coloridos . . . . . . . . . . . . . . . . 57

3.7 Exemplo de calibração de cor . . . . . . . . . . . . . . . . 58

3.8 Detecção de cor e fronteira . . . . . . . . . . . . . . . . . 59

3.9 Decodificação das transições de faixas usando (6, 2)-BCSL . . . . 61

3.10 Esquema de captura da textura e da geometria . . . . . . . . 63

3.11 Sequiência de passos do sistema do IMPA . . . . . . . . . . . 65

3.12 Composição de cena virtual . . . . . . . . . . . . . . . 66

3.13 Reconstrução de coelho e caixa . . . . . . . . . . . . . . . . . 66

3.14 Movimento de face e boca . . . . . . . . . . . . . . 66

3.15 Pessoa caminhando em frente a um plano . . . . . . . . . . 67

4.1 Taxa de Nyquist . . . . . . . . . . . . . . . . . . 72

4.2 Sistemas de coordenadas . . . . . . . . . . . . . . 73

4.3 Sistema de coordenadas da câmera . . . . . . . . . . . . . 75

4.4 Proximidade no espaço discreto $(\mathrm{p}, \mathrm{v}) \ldots \ldots \ldots 76$

4.5 Possíveis casos . . . . . . . . . . . . . . . . 78

4.6 Área de sobreposição em quadros subseqüentes . . . . . . . . . 78

4.7 Rastreamento de componentes conexas que são divididas . . . . . 80

5.1 Rastreamento de componentes conexas em vídeo 3D . . . . . . 86

5.2 Segmentação da textura . . . . . . . . . . . . . . . . 87 
5.3 Translação baseada no casamento de textura . . . . . . . . . . . . 87

5.4 Dados de profundidade e pontos salientes . . . . . . . . . . 88

5.5 Casamento feito pelo algoritmo ICP . . . . . . . . . . . . . . 89

5.6 Aplicação da malha dinâmica adaptativa . . . . . . . . . . . . . . . . . . 90

5.7 Sistema de visualização . . . . . . . . . . . . . . . . . . . . . . . . . . 91

5.8 Visualizações do vídeo 3D . . . . . . . . . . . . . . . . . 92 


\section{Lista de Tabelas}

Símbolos usados ................... . . xi

1.1 Atividades concluídas no mestrado . . . . . . . . . . . . . 12

3.1 Tabela de decodificação para $(3,2)$-BCSL . . . . . . . . . . . 51 



\section{Resumo}

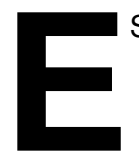

STE DOCUMENTO APRESENTA UMA DISSERTAÇÃO sobre o desenvolvimento de um sistema de integração de dados para geração de estruturas tridimensionais a partir de vídeo 3D.

O trabalho envolve a extensão de um sistema de vídeo 3D em tempo real proposto recentemente [Vieira et al., 2005]. Esse sistema, constituído por projetor e câmera, obtém imagens de profundidade de objetos por meio da projeção de slides com um padrão de faixas coloridas. Tal procedimento permite a obtenção, em tempo real, tanto do modelo $2 \frac{1}{2} \mathrm{D}$ dos objetos quanto da textura dos mesmos, segundo uma técnica denominada luz estruturada. Os dados são capturados a uma taxa de 30 quadros por segundo e possuem alta qualidade: resoluções de $640 \times 480$ pixeis para a textura e de $90 \times 240$ pontos (em média) para a geometria.

A extensão que essa dissertação propõe visa obter o modelo tridimensional dos objetos presentes em uma cena por meio do registro dos dados (textura e geometria) dos diversos quadros amostrados. Assim, o presente trabalho é um passo intermediário de um projeto maior, no qual pretende-se fazer a reconstrução dos modelos por completo, bastando para isso apenas algumas imagens obtidas a partir de diferentes pontos de observação. Tal reconstrução deverá diminuir a incidência de pontos de oclusão (bastante comuns nos resultados originais) de modo a permitir a adaptação de todo o sistema para objetos móveis e deformáveis ${ }^{1}$. Até onde pudemos averiguar, nenhuma técnica já foi aplicada com este propósito.

Este texto descreve o trabalho já desenvolvido, o qual consiste em um método para detecção, rastreamento e casamento espacial de componentes conexas presentes em um vídeo 3D. A informação de imagem do vídeo (textura) é combinada com posições tridimensionais (geometria) a fim de alinhar partes de superfícies que são vistas em quadros subseqüentes. Esta é uma questão chave no vídeo 3D, a qual pode ser explorada em diversas aplicações tais como compressão, integração geométrica e reconstrução de cenas, dentre outras. A abordagem que adotamos consiste na detecção de características salientes no espaço do mundo, provendo um alinhamento de geometria mais completo. O processo de registro é feito segundo a aplicação do algoritmo ICP-Iterative Closest Point-introduzido por Besl \& McKay [1992]. Resultados experimentais bem sucedidos [Pires et al., 2005] corroborando nosso método são apresentados.

\footnotetext{
${ }^{1}$ No estado atual, o sistema é robusto apenas para objetos estáticos e rígidos.
} 



\section{Abstract}

HIS DOCUMENT PRESENTS A MSC THESIS focused on the development
of a data integration system to generate tridimensional structures from 3D
video.

The work involves the extension of a recently proposed real time 3D video system [Vieira et al., 2005]. This system, composed by a video camera and a projector, obtains range images of recorded objects using slide projection of a coloured stripe pattern. This procedure allows capturing, in real time, objects texture and $2 \frac{1}{2} \mathrm{D}$ model, at the same time, by a technique called structured light. The data are acquired at 30 frames per second, being of high quality: the resolutions are $640 \times 480$ pixels and $90 \times 240$ points (in average), respectively.

The extension that this thesis proposes aims at obtaining the tridimensional model of the objects present in a scene through data matching (texture and geometry) of various sampled frames. Thus, the current work is an intermediary step of a larger project with the intent of achieving a complete reconstruction from only a few images obtained from different viewpoints. Such reconstruction will reduce the incidence of occlusion points (very common on the original results) such that it should be possible to adapt the whole system to moving and deformable objects ${ }^{1}$. To the best of our knowledge, there is no method that has fully solved this problem.

This text describes the developed work, which consists of a method to perform detection, tracking and spatial matching of connected components present in a 3D video. The video image information (texture) is combined with tridimensional sites (geometry) in order to align surface portions seen on subsequent frames. This is a key step in the 3D video that may be explored in several applications such as compression, geometric integration and scene reconstruction, to name but a few. Our approach consists of detecting salient features in both image and world spaces, for further alignment of texture and geometry. The matching process is accomplished by the application of the ICP-Iterative Closest Point-algorithm, introduced by Besl \& McKay [1992]. Succesful experimental results [Pires et al., 2005] corroborating our method are shown.

\footnotetext{
${ }^{1}$ In the current state, the system is robust only to static and rigid objects.
} 



\section{Apresentação}

A PRESENTE VERSÃO DESTE DOCUMENTO é própria para impressão. Uma versão eletrônica adequada para ser lida em um computador, contendo apontadores para as páginas citadas e para referências cruzadas, pode ser encontrada na URL citada na ficha técnica, última seção desta apresentação. Foi evitado ao máximo, em todo o texto, a referência a endereços na internet, devido às recorrentes mudanças que estes sofrem.

Espera-se que este documento seja útil para o aprendizado de alguns conceitos que foram dominados durante o mestrado e que desperte o interesse por uma continuação da pesquisa nesta área, que ainda tem tanto por fazer.

\section{Traduções Adotadas}

Levando em conta que nem sempre o jargão de um grupo de pesquisadores é o mesmo adotado sumariamente na área, segue uma pequena lista de termos técnicos que sofreram uma tradução livre na escrita deste documento, facilitando assim a correspondência com outros textos escritos na língua inglesa.

Também foram incluídos alguns itens que facilmente podem ser traduzidos de forma errônea se não for tomado o devido cuidado. O intuito deste segundo grupo de termos é de informar ou, no mínimo, entreter.

A decisão sobre o que é certo, errado ou razoável presente neste item foi tomada baseando-se em consultas feitas em diversos dicionários, gramáticas e artigos [e.g., Faraco \& Moura, 1992; Ferreira, 1986; Kon, 2006; Michaelis, 2000].

\section{Lista de traduções}

2-D Traduzido para 2D. Veja 3-D.

3-D Como já é de uso comum em textos da língua portuguesa, optou-se pela sigla $3 D$, refletindo melhor o termo tridimensional, que é adjetivo simples, diferentemente de seu correspondente em inglês, three-dimensional, que é adjetivo composto.

4-D Traduzido para 4D. Veja 3-D.

API Manteve-se a sigla API, do inglês Application Programming Interface, embora em português a tradução seja "Interface de Programação de Aplicativos". 
deformable Deformável, que pode ter sua forma alterada.

filtering Qual a tradução correta: filtragem, filtração ou filtramento? A resposta é qualquer uma. Escolha a que mais lhe agrada.

fps Sigla que vem do inglês frames per second. Traduzida para "qps", de "quadros por segundo".

half-edge Traduzido para meia-aresta.

mesh Traduzido para malha.

malleable Maleável, dúctil, flexível, dobrável.

pipeline Seqüência de passos a serem seguidos numa determinada ordem. Esse termo não foi traduzido, dado seu uso comum na área de ciência da computação.

predictive Encontra-se, em muitos textos, a tradução preditivo. No entanto, nenhuma das fontes consultadas inclui tal entrada. Como o significado é de aquele ou aquilo que prediz, profetiza ou diz antecipadamente, a tradução adotada foi preditor.

range image Imagem de profundidade, de alcance. Embora, devido à nomenclatura, possa parecer que uma imagem de profundidade possua informação de geometria para todo pixel da imagem, o que ocorre na verdade é que, devido às formas de obteção destas imagens (scanners laser, luz estruturada, etc.) a resolução da textura é significativamente maior que a da geometria. Não confundir com HDRI, do inglês High Dynamic Range Image, que é um tipo de imagem obtida a partir de técnicas que reúnem a informação de um grande intervalo dinâmico de exposições, ou seja, com uma grande diferença entre áreas escuras e claras.

register Registro, casamento. Registrar duas nuvens de pontos significa encontrar uma transformação que deva ser aplicada a uma delas de modo a minimizar uma determinada medida de distância.

upright Traduzido para "direita", termo usado para indicar que uma fonte está em sua forma normal, sem aplicação de itálico, inclinação ou versal.

\section{Ficha Técnica}

Seguem alguns dados referentes ao mestrado, às máquinas usadas para os experimentos e ao conteúdo deste documento.

Mestrado: 
Início: $1^{\circ}$ de março de 2004.

Exame de proficiência em línguas: aprovado em 19 de maio de 2005.

Exame de qualificação: fevereiro de 2006.

Defesa: 17 de agosto de 2007.

Formação anterior: Bacharel em Ciência da Computação-IME/USP.

Máquinas:

CPUs: Pentium IV com Hyper-threading e AMD Opteron 64 bits.

Memória RAM: 2 GB.

Banda de rede: gigabit, incluindo Rede Giga, da RNP (Rede Nacional de Ensino e Pesquisas do Ministério da Ciência e Tecnologia).

Conteúdo:

Assunto: Visão computacional e computação gráfica.

Palavras-chave: vídeo 3D, rastreamento de componentes conexas, casamento de componentes conexas, representação de componentes conexas, modelagem 3D, reconstrução 3D, geometria computacional.

Versão eletrônica: http://www.vision.ime.usp.br/ davidsp/ mestrado/dissertacao.pdf 



\section{Agradecimentos}

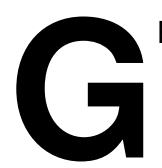

RANDE PARTE DO CONTEÚDO DESTE DOCUMENTO deve-se ao trabalho que desenvolvi em conjunto com meu orientador, Roberto Marcondes Cesar Junior, e com o professor Luiz Velho e o pós-doutorando Marcelo Bernardes Vieira, ambos do IMPA (Instituto Nacional de Matemática Pura e Aplicada). Devo sinceros agradecimentos a vocês três, autores de idéias originais e ótimos parceiros no trabalho em equipe.

Parte do salto qualitativo dado a partir do texto apresentado no exame de qualificação até a presente versão deveu-se às críticas feitas e sugestões dadas pelos integrantes da banca, de modo que sou grato a Carlos Hitoshi Morimoto e a Junior Barrera.

De março de 2005 a fevereiro de 2006 recebi apoio financeiro da CAPES (Coordenação de Aperfeiçoamento de Pessoal de Nível Superior), à qual também sou grato.

Sempre fui um entusiasta do software livre, em especial do Linux e de programas da GNU. Sou incapaz de enumerar as ferramentas livres que tornaram possível o desenvolvimento da pesquisa feita, tamanha é a sua quantidade. Meus agradecimentos se estendem a toda a comunidade de programadores, artistas, músicos, advogados e tantos outros profissionais que tornam o software livre realidade.

Durante todo o período do mestrado, participei da administração da Rede Vision, uma rede de computadores do IME-USP que possui usuários de diversas áreas da computação. Aprendi muito - e muito ainda tenho que aprender-tanto sobre administração de redes quanto sobre modos de se lidar com usuários. Neste aprendizado, fui aluno de pessoas que considero grandes administradores: Caetano Jimenez Carezzato, Roberto Marcondes Cesar Junior, Jesús Mena Chalco, Roberto Hirata Junior e Daniel André Vaquero. A vocês, meus agradecimentos por todo o aprendizado.

Embora eu pudesse ter desenvolvido a maior parte do trabalho em outros lugares, sempre optei por fazê-lo no laboratório da universidade, dado o ambiente de trabalho descontraído e cheio de amigos prontos a ajudar (mesmo que a resposta ao problema possa ser encontrada na internet). Estes e outros amigos também estiveram presentes em animadas discussões na sala do café ou a caminho do bandejão. Agradeço, portanto, a essas pessoas que, de certa forma, ajudaram-me a 
enfrentar o dia-a-dia durante o mestrado: Jishu Ashimine, Philipe Dalla Bernardina, Clodis Boscarioli, Kelly Rosa Braghetto, Elier Broche Cristo, Daniel Oliveira Dantas, Gustavo Henrique Esteves, Beatriz Stransky Ferreira, Edijane Paredes Garcia, Ana Beatriz Vicentim Graciano, Thiago Guimarães, David Correa Martins Junior, André Yoshiaki Kashiwabara, Arnaldo Lara, Jorge de Jesus Gomes Leandro, Ariane Machado Lima, Fabrício Martins Lopes, Jesús Mena Chalco, Alexandre Noma, Márcio Katsumi Oikawa, Thiago Teixeira Santos, Ana Carolina Quirino Simões, Anderson Valtriani Siqueira, João Vitor Baldini Soares, Pedro Losco Takecian, Celina Maki Takemura, Nestor Walter Trepode, Daniel André Vaquero, Ricardo Zorzetto Nicoliello Vêncio, Daniel da Cruz Gouveia Vieira, Yossi Zana e Jihan Mohamad Zoghbi. Cada um de vocês pode estar certo de que parte do que sei e do que sou hoje deve-se ao contato que mativemos durante esses anos de meu mestrado. Sou grato a todos vocês.

Quero agradecer em particular a Yossi Zana, por ter me ensinado a adotar uma postura crítica diante de diversas situações.

Um agradecimento especial vai a meu orientador e amigo, Roberto Marcondes Cesar Junior, que, além de possuir uma energia contagiante tanto para o trabalho quanto para a pesquisa, mostrou-se um verdadeiro amigo ao ajudar-me inclusive quando minhas preocupações não resumiam-se apenas às acadêmicas. A você, Roberto, a minha mais sincera gratidão.

Por fim, agradeço à minha família, que sempre esteve presente e apoiou-me em todas as dificuldades que tive: meus pais Antônio Pires Eustáquio e Dulcinéia da Silva, e minha irmã Deise da Silva Pires.

David da Silva Pires

São Paulo, SP

7 de junho de 2009 


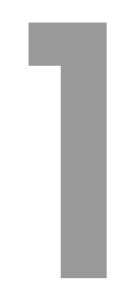

\section{Introdução}

STE CAPÍTULO INTRODUTÓRIO apresenta conceitos básicos de vídeo digital e a definição de vídeo 3D que foi adotada. Na seqüência, é dada uma explicação básica sobre modelagem 3D e uma idéia geral sobre a metodologia introduzida. O encerramento do capítulo se dá com uma descrição dos objetivos e de como o texto está organizado.

\section{Considerações Preliminares: Vídeo Digital}

\subsubsection{O Formato Digital}

O advento do vídeo digital causou uma revolução tecnológica que alterou de diversas formas a comunicação audiovisual.

O formato digital é, por sua própria natureza, robusto com relação a degradações. Diferentemente do formato analógico, o armazenamento e a transmissão de dados digitais são menos suscetíveis a erros. Além disso, o uso de algoritmos existentes tanto para detecção como para correção de erros em dados digitais praticamente elimina os possíveis erros que possam surgir.

Uma outra grande vantagem do formato digital é que ele é perfeito para o processamento computacional. Certamente, dados analógicos podem sofrer conversões e então serem tratados por computador, mas o que se quer chamar atenção é para a prontidão imediata que os dados digitais têm para serem transferidos e posteriormente carregados como entrada para um programa. 
Como conseqüência, o vídeo digital tem um grande impacto na televisão e na indústria cinematográfica. A geração de efeitos especiais, antes feita apenas por meio de truques mecânicos e ópticos [Finch, 1984], encontra no formato digital miríades de opções a serem exploradas, tornando os efeitos cada vez mais realistas.

Velocidades maiores de processamento e transmissão, disponibilização de grande quantidade de memória para armazenamento, acesso a dispositivos de exibição com resoluções altíssimas, barateamento dos dispositivos físicos, estas e tantas outras características fazem do formato digital ideal para a implementação de projetos cada vez mais ambiciosos nas áreas de processamento de imagens, visão computacional e computação gráfica.

Nos dias de hoje, com a internet e os dispositivos de comunicação sem fio, o formato digital está modelando uma nova mídia. Vídeos, geralmente, demandam grandes quantidades de memória para serem armazenados e um longo tempo para transferência. No entanto, o advento de algoritmos para compressão e descompressão de vídeo e o desenvolvimento de tecnologias de transmissão em banda larga têm permitido às pessoas assistir a vídeos remotamente via uma rede de computadores conectados à internet ou até mesmo em dispositivos que não têm o vídeo como fim, tal como os telefones celulares.

Não é, portanto, exagero afirmar que o vídeo digital causou uma revolução frente ao vídeo analógico.

\subsubsection{A Revolução do Vídeo Digital}

Pode-se dizer que a revolução do vídeo digital foi caracterizada por dois tipos de aspectos: os evolucionários e os revolucionários.

\section{Aspectos Evolucionários}

O desenvolvimento das gerações iniciais de vídeo digital era focado no estabelecimento de novos padrões (tais como formatos de arquivos e tipos de compressão, descompressão e transmissão) e na fundamentação tecnológica, culminando em diversas melhorias diretas para o vídeo digital, como por exemplo a grande melhora na resolução da imagem que compõe cada quadro. 
Desta forma, o resultado foi uma melhora significativa de aspectos evolucionários do vídeo digital. No entanto, os tipos de dados que compõem o vídeo permaneceram os mesmos-ou seja, informações por meio de cores e sons.

\section{Aspectos Revolucionários}

As próximas gerações de vídeo deverão ser o resultado da incorporação de novos tipos de dados à mídia, trazendo inovações que caracterizarão os aspectos revolucionários do vídeo digital. Certamente, uma candidata natural à extensão dos dados existentes é a informação sobre profundidade. Ela não só combina com o sistema de percepção humano como também facilita a análise de cenas por computadores a fim de extrair informação a níveis mais elevados.

\section{SEÇÃO 1.2 \\ O Que É Vídeo 3D?}

De início, pode-se definir vídeo $3 D$ da seguinte forma:

Definição (Ingênua). Vídeo 3D é um vídeo que inclui uma terceira dimensão.

Esta descrição simples pode levar a interpretações errôneas. Por exemplo, uma pessoa poderia defender a idéia de que o vídeo, como ele é hoje, é um vídeo 3D. A Figura 1.1 poderia ser usada para sustentar tal argumentação. Olhando para ela, pode-se identificar três losangos. Também pode-se dizer que há um hexágono, tomando os segmentos de reta que determinam as bordas do casco convexo da figura. Mas se olha-se com mais atenção, pode-se dizer que esta é a representação de um cubo. Um pouco

$\overline{\text { Figura 1.1 Representação 3D em su- }}$ perfícies 2D. Que formas diferentes podem ser identificadas nesta figura? É possível visualizar algo $3 D$ nela?

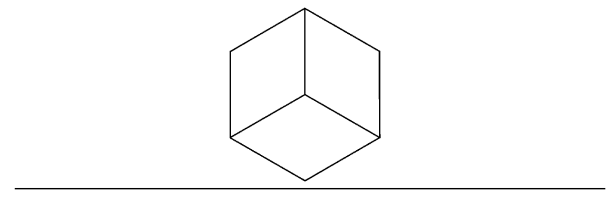
mais de concentração e pode-se inclusive enxergar o interior de um cubo.

O que acontece aqui é uma confusão típica de quando objetos tridimensionais são representados em um plano. Apesar de se conseguir perceber a informação sobre profundidade, ela não está presente na figura, uma vez que esta só fornece 
Figura 1.2 Exemplo de um tour into the picture. A entrada (figura à esquerda) para o método é uma única imagem. A partir desta, faz-se um passeio tridimensional pela cena, como mostrado na figura à direita (Fonte: http: //www.siggraph.org/publications/newsletter/v33nl/contributions/ Anjyo.htmI).

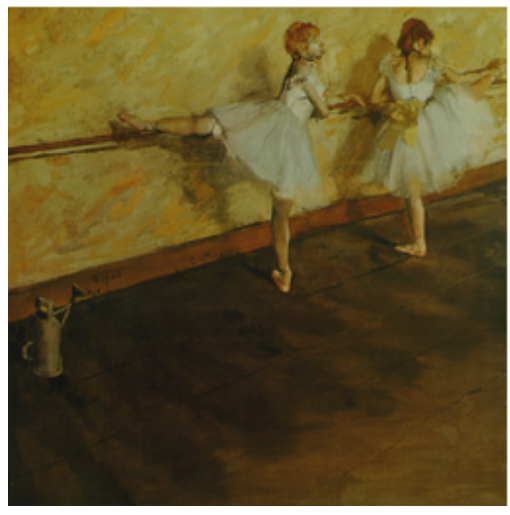

Entrada.

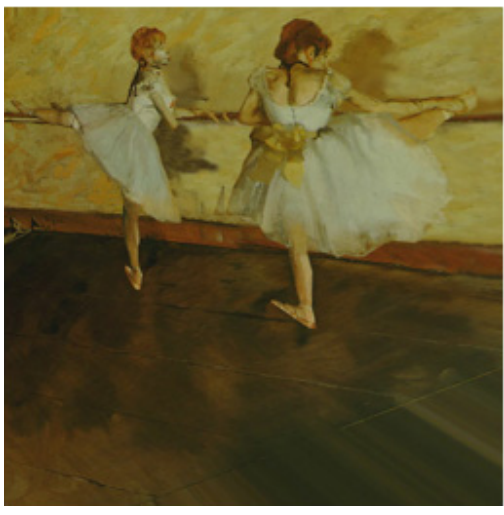

Um dos quadros da saída.

informação bidimensional, que é o valor de cada pixel presente em cada linha e coluna que compõem a imagem.

Embora a TV atual não sirva como exemplo de um vídeo 3D, pode-se enumerar alguns outros que estariam mais próximos da definição que se quer alcançar. Um exemplo aceitável seria o que é conhecido hoje como tour into the picture. Trata-se de uma técnica para obter efeitos de animação 3D convincentes a partir de apenas uma imagem 2D [Anjyo, 1997]. Segundo este conceito, uma animação é criada a partir de um ponto de observação de uma câmera virtual que faz um passeio tridimensional pela imagem (Figura 1.2). Para construir tal animação, técnicas convencionais de visão computacional não podem ser aplicadas no processo de modelagem 3D da cena devido à limitação de só se poder usar uma imagem 2D. Sendo assim, este método emprega uma malha em forma de teia de aranha para obter um modelo simples da cena por meio de uma interface gráfica.

Um outro exemplo é um tipo de efeito especial que tem aparecido muito nas produções cinematográficas atuais e que foi lançado no filme Matrix: uma mesma cena é gravada ao mesmo tempo por diversas câmeras localizadas em posições diferentes, próximas o suficiente para que a mudança de visão de uma para outra 
Figura 1.3 O vídeo interativo. (Fonte: Descobrir - Uma Aventura no Mundo da Ciência, Editora Globo S.A., 1990).

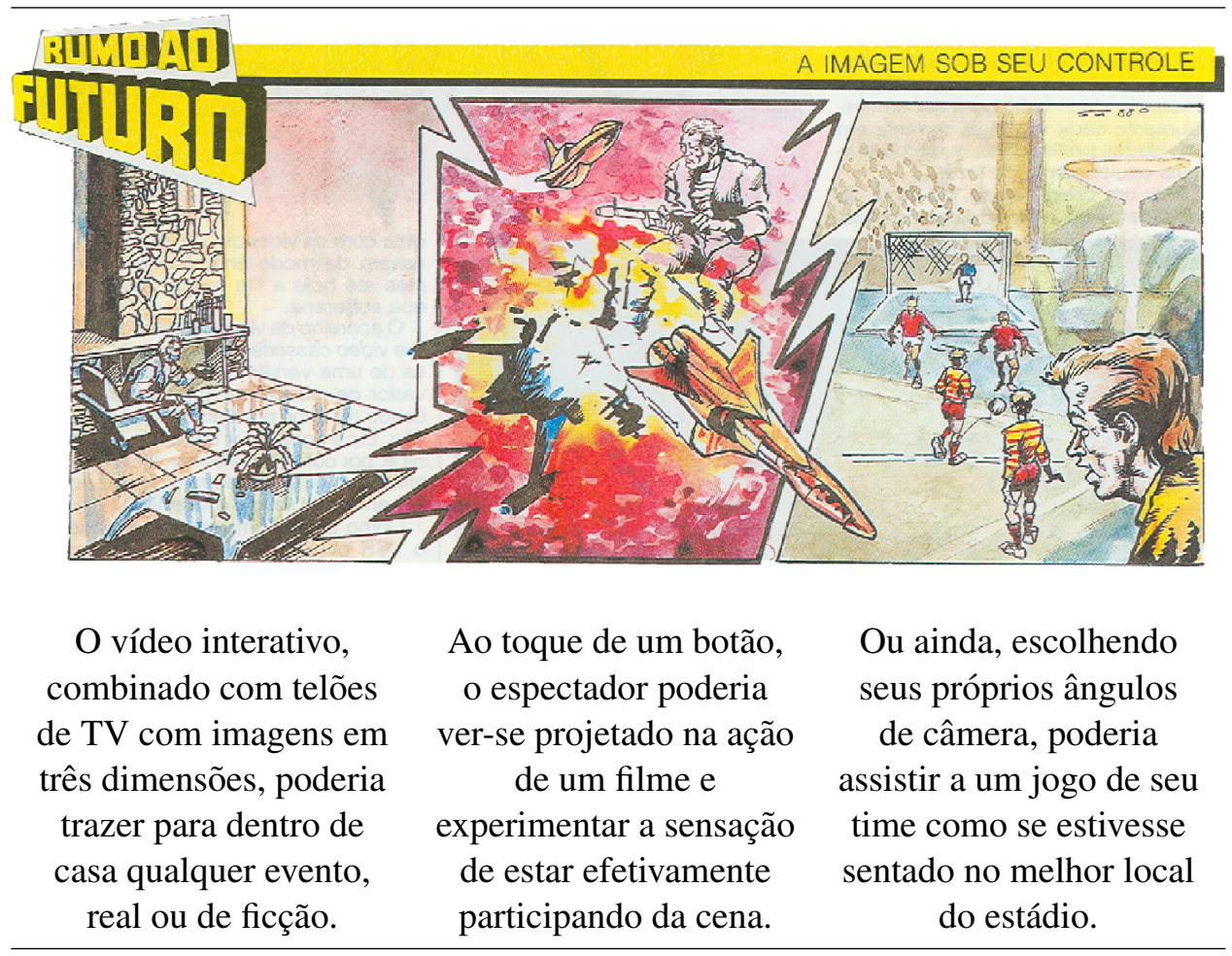

seja imperceptível. Assim, é possível congelar a cena e fazer um passeio em torno dela, tal como foi feito com o personagem Neo quando este desviava de balas de revólver no filme Matrix.

Contudo, o exemplo que mais se aproxima da definição almejada é o que costuma aparecer em diversas reportagens e matérias sobre tecnologias do futuro e os tipos de facilidades que estarão disponíveis. Dentre as inovações, uma que se destaca bastante é a chamada TV do futuro (Figura 1.3). Nela, o telespectador tem a liberdade de escolher o ângulo de visão que quiser. Num jogo de futebol, por exemplo, poderia-se assistir a um gol de seu time tanto do lado de sua torcida organizada, quanto do lado da torcida adversária; ou então por trás do gol; ou ainda, do ponto em que o artilheiro chutou. Obviamente, não seria possível obter tantos ângulos de visão espalhando câmeras por todos os pontos do estádio. Seria necessário um modo para obter visões intermediárias a partir da gravação obtida com a instalação 
de algumas câmeras em pontos estratégicos.

Logo, pode-se enfim moldar uma definição mais precisa:

Definição (Adotada). Chama-se de vídeo 3D a uma seqüência de diferentes imagens exibidas durante intervalos regulares de tempo e que possuem informação de cor, luminância e profundidade.

A diferença da definição adotada para a ingênua é justamente a inclusão da informação de profundidade nos dados do vídeo em vez de esta ser intuída por parte do espectador. Assim, por meio do modelo tridimensional fornecido pelo vídeo 3D, pode-se obter visões de um mesmo objeto a partir de diversos ângulos, inclusive em pontos onde não há câmeras presentes durante a gravação do vídeo. Note que o som não é levado em conta no vídeo.

\subsubsection{A Execução em Tempo Real}

Um sistema de tempo real é aquele em que o tempo cumpre um papel essencial, próprio para quando existem requisitos rígidos relativos ao tempo sobre a operação de um processador ou sobre o fluxo de dados, sendo assim freqüentemente usado como um dispositivo de controle em uma aplicação dedicada a um propósito específico [Silberschatz \& Galvin, 2000; Tanenbaum \& Woodhull, 1997]. Tipicamente, um ou mais equipamentos físicos externos ao computador geram estímulos aos quais o computador deve reagir prontamente dentro de uma quantidade de tempo pré-fixada.

Pode-se citar como exemplos:

players de música de $\mathrm{CD}$;

monitoramento de pacientes em UTIs;

piloto automático de aviões, e

controle de segurança em reatores nucleares.

No projeto em questão, discutido neste documento, a necessidade do tempo real decorre do fato de que a captura de movimentos sutis de componentes conexas permite tanto a exploração de coerência no tempo quanto a redução de problemas de casamento durante a análise espaço-temporal. 


\section{Modelagem 3D}

São apresentados, abaixo, alguns conceitos básicos para a compreensão do trabalho desenvolvido.

\subsubsection{Modelagem 3D Passo a Passo}

$\mathrm{Na}$ modelagem 3D de objetos reais, freqüentemente se aplica uma seqüência de quatro operações:

(1) aquisição de dados de geometria;

(2) registro das imagens;

(3) integração das imagens, e

(4) aquisição de dados de reflexão.

Segue uma descrição básica dessas etapas.

\subsubsection{Aquisição de Dados de Geometria}

A fase de aquisição de dados de geometria, explicada nesta subseção, geralmente enfrenta algumas dificuldades, listadas a seguir:

auto-oclusão em relação aos dispositivos sensores;

objetos com superfícies brilhantes e que refletem muito, e

objetos que absorvem luz e não podem ser totalmente percebidos pelo sistema de visão.

O primeiro desafio do vídeo 3D é o desenvolvimento de um dispositivo de aquisição para fazer a captura das imagens. A escolha do tipo de dispositivo a ser usado determinará a adoção de um dos seguintes métodos:

estéreo passivo, ou

estéreo ativo. 


\section{Método Estéreo Passivo}

Um método estéreo passivo é um sistema baseado em pelo menos um par de câmeras, usando no mínimo duas imagens de um mesmo objeto visto a partir de dois pontos diferentes [Barnard \& Fischler, 1982]. Geralmente são necessários equipamentos bem simples para sua construção. Outra característica é o uso de luz ambiente.

\section{Método Estéreo Ativo}

Composto por uma (ou mais) câmeras e um projetor, um sistema baseado no método estéreo ativo é aquele no qual um padrão de luz é projetado sobre o objeto a fim de resolver o problema de encontrar pontos correspondentes entre as imagens de duas (ou mais) câmeras [Besl, 1988; Brady et al., 1988; Jarvis, 1993, 1983; Rocker \& Kiessling, 1975].

\section{Estéreo Passivo $\times$ Estéreo Ativo: Diferenças, Vantagens e Desvantagens}

No método estéreo passivo, encontrar a correspondência entre as duas imagens é um problema extremamente difícil de ser resolvido, já que se trata de um problema inverso mal-posto. Além disso, se há requisições de execução em tempo real, as dificuldades são ainda maiores.

Já o método estéreo ativo possui a vantagem do uso de algoritmos existentes que lidam com estéreo restrito, que são simples e robustos. O preço é que um padrão de luz deve ser projetado sobre a cena.

\subsubsection{Registro}

O segundo passo na reconstrução 3D é o registro. Como na aquisição dos dados de geometria cada objeto é gravado com seu próprio sistema de coordenadas, é necessário registrar as múltiplas imagens de profundidade em um sistema de coordenadas comum, chamado de coordenadas do mundo. 


\section{Visão Geral}

Uma simples varredura feita por um scanner de luz estruturada tipicamente fornece uma imagem de profundidade que cobre apenas parte do objeto. Portanto, múltiplas varreduras feitas a partir de diferentes pontos de observação são necessárias para capturar a superfície completa do objeto. Estas múltiplas imagens de varredura geram um problema bem conhecido chamado registro-alinhar todas as imagens de profundidade em um sistema de coordenadas comum.

O algoritmo ICP (do inglês Iterative Closest Point) [Besl \& McKay, 1992; Chen \& Medioni, 1992; Zhang, 1994] foi uma contribuição significativa na resolução do problema do registro. Trata-se de um algoritmo iterativo para registrar dois conjuntos de dados. Em cada iteração, são selecionados os pontos mais próximos entre os dois conjuntos de dados como pontos correspondentes, sendo então calculada uma transformação rígida que minimiza as distâncias entre os pontos correspondentes. O conjunto de dados é atualizado por meio da aplicação da transformação calculada. As iterações continuam até que o erro entre pontos correspondentes fique abaixo de um limiar pré-determinado. Uma vez que o algoritmo envolve a minimização de distâncias quadradas médias, pode ocorrer uma convergência para um mínimo local em vez de para um mínimo global. Isto implica que um bom registro inicial precisa ser dado como um ponto de partida. Caso contrário, o algoritmo pode convergir para um mínimo local que seja distante da melhor solução. Portanto, faz-se necessária uma técnica que forneça um bom registro inicial.

\subsubsection{Integração e Aquisição de Dados de Reflexão}

O terceiro passo na reconstrução 3D é a integração. Tipicamente, o registro de imagens de profundidade obtidas a partir de posições adjacentes contém superfícies sobrepostas. A integração das imagens registradas tem o objetivo de obter um único modelo de superfície conectado.

O passo final na reconstrução 3D é a aquisição de dados de reflexão. A fim de obter uma visualização foto-realística, o quarto e último passo adquire propriedades de reflexão da superfície do objeto. Esta informação é adicionada ao modelo geométrico.

Todos as etapas que constituíram o trabalho desenvolvido são ilustradas na Fi- 
Figura 1.4 Etapas que constituíram o trabalho. As etapas consistiram na captura, segmentação, rastreamento, registro e integração.
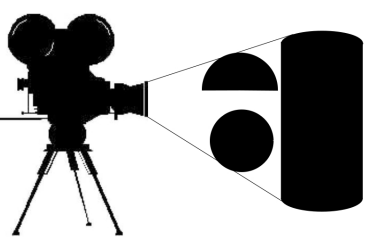

captura

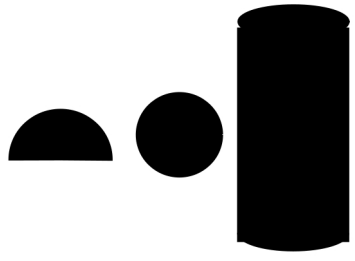

segmentação

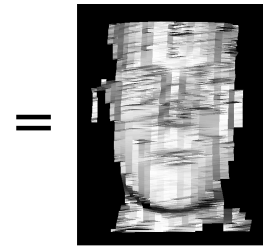

registro

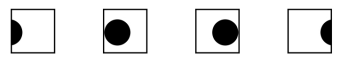

rastreamento

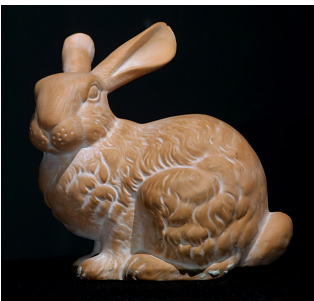

integração

gura 1.4. Já na Figura 1.5 é mostrado um fluxograma que representa todos os passos que este trabalho seguiu como sendo um projeto típico de visão computacional.

\section{Breve Descrição da Metodologia Introduzida}

Para fazer a integração dos dados geométricos, primeiramente é preciso detectar as componentes conexas presentes em uma cena, o que pode ser feito segundo a distância no eixo das $\operatorname{cotas}^{1}$. Tal necessidade deve-se ao fato de que o casamento entre todas as componentes conexas (casamento global) é melhor feito quando cada uma delas é registrada individualmente, uma vez que é eliminada a influência do movimento relativo entre elas. Neste ponto, qualidade é crucial para a obtenção de análises e sínteses precisas. O sistema de captura 3D deve fornecer essa qualidade em tempo real tanto para as imagens quanto para a geometria.

\footnotetext{
nadas

${ }^{1}$ Terceiro eixo no sistema de coordenadas cartesiano, além dos eixos das abscissas e das orde-
} 
Figura 1.5 Projeto de visão computacional. Este trabalho seguiu todos os passos de um projeto típico de visão computacional.

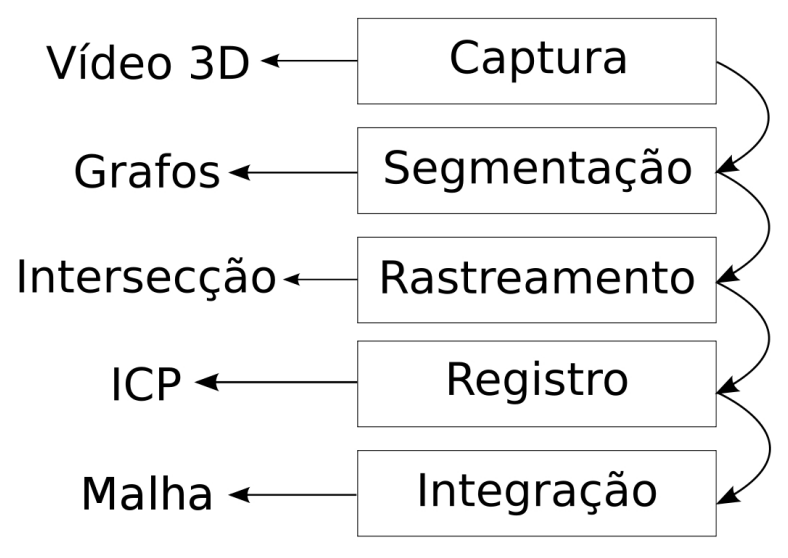

Dado que sistemas de vídeo 3D geralmente adquirem a textura da cena com uma resolução maior que a da geometria da mesma, uma abordagem razoável é usar a textura para melhorar o casamento da geometria. Trata-se de um passo intermediário importante e este documento contém o estudo que já foi desenvolvido nesse sentido.

Com a definição de vídeo 3D adotada, pode-se enumerar algumas contribuições pretendidas do presente trabalho bem como alguns passos intermediários que são necessários para os avanços que vêm sendo feitos. Toda a discussão feita nesta subseção e posteriormente no Capítulo 4 pode ser acompanhada em conjunto com o fluxograma dado na Figura 1.6 e com as informações fornecidas pela Tabela 1.1.

Os primeiros passos dados no sentido de fazer a integração dos dados podem ser discriminados em três etapas: (1) rastreamento das componentes conexas; (2) identificação de pontos salientes correspondentes; (3) estimação de uma transformação geométrica para o registro tridimensional das componentes conexas. Esta sequiência de passos é esquematizada na Figura 1.7.

O rastreamento baseia-se na intersecção existente entre a componente conexa de interesse e todas as outras presentes no quadro anterior. Logo após, são calculados os pontos salientes na geometria, que seriam os mais importantes para o 
Tabela 1.1 Atividades concluídas no mestrado. Explicação mais detalhada sobre as atividades apresentadas no fluxograma da Figura 1.6.

\begin{tabular}{|l|l|}
\hline \multirow{2}{*}{ identificação das CCs } & $\begin{array}{l}\text { O código desta parte da aplicação foi totalmente } \\
\text { desenvolvido no IMPA. Envolve a construção } \\
\text { de um grafo de conexão de pontos 3D e leva em } \\
\text { consideração a distância entre os mesmos. }\end{array}$ \\
\hline rastreamento das CCs & $\begin{array}{l}\text { Leva em conta a intersecção de CCs correspon- } \\
\text { dentes em quadros subseqüentes. Trata de diver- } \\
\text { sos casos particulares, como união e divisão de } \\
\text { CCs, surgimento, desaparecimento, movimento e } \\
\text { mudança de forma das mesmas. }\end{array}$ \\
\hline $\begin{array}{l}\text { cálculo da } \\
\text { transformação afim ba- } \\
\text { seada na textura }\end{array}$ & $\begin{array}{l}\text { A textura é usada para adaptar a geometria do } \\
\text { quadro } t \text { em relação ao quadro } t-1 .\end{array}$ \\
\hline $\begin{array}{l}\text { aplicação da } \\
\text { transformação afim cal- } \\
\text { culada nos dados da } \\
\text { geometria }\end{array}$ & $\begin{array}{l}\text { A alta resolução apresentada pela textura traz van- } \\
\text { tagens ao cálculo da correspondência entre dois } \\
\text { quadros. }\end{array}$ \\
\hline $\begin{array}{l}\text { interpolação da geome- } \\
\text { tria do quadro } t\end{array}$ & $\begin{array}{l}\text { A interpolação é feita para uma maior fidelidade } \\
\text { às informaçôes. }\end{array}$ \\
\hline $\begin{array}{l}\text { identificação de pontos } \\
\text { salientes na geometria } \\
\text { do quadro } t\end{array}$ & $\begin{array}{l}\text { São tomados como pontos salientes os conjuntos } \\
\text { de pontos máximo e mínimo locais ao longo de } \\
\text { cada faixa de luz. }\end{array}$ \\
\hline $\begin{array}{l}\text { identificação dos pon- } \\
\text { tos correspondentes no } \\
\text { quadro } t-1\end{array}$ & $\begin{array}{l}\text { Devido ao alinhamento por correlação, geralmente } \\
\text { este passo exige uma interpolação dos dados de } \\
\text { geometria. }\end{array}$ \\
\hline $\begin{array}{l}\text { registro das nuvens de } \\
\text { pontos correspondentes } \\
\text { nos quadros } t-1 \text { e } t \\
\text { usando o ICP }\end{array}$ & $\begin{array}{l}\text { Com todo o procedimento descrito acima, o regis- } \\
\text { tro é menos influenciado pela tendência definida } \\
\text { pelas linhas retas que caracterizam a geometria na } \\
\text { imagem de profundidade. }\end{array}$ \\
\hline \hline
\end{tabular}


Figura 1.6 Fluxograma das atividades concluídas no mestrado. Este esquema permite identificar toda a seqüência de execução dos algoritmos desenvolvidos durante o mestrado.

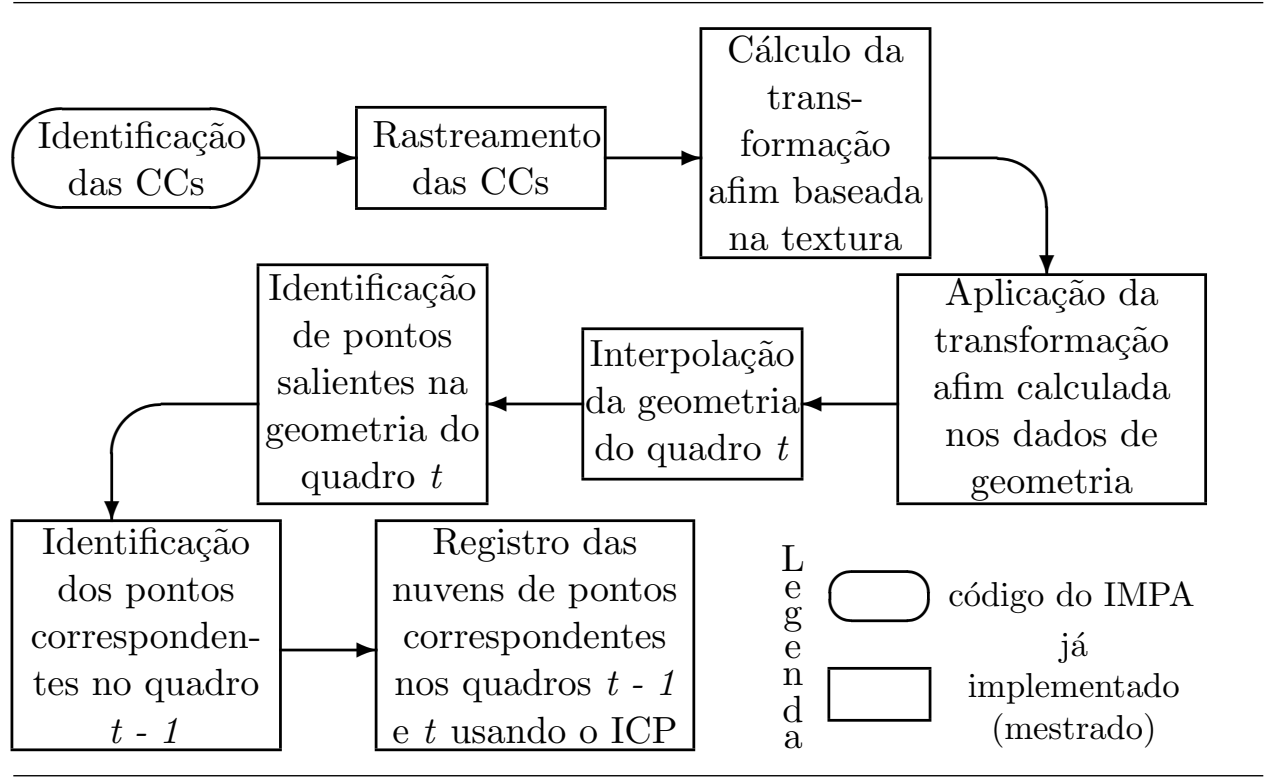

registro dos dados. Também são calculados, por meio de interpolação, os pontos salientes do quadro anterior, caracterizando a segunda etapa. Finalmente, a terceira etapa consiste em estimar uma transformação geométrica que melhor aproxime a nuvem de pontos de uma componente conexa com a nuvem de pontos de sua correspondente no quadro antecessor, fazendo assim o registro.

Uma vez que as nuvens de pontos estejam registradas, é gerada uma malha para cada uma delas. Para tanto, utiliza-se uma biblioteca de malhas dinâmicas baseada em operadores estelares.

De posse de tais malhas, podemos por fim fazer a integração das mesmas, tomando-as duas a duas e gerando uma malha final que acomode melhor as componentes conexas casadas. Este é um tópico que pretende-se abordar na continuação deste trabalho.

A tarefa de atualização do modelo 3D da cena conforme novos quadros do vídeo são processados constitui um tópico de pesquisa complexo e desafiador. Dificuldades surgem com a presença de ruído nos dados (especialmente na geometria 
Figura 1.7 Visão geral do esquema proposto. Rastreamento e casamento de componentes conexas em um vídeo $3 D$.

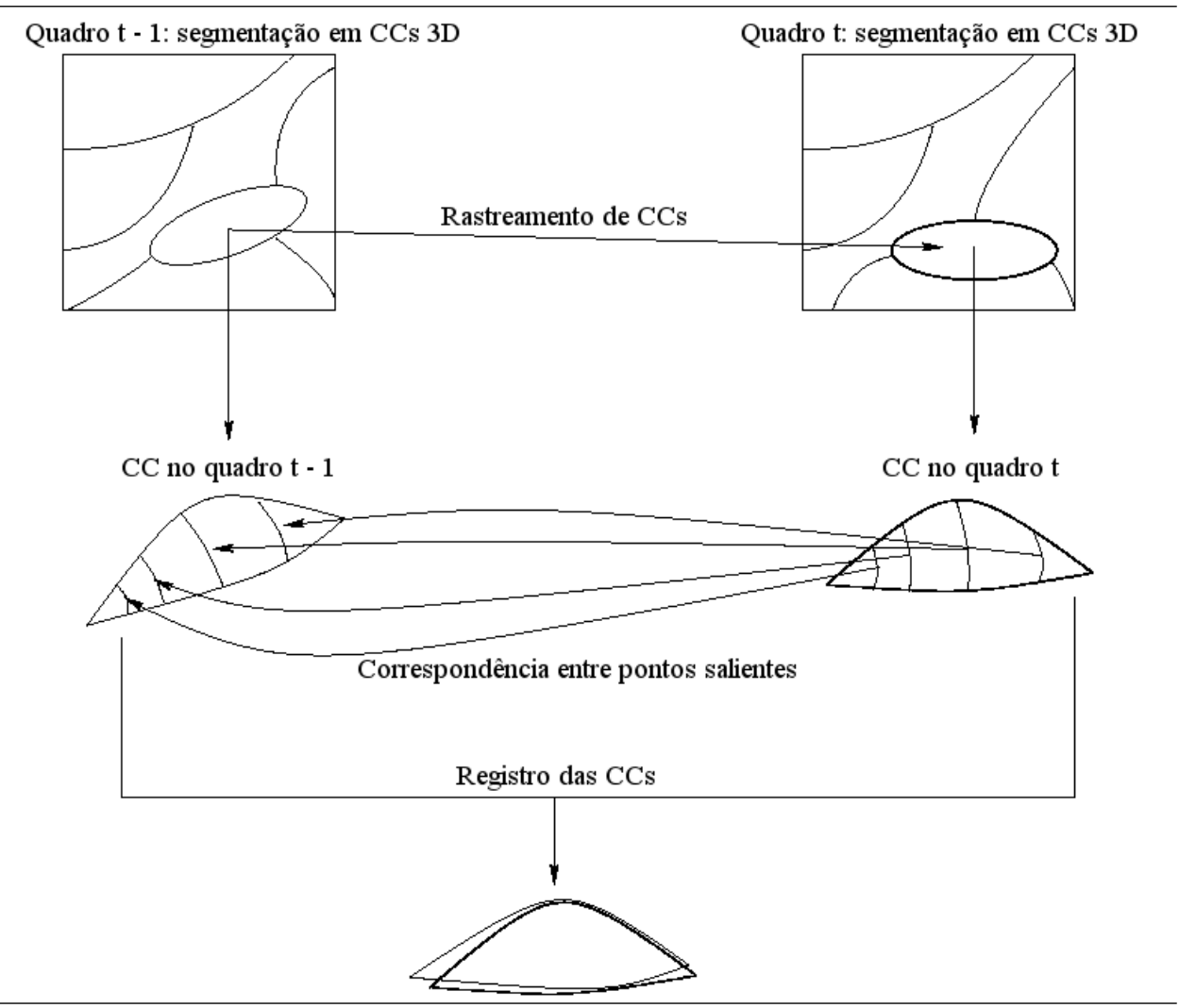

das bordas das componentes conexas), grande movimentação relativa entre as componentes conexas e, principalmente, o caráter móvel e maleável dos objetos, caráter este que é comum de ocorrer, já que estamos lidando com vídeo real.

Este trabalho é fruto de uma colaboração com o Instituto Nacional de Matemática Pura e Aplicada (IMPA), estando inserido em um projeto mais amplo chamado Vídeo 4D, o qual define o conceito como sendo um vídeo 3D composto de objetos genéricos que sofrem alterações com o passar do tempo. 


\section{SEÇÃO 1.5}

\section{Objetivos}

O objetivo original deste trabalho é a integração de dados de geometria adquiridos a partir de um sistema de vídeo 3D a fim de obter um modelo tridimensional dos objetos presentes na cena. Mais especificamente, a concentração deste trabalho está no tratamento das componentes conexas, a fim de obter um casamento global mais preciso obtido a partir do registro individual de cada componente, fazendo uso da informação de geometria e de textura.

\section{Organização do Texto}

Este documento está organizado da seguinte forma: inicialmente, o Capítulo 2 revisa um pouco da literatura relevante a fim de contextualizar o presente trabalho. O Capítulo 3 versa sobre a plataforma de vídeo 3D existente no IMPA, de onde originam-se os dados com que lidamos. A estrutura proposta para os procedimentos de rastreamento e casamento de CCs presentes em uma cena é apresentada no Capítulo 4. O Capítulo 5 mostra alguns resultados experimentais que corroboram nossa abordagem. Por fim, esta dissertação é concluída no Capítulo 6, com uma discussão sobre o trabalho desenvolvido e alguns comentários sobre os futuros passos. O Apêndice A fornece informações acerca de alguns parâmetros importantes no código fonte bem como cálculos úteis para alocação de memória para visualização dos dados. 



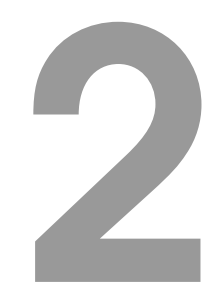

\section{Revisão Bibliográfica}

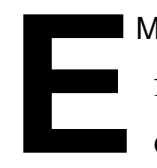

M GERAL, métodos de aquisição 3D em visão computacional dependem fortemente de correspondência e calibração. A calibração pode ser necessária entre as câmeras que funcionam como dispositivos de aquisição ou entre câmeras e projetores. Estes métodos podem ser classificados baseando-se no tipo de dados de entrada usados e na forma como a correspondência é obtida.

A escolha mais usada para aquisição 3D costuma ser um sistema baseado num par de câmeras e o uso de métodos estéreo passivos. No entanto, estéreo geral completo é um problema inverso mal-posto, sendo portanto muito difícil de resolver-e as requisições de tempo real tornam as coisas ainda piores. Grande parte dos algoritmos propostos não pode ser executada em tempo real desprovidos de algum tipo de aceleração por hardware. Neste contexto, uma nova tendência tem sido tirar vantagem de GPUs (unidades de processamento gráfico, do inglês Graphical Processing Units) programáveis [Huang et al., 2003]. Outra opção é usar múltiplas câmeras fixas e fazer uma análise da cena para obter a decomposição da mesma em frente e fundo. Esta é a base para métodos de casco visual e fotográfico [Gross et al., 2003; Matusik et al., 2000].

Uma alternativa a algoritmos estéreo passivos é um sistema baseado em um conjunto de câmera e projetor e em estéreo ativo. Esta opção tem a vantagem de usar algoritmos para estéreo restrito, que são mais simples e robustos, mas que precisam que um padrão de luz seja projetado sobre a cena. Trabalhos recentes nesta área investigam diferentes configurações de câmeras e projetores [Huang et al., 2003; Zhang et al., 2004]. Algumas abordagens que seguem esta linha de pesquisa 
usam padrões coloridos visíveis de um projetor [Zhang et al., 2004], um conjunto de fontes esparsas de laser [Popescu et al., 2004] ou até mesmo padrões invisíveis de infravermelho [Frueh \& Zakhor, 2005].

O sistema de vídeo 3D usado neste trabalho [Vieira et al., 2005] é baseado em um par câmera/projetor, sendo estéreo ativo. O hardware é construído com equipamento comumente encontrado no mercado, o que traz muitas vantagens, tais como uma ótima relação custo-benefício e compatibilidade. Não obstante, como veremos mais adiante, o código de cores estéreo ativo é simples e eficaz.

Para o registro de imagens range obtidas a partir de diferentes pontos de observação [Silva et al., 2003] é utilizado o algoritmo ICP. Uma breve discussão sobre o ICP é feita na Seção 2.3.

Uma ótima referência para consulta sobre visão computacional 3D é o livro de Klette et al., Computer Vision-Three Dimensional Data from Images, de 2001. Já para assuntos referentes às técnicas de luz estruturada para resolução do problema da correspondência, vale a pena consultar o artigo de Batlle et al., Recent Progress in Coded Structured Light as a Technique to Solve the Correspondence Problem: A Survey, de 1998. Grande parte desta revisão baseia-se principalmente nestas duas fontes.

\section{Visão Computacional: Dados Tridimensionais a partir de Imagens}

A reconstrução de superfícies de objetos é uma matéria especial na área de visão computacional. Esta matéria preocupa-se com a recuperação das formas de objetos ou com a recuperação da distância entre a câmera e os objetos em uma cena. Os dados capturados por uma ou mais câmeras constituem a informação inicial. Possíveis áreas de aplicação da recuperação de formas são a modelagem por computador de objetos tridimensionais (e.g., arquitetura, engenharia mecânica, cirurgia), a medida de distâncias ou a estimação grosseira da posição de obstáculos (e.g., controle veicular, robótica), a inspeção de superfícies (e.g., controle de qualidade), estimação aproximada ou exata da localização de objetos tridimensionais (e.g., montagem automatizada) ou a localização rápida de obstáculos sem a necessidade de um re- 
conhecimento (e.g., navegação).

O processo de reconstrução de formas de objetos tridimensionais geralmente também contém procedimentos de processamento de imagens (filtragem, restauração e realçamento, dentre outros) ou análise de padrões (detecção de bordas, segmentação de figuras, identificação de características, etc.).

Duas câmeras com um alinhamento coplanar ideal em relação a cada uma são usadas como um exemplo introdutório para a tarefa de determinar a posição de alguns pontos da superfície.

\subsubsection{Reconstrução de Formas}

Em visão computacional, a reconstrução de formas de objetos tridimensionais baseia-se em dados visuais. Estes dados são obtidos por sensores visuais (uma ou mais câmeras), os quais reproduzem uma cena estática ou dinâmica. Em uma cena estática não ocorrem movimentos do objeto no intervalo de tempo de captura das imagens tampouco mudanças na iluminação ou nos parâmetros das câmeras. Para uma cena dinâmica tais mudanças ou movimentos são possíveis durante este intervalo de tempo. Como um exemplo, durante o intervalo de tempo da captura de uma foto de uma cena dinâmica, a(s) câmera(s) pode(m) ser fixada(s) espacialmente e seus parâmetros intrínsecos (e.g., a distância focal) podem ser alterados (e.g., controlados por computador). Se um movimento da câmera não pode ser especificado, então este tipo de captura também é conhecido como aquisição de imagem dinâmica.

\section{Luz Estruturada e o Problema da Correspondência}

Quando necessita-se da informação tridimensional de uma determinada superfície, é preciso escolher entre um método passivo ou ativo. O método passivo mais amplamente conhecido é a visão estéreo, a qual pode ser obtida segundo dois modos diferentes. No primeiro deles, move-se um sensor óptico de modo que fiquem conhecidas posições relativas na cena. No segundo modo, dois ou mais sensores ópticos são previamente fixados em posições conhecidas. A superfície a ser medida é projetada no plano de imagem de cada sensor através de cada ponto focal. 
As coordenadas 3D de um ponto de um objeto podem ser obtidas por trigonometria a partir de projeções conhecidas de um outro ponto e também a partir da relação entre os sensores ópticos. Mas para tanto tem-se que saber, com precisão, para cada ponto do objeto, suas projeções nos planos de imagem de cada sensor óptico. $\mathrm{Na}$ verdade, para obter as coordenadas $3 \mathrm{D}$ de um dado ponto a partir de $n$ projeções dadas (uma para cada sensor), estas projeções devem ser necessariamente do mesmo ponto do objeto. Esse problema é conhecido como o da correspondência.

O problema da correspondência pode ser consideravelmente minimizado por um método ativo. Um dos métodos ativos mais amplamente usados é baseado na projeção de luz estruturada. Geralmente, apenas uma câmera é usada para capturar a imagem da projeção de um determinado padrão sobre a superfície a ser medida. A informação 3D manifesta-se nas deformações aparentes da imagem capturada do padrão a partir do qual foi projetado. Por meio da análise de tais deformações, pode-se obter informação sobre a posição, a orientação e a textura da superfície sobre a qual o padrão está sendo projetado. A análise 3D também pode ser muito facilitada usando um código de luz estruturada. Esta técnica permite que se saiba, para cada ponto amostrado, seu ponto original no plano emitido pelo projetor. Assim, o problema da correspondência pode ser diretamente resolvido, de forma que não é necessário usar restrições geométricas para tanto.

\subsubsection{Visão Estéreo}

Um sistema de visão estereoscópica bem conhecido consiste em um sensor óptico (ou câmera), o qual pode ser movido de modo que suas posições relativas sejam conhecidas a qualquer momento. Um outro sistema estereoscópico também comum é formado por dois ou mais sensores que mantêm sempre as mesmas conhecidas posições relativas a cada um. Se mais de um sensor for usado, supõe-se que todos sejam idênticos e que cada um possa ser modelado como uma câmera ideal, freqüentemente chamado de modelo pinhole.

Na prática, uma câmera não funciona como um modelo pinhole uma vez que a imagem é obtida por um conjunto de lentes. Ao contrário do modelo pinhole, as distâncias entre os centros das lentes e o plano da imagem não são constantes e não equivalem à distância focal; certamente, este sistema é um pouco difícil para ser 
Figura 2.1 Sistema estereoscópico. Um sistema estereoscópico genérico formado pela relação entre dois sensores ópticos.

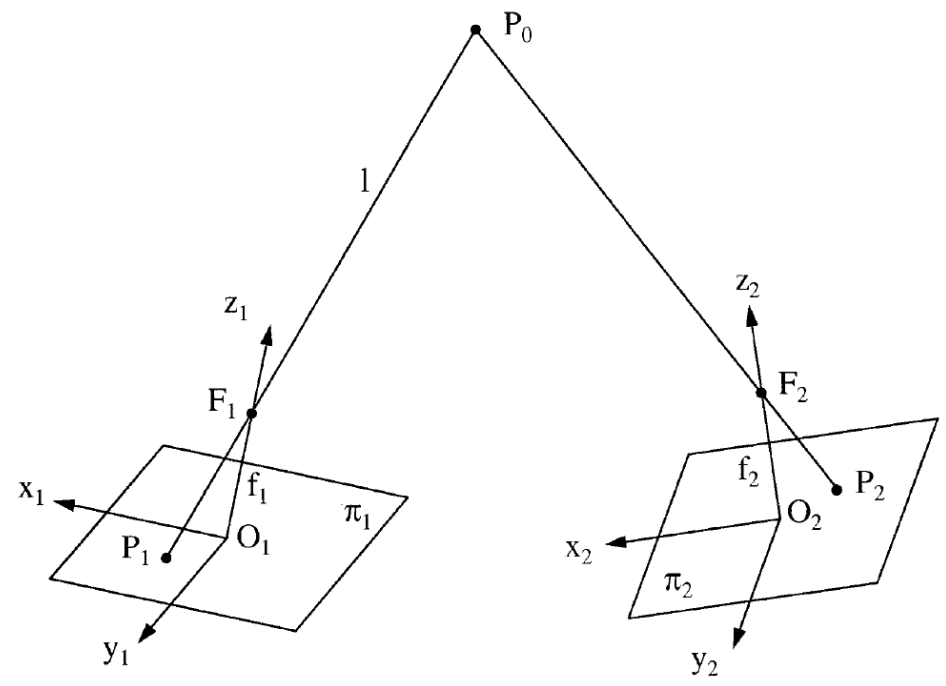

modelado. Mesmo para objetos a serem medidos localizados a grandes distâncias em relação à distância focal, pode-se assumir que a distância entre os centros das lentes e o plano de imagem é constante para qualquer projeção.

Nas discussões que se seguem, assume-se um sistema estereoscópico genérico formado pela relação entre duas câmeras, como mostrado na Figura 2.1. Em tal modelo, define-se um sistema de coordenadas geral com origem $O=O_{1}$ e vetores de coordenadas $(x, y, z)$ iguais a $\left(x_{1}, y_{1}, z_{1}\right)$, respectivamente. Supõe-se que sensores ópticos podem ser modelados segundo um modelo pinhole, com um eixo óptico que coincide com o eixo $z_{1}$ e um ponto focal $F_{1}$ localizado a uma distância $f_{1}$ da origem ao longo do mesmo eixo. Ademais, assume-se que o plano de imagem $\pi_{1}$, com centro $O_{1}$, localiza-se no plano de imagem $x_{1} y_{1}$. Certamente a segunda câmera possui as mesmas propriedades que a primeira, com um sistema de coordenadas $\left(x_{2}, y_{2}, z_{2}\right)$ e origem $\mathrm{O}_{2}$, no qual $z_{2}$ coincide com seu eixo óptico, uma distância focal $f_{2}$ ao longo do eixo $z_{2}$ e um plano de imagem $\pi_{2}$ que fica no plano de imagem $x_{2} y_{2}$. Este segundo sistema de coordenadas pode ser relacionado ao 
primeiro usando

$$
\left[\begin{array}{l}
x_{2} \\
y_{2} \\
z_{2}
\end{array}\right]=\mathrm{R}\left[\begin{array}{l}
x_{1} \\
y_{1} \\
z_{1}
\end{array}\right]+\mathrm{T},
$$

em que $\mathrm{R}$ é uma matriz ortonormal $3 \times 3$, a qual descreve a rotação, e $\mathrm{T}$ é um vetor que descreve a translação do sistema de coordenadas $O_{2}$ em relação ao $O_{1}$.

Seja um ponto $P_{0}$ de um objeto no espaço $3 \mathrm{D}$, o qual possui uma projeção $P_{1}$ no plano de imagens $\pi_{1}$, em que as coordenadas de $P_{0}$ com relação a $O_{1}$ são $\left(x_{P_{0}}, y_{P_{0}}, z_{P_{0}}\right)$ e as coordenadas de $P_{1}$ com relação a $O_{1}$ são $\left(x_{P_{1}}, y_{P_{1}}, 0\right)$. Então a projeção $P_{1}$, que corresponde ao ponto $P_{0}$ do objeto, deve ser feita através do ponto focal, de modo que

$$
P_{1}=F_{1}+\alpha\left(P_{0}-F_{1}\right)
$$

a qual pode ser expressa usando uma relação entre matrizes, como

$$
\left[\begin{array}{c}
x_{P_{1}} \\
y_{P_{1}} \\
0
\end{array}\right]=\left[\begin{array}{c}
0 \\
0 \\
f_{1}
\end{array}\right]+\alpha\left[\begin{array}{c}
x_{P_{0}} \\
y_{P_{0}} \\
z_{P_{0}}-f_{1}
\end{array}\right]
$$

Portanto, os dois sistemas de coordenadas podem ser relacionados como a seguir:

$$
\frac{x_{P_{0}}}{x_{P_{1}}}=\frac{y_{P_{0}}}{y_{P_{1}}}=\frac{f_{1}-z_{P_{0}}}{f_{1}} .
$$

Seja agora uma segunda projeção de $P_{0}$ no plano de imagem $\pi_{2}$, chamada $P_{2}$, com coordenadas $\left(x_{P_{2}}, y_{P_{2}}, 0\right)$ em relação a $O_{2}$. Se as coordenadas $\left(x_{P_{0}}^{\prime}, y_{P_{0}}^{\prime}, z_{P_{0}}^{\prime}\right)$ expressam $P_{0}$ em relação a $\mathrm{O}_{2}$, ambos os sistemas de coordenadas podem ser relacionados como se segue:

$$
\frac{x_{P_{0}}^{\prime}}{x_{P_{2}}}=\frac{y_{P_{0}}^{\prime}}{y_{P_{2}}}=\frac{f_{2}-z_{P_{0}}^{\prime}}{f_{2}} .
$$

Assim, se supusermos que $P_{0}$ é um ponto de um objeto, as fórmulas (2.1), (2.4) e (2.5) podem ser usadas para obter as posições $\left(x_{P_{0}}, y_{P_{0}}, z_{P_{0}}\right)$ ou $\left(x_{P_{0}}^{\prime}, y_{P_{0}}^{\prime}, z_{P_{0}}^{\prime}\right)$ a 
partir das projeções $P_{1}$ e $P_{2}$. Obviamente, antes do cálculo das coordenadas de $P_{0}$, o mais importante é garantir que $P_{1}$ e $P_{2}$ sejam projeções do mesmo ponto $P_{0}$ do objeto.

Escolhe-se um ponto imagem $P_{1}$ em $\pi_{1}$ como sendo a projeção de um ponto objeto $P_{0}$ ao longo da linha $l$ definida por $F_{1}$ e $P_{0}$. Como $P_{0}$ pode ser localizado em qualquer ponto na linha epipolar $l$, não há uma posição única de $P_{2}$ em $\pi_{2}$ se deseja-se apenas aplicar restrições geométricas. No entanto, pode-se afirmar que a projeção $P_{2}$ em $\pi_{2}$ deve situar-se no segmento formado pela intersecção entre o plano definido pelos pontos $F_{1}, F_{2}$ e $P_{1}$ e o plano de imagem $\pi_{2}$. Esta restrição é conhecida como epipolar.

Se o ponto de projeção $P_{1}$ em $\pi_{1}$ for conhecido, a restrição epipolar permite encontrar o ponto de projeção $P_{2}$ em $\pi_{2}$ em apenas uma direção. Claro, não se pode saber se a projeção de $P_{0}$ foi amostrada no plano de imagem $\pi_{2}$. Ela pode sofrer oclusão pela superfície de qualquer outro objeto da cena ou pode ser projetada fora do alcance da câmera. A relação entre as duas projeções é conhecida como o problema da correspondência, um dos tópicos mais interessantes na visão estéreo [Batlle et al., 1998].

\subsubsection{Luz Estruturada}

A solução matemática para o problema da correspondência pode ser simplificada deixando de lado métodos passivos, como o estéreo, e partindo para um método ativo baseado no conceito de luz estruturada [Hu \& Stockman, 1989a; Sá et al., 2002]. Neste método, a segunda câmera estéreo é substituída por uma fonte de luz, a qual projeta um padrão de luz conhecido na cena a ser medida. Uma única câmera captura a cena iluminada. A informação 3D requisitada pode ser obtida por meio da análise das deformações do padrão capturado em relação ao projetado. Certamente algumas correspondências entre o padrão projetado e o capturado devem ser resolvidas.

Se um único ponto de luz ou uma linha estreita é projetada na cena, então não há problema de correspondência a ser resolvido, mas toda a cena deve ser escaneada para a obtenção do mapa 3D. Shirai \& Suwa, em 1971, propuseram a projeção de uma linha estreita para reconhecer objetos poliédricos. Em 1973, Agin 
\& Binford generalizaram esta idéia para reconhecer objetos curvilíneos. Dois anos depois, Popplestone et al. propuseram um sistema mais geral que reconhece tanto objetos poliédricos como curvilíneos. Em 1986, Yamamoto et al. propuseram um sistema de iluminação de meio-plano em vez de uma linha estreita. Na verdade, binarizar a imagem de uma cena iluminada por um padrão de meio-plano corresponde à detecção das bordas entre a área iluminada e a obscura. Recentemente, alguns sistemas para a obtenção de mapas 3D de uma cena foram apresentados. Os sistemas mais comuns são similares ao método de alta velocidade apresentado por Ozeki et al. [1986] e ao método a taxa de vídeo apresentado por Yokoyama et al. [1994]. Há também autores, como Sato et al. [1982], que projetaram duas linhas estreitas com orientações e posições diferentes no sistema de coordenadas 3D. De modo similar, Kemmotsu \& Kanade [1992, 1995] optaram por projetar três linhas na cena a ser medida.

Com o intuito de melhorar a precisão do sistema, uma forma alternativa é a projeção de uma grade de pontos ou linhas na cena a fim de cobrir completamente a área de captura da câmera. Asada et al. [1986, 1988] e Asada \& Tsuji [1985] propuseram o uso de um padrão formado por um conjunto de faixas de linhas verticais, paralelas e eqüidistantes. Wang [1991], Wang \& Liang [1989] e Wang et al. [1987] estenderam a idéia de Asada com a projeção seqüencial de dois padrões de faixas ortogonais. Além disso, com o objetivo de obter propriedades de superfícies 3D, Hu et al. [1986], Hu \& Stockman [1989a], Stockman \& Hu [1986] e Shrikhande \& Stockman [1989] propuseram a largamente conhecida projeção de uma grade. Outros autores também usam a informação fornecida por uma imagem de intensidade para obter, com uma maior precisão, as bordas da cena [Hoshino et al., 1990; Hu \& Stockman, 1989b; Ikeuchi \& Sato, 1991; Vemuri \& Aggarwal, 1986; Wang $\&$ Cheng, 1992]. Assim, um problema de correspondência mais fácil deve ser resolvido, no qual deve-se identificar, para cada ponto do padrão capturado, o ponto correspondente do padrão projetado.

Todos estes métodos permitem encontrar informação 3D a partir de propagação da restrição geométrica e algumas delas são um tanto limitadas para as superfícies a serem medidas com descontinuidades na profundidade.

O problema da correspondência pode ser diretamente resolvido por meio da codificação do padrão projetado [Faugeras \& Toscani, 1986] de modo que cada 
ponto de luz projetado carrega alguma informação. Quando o ponto é projetado em $\pi_{1}$, esta informação pode ser usada para determinar suas coordenadas em $\pi_{2}$, a partir de onde ele foi emitido.

Na sequiência, toda a base matemática usada para obter informação 3D de profundidade de uma cena a ser medida é apresentada. As equações formuladas foram adaptadas para a projeção de uma imagem e a captura de outra, mas conforme pode ser visto, não há muita diferença da triangulação usada em um sistema estereoscópico.

\subsubsection{Mensuração de Superfícies}

\section{Princípio Geral}

Para entender o princípio de medida de superfícies, considera-se útil explicar a base matemática usada para obter informação 3D a partir de triangulação. Para maiores detalhes, o leitor pode consultar as referências Haralick \& Shapiro [1982], Hall et al. [1982] e Faugeras [1993].

Considere um sistema de coordenadas global $O$ localizado no centro da imagem capturada, como mostrado na Figura 2.2. O ponto focal do sistema da imagem capturada está localizado em $F_{1}=\left(0,0, f_{1}\right)^{T}$. Logo, dado um ponto objeto $P_{0}=\left(x_{P_{0}}, y_{P_{0}}, z_{P_{0}}\right)^{T}$, o ponto correspondente no plano de imagem, $P_{1}=$ $\left(x_{P_{1}}, y_{P_{1}}, 0\right)^{T}$, precisa estar na linha que começa em $P_{0}$ e passa por $F_{1}$, de modo que

$$
P_{1}=F_{1}+\alpha\left(P_{0}-F_{1}\right)
$$

a qual pode ser expressa em forma matricial como:

$$
\left[\begin{array}{c}
x_{P_{1}} \\
y_{P_{1}} \\
0
\end{array}\right]=\left[\begin{array}{c}
0 \\
0 \\
f_{1}
\end{array}\right]+\alpha\left[\begin{array}{c}
x_{P_{0}} \\
y_{P_{0}} \\
z_{P_{0}}-f_{1}
\end{array}\right] .
$$

Assuma um segundo plano de imagem, como mostrado na Figura 2.2. Além disso, assuma que a origem deste segundo sistema de coordenadas possui a mesma orientação que o primeiro e que também está centrado com relação ao plano de 


\section{Figura 2.2 Sistema de mensuração usado em luz estruturada.}

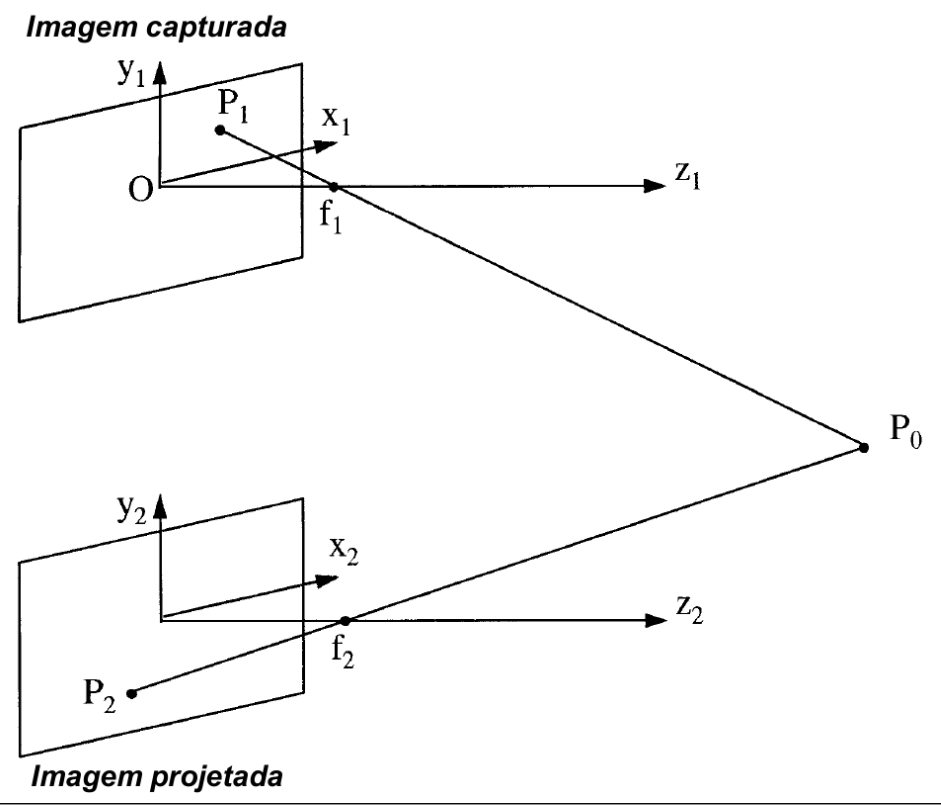

imagem. Assim, com relação a $O$, ele se localiza em

$$
O_{2}=\left[\begin{array}{l}
x_{2} \\
y_{2} \\
z_{2}
\end{array}\right] .
$$

Suponha que o ponto focal, com relação a $\mathrm{O}_{2}$, esteja localizado na posição

$$
F_{2}=\left[\begin{array}{c}
0 \\
0 \\
f_{2}
\end{array}\right] \text {. }
$$

Em relação ao sistema de coordenadas global $O, F_{2}$ está localizado em

$$
F_{2}=\left[\begin{array}{c}
x_{2} \\
y_{2} \\
z_{2}+f_{2}
\end{array}\right]
$$


Assim, se puder ser suposto que o ponto capturado no primeiro plano de imagem foi projetado pelo segundo sistema de imageamento, o ponto imagem $P_{2}=$ $\left(x_{P_{2}}, y_{P_{2}}, 0\right)^{T}$ com relação ao sistema de coordenadas global pode ser expresso como

$$
P_{2}=\left[\begin{array}{c}
x_{2} \\
y_{2} \\
z_{2}
\end{array}\right]+\left[\begin{array}{c}
x_{P_{2}} \\
y_{P_{2}} \\
0
\end{array}\right]=\left[\begin{array}{c}
x_{2}+x_{P_{2}} \\
y_{2}+y_{P_{2}} \\
z_{2}
\end{array}\right] .
$$

Uma vez que o mesmo ponto objeto é considerado, tem-se:

$$
\begin{gathered}
P_{2}=F_{2}+\beta\left(P_{0}-F_{2}\right) \\
{\left[\begin{array}{c}
x_{2}+x_{P_{2}} \\
y_{2}+y_{P_{2}} \\
z_{2}
\end{array}\right]=\left[\begin{array}{c}
x_{2} \\
y_{2} \\
z_{2}+f_{2}
\end{array}\right]+\beta\left[\begin{array}{c}
x_{P_{0}}-x_{2} \\
y_{P_{0}}-y_{2} \\
z_{P_{0}}-z_{2}-f_{2}
\end{array}\right] .}
\end{gathered}
$$

Logo, sumarizando, das equações (2.7) e (2.13) obtém-se:

$$
\begin{gathered}
x_{P_{0}}=\frac{f_{1}-z_{P_{0}}}{f_{1}} x_{P_{1}}, \\
y_{P_{0}}=\frac{f_{1}-z_{P_{0}}}{f_{1}} y_{P_{1}}, \\
x_{P_{0}}=x_{2}+\frac{f_{2}+z_{2}-z_{P_{0}}}{f_{2}} x_{P_{2}} \quad \mathrm{e} \\
y_{P_{0}}=y_{2}+\frac{f_{2}+z_{2}-z_{P_{0}}}{f_{2}} y_{P_{2}} .
\end{gathered}
$$

Portanto, igualando a primeira com a terceira e a segunda com a quarta equações da seqüência acima, tem-se:

$$
\begin{gathered}
\frac{f_{1}-z_{P_{0}}}{f_{1}} x_{P_{1}}=x_{2}+\frac{f_{2}+z_{2}-z_{P_{0}}}{f_{2}} x_{P_{2}} \quad \text { e } \\
\frac{f_{1}-z_{P_{0}}}{f_{1}} y_{P_{1}}=y_{2}+\frac{f_{2}+z_{2}-z_{P_{0}}}{f_{2}} y_{P_{2}} .
\end{gathered}
$$


Estas últimas, quando simplificadas, fornecem

$$
\begin{gathered}
z_{P_{0}}=\frac{f_{1} f_{2}}{f_{1} x_{P_{2}}-f_{2} x_{P_{1}}}\left(x_{2}+x_{P_{2}}-x_{P_{1}}+\frac{z_{2} x_{P_{2}}}{f_{2}}\right) \mathrm{e} \\
z_{P_{0}}=\frac{f_{1} f_{2}}{f_{1} y_{P_{2}}-f_{2} y_{P_{1}}}\left(y_{2}+y_{P_{2}}-y_{P_{1}}+\frac{z_{2} y_{P_{2}}}{f_{2}}\right) .
\end{gathered}
$$

Em resumo, note que $z_{P_{0}}$, e conseqüentemente $x_{P_{0}}$ e $y_{P_{0}}$, pode ser calculado dadas as coordenadas $\left(x_{P_{1}}, y_{P_{1}}\right)$ de seu ponto imagem na imagem capturada e as coordenadas $\left(x_{P_{2}}, y_{P_{2}}\right)$ no sistema de imagem projetado. Evidentemente, $f_{1}, f_{2}$, $x_{2}, y_{2}$ e $z_{2}$ devem ser previamente determinados no processo de calibração.

Note que $z_{P_{0}}$ pode ser obtido somente conhecendo-se a coordenada $x_{P_{2}}$ ou a coordenada $y_{P_{2}}$. Esta dedução é muito importante quando a luz de projeção é codificada para obter diretamente as coordenadas de $P_{2}$ que corresponde ao ponto capturado $P_{1}$. A técnica de projeção codificada será discutida com mais detalhes.

Se a orientação de ambos os planos de imagem não for a mesma, então uma matriz de rotação deve ser incluída com o vetor de translação descrito de modo que uma nova matriz $\mathrm{M}$, a qual descreve a rotação e a translação do sistema de coordenadas $\mathrm{O}_{2}$ em relação ao sistema de coordenadas global $O$, deve ser definida. A equação (2.22) mostra a representação com relação a $O$ de um determinado ponto projetado $P_{2}$ expresso com relação a $\mathrm{O}_{2}$.

$$
\overline{P_{2}}=\mathrm{M} P_{2}
$$

\subsubsection{Codificação do Padrão Projetado}

Diversos padrões diferentes têm sido propostos para fazer a correspondência entre o plano de imagem e a imagem projetada com uma certa precisão. Eles podem ser classificados como: ponto único, linha reta, grade e matriz de pontos. No entanto, a fim de resolver o problema da correspondência, muitos desses padrões possuem variados problemas. Para qualquer tipo de objeto e superfície também há o problema devido à perda de pontos projetados que não têm uma projeção no plano da imagem. Esta característica pode dever-se à baixa reflexão da superfície, a uma oclusão da superfície ou simplesmente porque alguns pontos são refletidos fora do escopo 
da câmera. Todos esses problemas podem ser resolvidos se o padrão projetado for convenientemente codificado, de modo que a luz projetada carregue informação sobre o ponto $\left(x_{P_{2}}, y_{P_{2}}\right)$ a partir do qual foi emitido.

Na seqüência, algumas classificações de padrões de luz estruturada codificada são apresentadas. As diferentes técnicas que codificam o padrão estruturado sofreram três classificações. Levando em conta somente a dependência temporal, o padrão pode ser classificado em:

Estático: O padrão é limitado a cenas estáticas com objetos sem movimento. Isto deve-se sempre à necessidade de se projetar um conjunto de diferentes padrões para obter, de forma codificada, o rótulo para cada coluna (ou linha) do padrão. Qualquer movimento na cena entre dois quadros de projeção do padrão sempre produz um erro de correspondência.

Dinâmico: O padrão não é limitado a cenas estáticas. Assim, se os objetos da cena podem se mover, a coluna ou linha da imagem do projetor deve ser codificada com uma única projeção de padrão.

Olhando somente para a luz projetada, o padrão pode ser classificado em:

Binário: Qualquer um dos pontos $\left(x_{P_{2}}, y_{P_{2}}\right)$ do padrão pode possuir somente um de dois possíveis valores, os quais são codificados como 0 ou 1. Este valor binário geralmente representa opacidade e transparência, a ausência ou presença da luz projetada no objeto.

Nível de cinza: Cada ponto do padrão pode ter um valor de cinza associado, o qual representa o nível de transparência (ou opacidade) do ponto em detrimento da luz projetada. Uma vez que a informação é codificada como um nível de luz cinza, normalmente são necessários dois passos a fim de se obter a informação 3D. Primeiramente, tem-se que obter uma imagem da cena iluminada com a mesma intensidade de luz para cada ponto (sem codificação alguma). Em segundo lugar, precisa-se obter a luz de referência necessária para cancelar o efeito de reflexão da superfície, o que depende do tipo de superfície em que a luz é refletida. Esta limitação significa que o padrão também deve ser classificado como um padrão estático. 
Colorido: Cada ponto do padrão deve ser associado a um valor de matiz. Com o objetivo de usar a propriedade de constância da cor, os valores de brilho usados devem ser muito diferentes entre si. A principal meta é obter uma segmentação eficiente e precisa. Já que o sistema projeta cor na cena, seu uso é limitado a uma cena neutra em relação a cores, pois objetos coloridos altamente saturados podem produzir regiões de padrão perdido no passo de segmentação e posterior decodificação.

Não obstante, uma outra classificação pode ser proposta, a qual classifica o padrão a partir de sua dependência das descontinuidades presentes na profundidade da superfície. Portanto, olhando para esta dependência, ele pode ser classificado como:

Periódico: A codificação é periodicamente repetida ao longo do padrão. Comumente, essa técnica é usada para reduzir o número de bits que codifica o padrão, mas produz uma limitação na descontinuidade da profundidade, a qual não pode ser maior que a metade do comprimento do período.

Absoluto: Cada coluna ou linha do padrão projetado possui uma codificação única. Assim, não há qualquer dependência de descontinuidade da profundidade.

\subsubsection{Conclusões}

A precisão da mensuração de superfície depende altamente do sistema de visão usado. É amplamente conhecido que um sistema de visão baseado em estereoscopia é útil para medir superfícies com bordas bem definidas. Um algoritmo para reconhecer pontos singulares pode ser usado para resolver o problema da correspondência entre pontos em ambos os planos de imagem. Mas o sistema de estereoscopia torna-se um tanto ineficiente para medir superfícies contínuas, nas quais não há muitos pontos de referência. Também há diversos problemas em superfícies com textura ou com muitas descontinuidades. Nesses ambientes, a abundância de pontos de referência pode produzir erros de casamento. Em tais casos, um sistema ativo baseado no conceito de luz estruturada é útil. 
Em luz estruturada, uma correspondência entre o padrão capturado, amostrado pela câmera, e o padrão projetado na cena deve ser determinada. Resolver o problema de correspondência pode demandar muito tempo de computação, e às vezes pode ser contraproducente, usando apenas restrições geométricas entre a câmera e o projetor. Nos últimos anos, várias técnicas de luz estruturada codificada foram propostas, de maneira que a luz emitida carrega informação sobre a posição em relação ao sistema de coordenadas do projetor a partir do qual ela veio. Essa informação permite resolver a correspondência câmera-projetor diretamente.

Muitos trabalhos tratam de diferentes técnicas para a codificação do padrão projetado na cena, cada um possuindo suas vantagens e desvantagens. Dentre estes, podemos citar os seguintes métodos: (a) mensuração de cenas dinâmicas, nas quais somente um padrão pode ser projetado para determinar a correspondência, e de cenas estáticas, nas quais a projeção seqüencial de diversos padrões é permitida, (b) mensuração de cenas compostas por objetos coloridos altamente saturados, com basicamente apenas padrões binários projetados (baseado na presença ou ausência de luz emitida); ou a mensuração de cenas com um conteúdo colorido predominantemente neutro, na qual a emissão de cor é permitida para fazer uma fácil codificação do padrão; superfícies especulares ou metálicas também podem ser incluídas, mas elas sempre levam a um sistema específico [Capson \& Eng, 1988; Hata, 1992; Sanderson et al., 1988]. A reflexão da região de um padrão em outra superfície já iluminada produz uma identificação errônea evidente da imagem capturada pela câmera; (c) mensuração de cenas com muitas descontinuidades, de várias profundidades diferentes, nas quais só é permitido uma codificação absoluta. Então, o padrão projetado é mais complicado e se não se quer reduzir a resolução, o número de bits deve ser aumentado; ou mensuração de cenas predominantemente contínuas, nas quais padrões periódicos muito simples podem ser projetados, fornecendo uma rápida identificação e uma solução de alta velocidade para o problema da correspondência.

O conhecimento sobre a presença ou ausência de controle sobre a luz de iluminação da cena é outro importante conceito em luz estruturada. Se for conhecido que na cena há somente a luz projetada pelo padrão ou se há qualquer outra fonte com propriedades conhecidas, então o padrão pode ser bastante simplificado. Recentemente, algumas novas fontes de luz foram propostas, tais como uma ma- 
triz de pontos que emite um conjunto de luzes pontuais de igual intensidade [Darlin et al., 1996] e uma matriz de blocos de intensidade com $100 \%$ de eficiência da luz [Glückstad, 1995], as quais tornam o processo de segmentação mais fácil. Também há alguns projetos baseados na integração de matrizes de microlaser para a projeção de padrões com alta resolução [Nahata \& Murdocca, 1996] e outros que projetam uma matriz de pontos em superfícies altamente refletoras e dinâmicas, como na análise de ondas do mar [Grant et al., 1995].

Contudo, muito trabalho resta a ser feito para obter um sistema de visão genérico que nos permita conseguir uma mensuração instantânea de uma cena desconhecida, obter um mapa 3D a partir dela e então classificar e reconhecer todos os objetos que formam a cena [Besl \& Jain, 1986; Hoffman \& Jain, 1987].

\section{O Algoritmo ICP (Iterative Closest Point)}

O algoritmo ICP foi introduzido por Besl \& McKay [1992] e se tornou a principal técnica para o registro de conjuntos de dados 3D. O algoritmo recebe dois conjuntos de dados 3D como entrada. Sejam $P$ e $Q$ dois conjuntos de dados contendo $N_{p}$ e $N_{q}$ pontos respectivamente. Ou seja, $P=\left\{p_{i}\right\}, i=1, \ldots, N_{p}$ e $Q=\left\{q_{i}\right\}, i=1, \ldots, N_{q}$. O objetivo é calcular uma matriz de rotação $R$ e um vetor de translação $t$ tais que o conjunto transformado $P^{\prime}=R P+t$ fique bem alinhado com $Q$. Segue abaixo um sumário do algoritmo (veja a Figura 2.3 para uma ilustração do funcionamento do ICP).

(1) Inicialização: $k=0$ e $P_{k}=P$.

(2) Cálculo do ponto mais próximo: Para cada ponto em $P_{k}$, calcula o ponto mais próximo em $Q$. Consequentemente, produz um conjunto de pontos mais próximos $C=\left\{c_{i}\right\}, i=1, \ldots, N_{p}$ em que $C \subset Q$ e $c_{i}$ é o ponto mais próximo a $p_{i}$. 
Figura 2.3 Ilustração do algoritmo ICP.

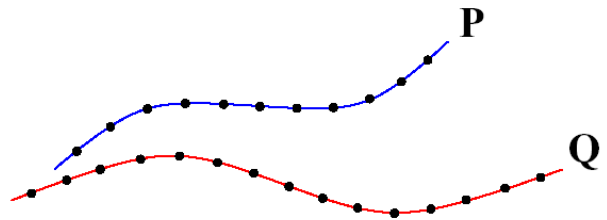

(a)

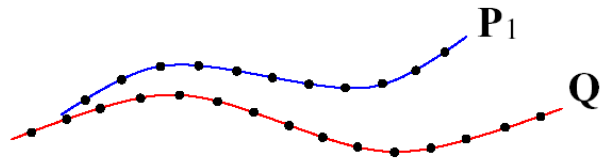

(c)

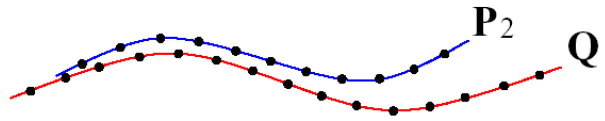

(e)

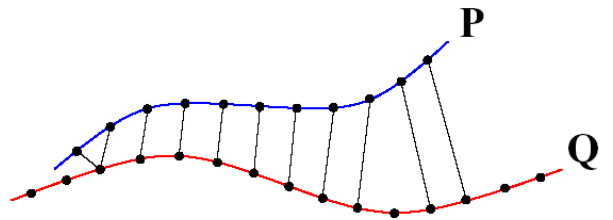

(b)

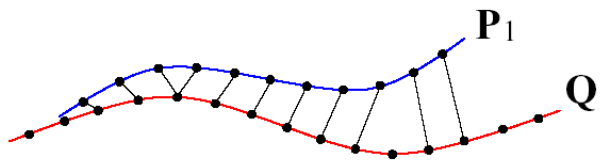

(d)

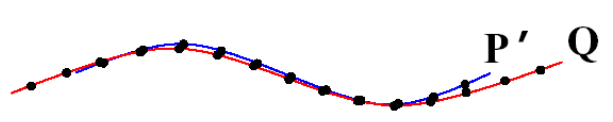

(f)

(3) Cálculo do registro: Dado o conjunto de pontos mais próximos $C$, a função objetivo de quadrados médios a ser minimizada é:

$$
f(R, t)=\frac{1}{N_{p}} \sum_{i=1}^{N_{p}}\left\|c_{i}-R p_{i}-t\right\|^{2}
$$

Note que $p_{i}$ é um ponto do conjunto original $P$, não de $P_{k}$. Portanto, o registro calculado aplica-se ao conjunto de dados originais $P$ ao passo que os pontos mais próximos são calculados usando $P_{k}$.

(4) Aplicação do registro: $P_{k+1}=R P+t$.

(5) Se a precisão desejada para o registro for alcançada: Finalize a iteração.

Senão: $k=k+1$. Repita os passos 2-5. 
Figura 2.4 Vantagem do algoritmo de Chen e Medioni. (a) Resultado do método de correspondência do ICP original na presença de ruído e outlier. (b) Uma vez que o algoritmo de Chen e Medioni usa pontos de controle em áreas suaves e suas direções normais, ele é menos sensível a ruídos e outliers.

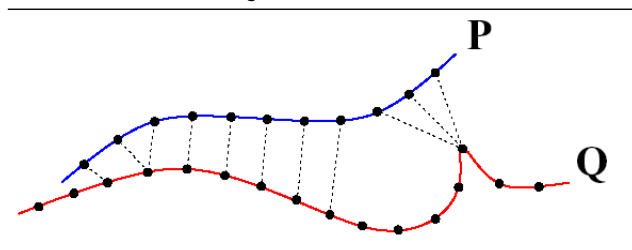

(a)

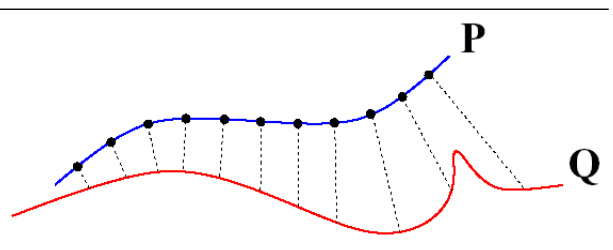

(b)

\subsubsection{Variantes do ICP}

Desde a introdução do algoritmo ICP, várias modificações foram desenvolvidas a fim de melhorar sua performance.

Chen \& Medioni [1992] desenvolveram um algoritmo similar ao mesmo tempo. A principal diferença é a estratégia para seleção de ponto e para encontrar a correspondência entre dois conjuntos de dados. O algoritmo primeiro seleciona pontos iniciais em uma grade regular e calcula a curvatura local destes pontos. Somente são selecionados pontos em áreas suaves, os quais eles chamam de pontos de controle. Seu método de seleção de ponto visa a economia de tempo de computação e a obtenção de direções normais confiáveis para os pontos de controle. Dados os pontos de controle de um conjunto de dados, o algoritmo encontra a correspondência por meio do cálculo da intersecção da linha que passa pelo ponto de controle na direção de sua normal e a superfície do outro conjunto de dados. Embora os autores não tenham mencionado em seu artigo, uma outra vantagem deste método é que a correspondência é menos sensível a ruídos e outliers. Conforme ilustrado na Figura 2.4, o método de correspondência do ICP original pode selecionar outliers no conjunto de dados $Q$ como pontos correspondentes, uma vez que a distância é a única restrição. No entanto, o método de Chen e Medioni é menos sensível a ruídos, já que as direções normais dos pontos de controle em $P$ são confiáveis e o ruído em $Q$ não possui efeito na busca pela correspondência. 


\subsubsection{Registro Inicial e Registro Multivisão}

\section{Registro Inicial}

Dados dois conjuntos de dados para registrar, o algoritmo ICP converge para diferentes mínimos locais dependendo das posições iniciais dos conjuntos de dados. Portanto, não é garantido que o algoritmo ICP convergirá para o mínimo global desejado e a única forma de assegurar o mínimo global é encontrando o mínimo de todos os mínimos locais. Esta é uma limitação fundamental do ICP, o que requer um bom registro inicial como ponto de partida para maximizar a probabilidade de convergência para o registro correto.

Conforme mencionado antes, pode-se providenciar registros iniciais por meio de um sistema de rastreamento que forneça as posições relativas de cada ponto de varredura. Uma outra opção é o fornecimento de registros iniciais manualmente por interação humana. Alguns pesquisadores propuseram outras técnicas para determinar registros iniciais [Chen et al., 1998; Faugeras \& Hebert, 1986; Hebert et al., 1995; Johnson \& Hebert, 1997], mas foi relatado [Pulli, 1999] que tais métodos não funcionam de modo confiável para dados arbitrários.

\section{Registro Multivisão}

Embora as técnicas vistas até este ponto somente lidem com registro pareado, elas podem ser facilmente estendidas para registro multivisão, registrando múltiplas imagens range enquanto minimiza o erro de registro entre todos os pares possíveis. Uma forma simples e óbvia é executar, seqüenciamente, um registro pareado para cada duas imagens range vizinhas. Esta abordagem, porém, acumula os erros de cada registro, o que pode resultar num grande erro entre a primeira e a última imagem range.

Chen e Medioni foram os primeiros a tratar as questões do registro multivisão. Seu registro multivisão possui os seguintes passos: primeiramente, um registro pareado entre duas imagens vizinhas é feito. O dado registrado resultante é chamado de metavisão. Então, um outro registro, entre uma nova imagem range ainda não registrada e a metavisão é realizado e os novos dados são adicionados à metavisão após o registro. Este processo é repetido até que todas as imagens range sejam 
registradas.

\section{Biblioteca de Malha Dinâmica Adaptativa baseada em Operadores Estelares}

Na conclusão deste trabalho, será usada uma biblioteca de malhas criada pelo professor Luiz Velho [Velho, 2004, 2006] chamada A48. Tal biblioteca mantém uma triangulação uniforme de superfícies que variam com o tempo. O usuário fornece uma malha inicial, um procedimento de amostragem da superfície e um conjunto de critérios de adaptação. Conforme a superfície sofre alterações com o tempo, a malha é automaticamente modificada, a fim de manter-se segundo as características definidas pelo usuário. A representação da malha é baseada em uma estrutura de dados conhecida por meia-aresta, desprovida de qualquer requisito extra para armazenamento. A malha possui uma estrutura subjacente de multiresolução semiregular. Além disso, a especificação das características da malha desejada pode ser baseada em regras de adaptação muito gerais. Este esquema facilita o desenvolvimento de aplicações gráficas que manipulam superfícies trianguladas.

\subsubsection{Visão Geral}

Malhas poligonais são indiscutivelmente a representação mais comum para superfícies em modelagem geométrica e computação gráfica.

Em muitas aplicações, a superfície é dinâmica e muda sua forma com o passar do tempo. Isso abrange um grande número de problemas, da animação de corpos deformáveis à multiescala progressiva para transmissão e visualização. Há outras aplicações em que a forma da superfície é fixa, mas a discretização da mesma deve ser alterada por razões computacionais. Isto ocorre, por exemplo, no caso de simulações de elemento finito (FEM, do inglês Finite Element Simulations) com corpos rígidos.

Nas situações descritas acima, a aplicação idealmente deveria estar preocupada com a resolução do problema em mãos, usando uma representação de malha somente como um meio de executar cálculos. 
Na prática, no entanto, é muito comum que uma parte significativa do esforço no desenvolvimento de tais aplicações deva-se à tarefa de manutenção da representação da malha. Pior ainda, às vezes é difícil separar partes da implementação relacionadas ao domínio principal do problema em questão de partes relacionadas à infraestrutura da malha, tornando o código menos portável e propenso a erros.

A fim de superar estes inconvenientes, é desejável possuir uma biblioteca de malha que possa encapsular toda a funcionalidade para o suporte à representação de malhas dinâmicas. A implementação deve ser robusta, computacionalmente eficiente e econômica em termos de espaço de memória. Não obstante, a API deve ser simples e fornecer o nível correto de abstração.

Esta subseção apresenta um esquema simples para criação e manutenção da representação de uma malha de superfícies que variam com o passar do tempo e que trata de todos os requisitos mencionados acima. Como um benefício adicional, a representação da malha possui uma estrutura subjacente de multiresolução semiregular, a qual pode ser explorada de diversas formas. A presente descrição baseiase no artigo em que a biblioteca A48 foi apresentada [Velho, 2004].

Mais especificamente, as características relevantes deste programa são:

Uma biblioteca de malha dinâmica adaptativa simples baseada na meia-aresta, uma estrutura de dados topológica padrão. A implementação desta nova funcionalidade de multiresolução adaptativa não requer nenhum armazenamento extra na representação. Também, uma vez que a meia-aresta é largamente adotada, é fácil incorporar a biblioteca em muitas aplicações.

Uma API mínima para criação e adaptação de malhas. Esta interface complementa os tradicionais operadores de consulta topológica e consiste de apenas poucas funções.

Uma estrutura de malhas conforme, que altera dinamicamente sua resolução baseada em critérios definidos pelo usuário. Isso torna as potencialidades de adaptação associadas muito gerais e poderosas.

Um mecanismo efetivo para o refinamento e a simplificação de malhas semiregulares que mantém uma estrutura de multiresolução restrita. Este mecanismo 
é baseado no conceito de uma multi-triangulação binária restrita e na teoria estelar.

O esquema da biblioteca é baseado em operadores de aresta. Operadores de aresta são comumente usados devido a suas boas propriedades de adaptação. Por exemplo, Bowden et al. [1997] empregam um modelo de balão inflável para reconstruir a superfície a partir de dados volumétricos. Neste modelo, a malha dinâmica é baseada em refinamento por bisecção de arestas. Kobbelt et al. [2000] propuseram uma representação multiresolução de formas baseada na suavização da geometria e malhas dinâmicas que são modificadas pela junção, divisão e inversão de arestas.

Esquemas existentes para malhas dinâmicas geralmente são desenvolvidos no contexto de aplicações específicas. Diferentemente de muitos trabalhos anteriores, o esquema da biblioteca A48 é independente da aplicação. Além disso, ela baseiase em movimentos estelares nas arestas, os quais têm o poder expressivo para a implementação de transformações arbitrárias em campos combinatórios [Lickorish, 1999].

A representação de malha dinâmica da biblioteca A48 possui uma estrutura subjacente de multiresolução. Representações de multiresolução podem ser definidas por meio de operações locais ou globais em uma malha [Garland, 1999]. Com o objetivo de dar suporte à adaptação, a estrutura de dados de multiresolução deve ser construída usando operações locais. Malhas progressivas [Hoppe, 1998] constituem um exemplo de tal estrutura de dados. Outro exemplo é a malha 4-K hierárquica [Velho \& Gomes, 2000]. Neste tipo de representação, diferentes malhas podem ser extraídas dinamicamente a partir da estrutura de dados. Contudo, operações locais precisam ser explicitamente armazenadas. No esquema em questão, somente a malha corrente é armazenada na representação. Os movimentos legais que alteram a resolução da malha são definidos implicitamente.

Até onde sabemos, não há nenhuma outra proposta para a representação de uma malha dinâmica que possua uma estrutura subjacente de multiresolução implícita e que seja independente da aplicação. Apesar disso, há um crescente interesse no desenvolvimento de bibliotecas de malhas genéricas [Fabri et al., 2000].

O esquema de adaptação usado pela biblioteca A48 é ortogonal à infraestrutura existente em uma biblioteca de malha geral. Neste sentido, ela complementa tais 
bibliotecas com a funcionalidade adicional de que pode ser implementada no topo das representações de malha baseadas em arestas, tais como a OpenMesh [Botsch et al., 2002]. 



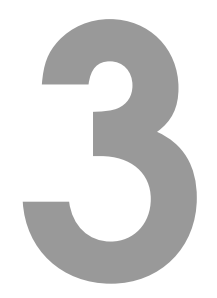

\section{Vídeo 3D}

ESTE CAPÍTULO é descrito o sistema de vídeo 3D em tempo real baseado em estéreo ativo desenvolvido no IMPA. Trata-se do sistema que fez a captura dos dados usados neste trabalho. Combinando equipamento composto por projetor e câmera no padrão NTSC e um código de cores adequado, as informações geométricas e fotométricas de uma cena são obtidas de forma robusta a 30 quadros por segundo. A principal motivação para o desenvolvimento deste sistema foi a criação de uma plataforma que permitisse investigar as questões que serão propostas pela próxima geração de vídeo digital e como ela modelará uma nova mídia. Este texto foi baseado em artigos que introduziram a técnica de vídeo 3D desenvolvida por pesquisadores do IMPA [Sá et al., 2002; Vieira et al., 2005].

A Seção 3.1 nos dá uma idéia geral do funcionamento do sistema de vídeo 3D. A Seção 3.2 fornece uma visão geral de trabalhos relacionados. Na Seção 3.3 é apresentado o código de cores (b, s)-BCSL, o qual é a base para a correspondência ativa entre os espaços das imagens da câmera e do projetor. Os requisitos, a configuração e a calibração do hardware para usar o código (b, s)-BCSL são apresentados na Seção 3.4. Os detalhes sobre como o fluxo de vídeo é gerado, capturado e processado no sistema são dados na Seção 3.5, juntamente com exemplos de funcionamento do sistema. Por fim, um sumário e uma conclusão são fornecidos na Seção 3.6. 


\section{SEÇÃO 3.1 \\ Introdução}

O desenvolvimento das primeiras gerações de vídeo digital foi focado em fundamentos tecnológicos, características do sistema e definição de padrões. Neste sentido, o resultado foi uma melhora significativa dos aspectos evolucionários, tal como a resolução das imagens. No entanto, o tipo de dados permaneceu o mesmoi.e., informações de cor e som.

A aquisição e manipulação de informação de vídeo 3D é um tópico chave da pesquisa recente em visão computacional e computação gráfica [Huang et al., 2003; Zhang et al., 2004]. Há vários problemas importantes em aberto na área e que a pesquisa no estado da arte começou a tratar nos últimos tempos.

A próxima geração de vídeo digital trará verdadeiras inovações revolucionárias por meio da incorporação de novos tipos de dados à mídia. A informação de profundidade é certamente a candidata mais natural como tipo de dado a ser acrescentado ao vídeo digital. Ela não só é consoante com o sistema de percepção humano como também facilita a análise de cenas por computadores, permitindo a extração de informação a níveis mais altos de abstração.

O conteúdo deste capítulo é a descrição de uma primeira fase do vídeo de quarta geração, um projeto que pretende investigar o próximo formato de vídeo digital. $\mathrm{O}$ sistema é uma plataforma completa para vídeo 3D, constituído por:

dispositivo de aquisição;

processamento de dados;

módulo de transmissão, e

módulo de visualização.

Este sistema gera vídeo 3D em tempo real a partir de cenas de diversos tipos, incluindo a presença de objetos fixos ou móveis, rígidos ou maleáveis, constituídos por diversos tipos de materiais, com cores e texturas variadas, etc.

O dispositivo de aquisição emprega estéreo ativo, sendo composto por uma câmera de vídeo e um projetor, sincronizados e calibrados tanto geométrica quanto fotometricamente. $\mathrm{O}$ módulo de processamento de dados extrai informação sobre 
profundidade a partir de um código de luz estruturada. O módulo de transmissão trata da entrada e saída de dados, bem como da compressão e descompressão do fluxo dos mesmos. Finalmente, o módulo de visualização renderiza vídeo 3D por meio do uso de geometria dinâmica baseada em pontos induzidos pelo código de cores usado.

A calibração é um componente muito importante do sistema. Ela inclui ambas as calibrações geométrica e fotométrica da câmera e do projetor. O uso de métodos probabilísticos baseados em conhecimento prévio torna o sistema mais robusto e confiável. Também é explorada a coerência espaço-temporal.

Este sistema de aquisição dos dados foi proposto recentemente e é conhecido como Vídeo 4D [Vieira et al., 2005]. Ele provê ambas as informações de geometria e textura dinâmicas da cena em tempo real. Este sistema é parte de um projeto para a obtenção de vídeo 4-dimensional, que é um conceito novo. Um vídeo 4D pode ser entendido como objetos $3 D$ genéricos variando no decorrer do tempo. Mais especificamente, ele pode representar objetos embutidos em volumes, mudando para qualquer forma em função de algumas variáveis independentes.

A idéia principal por trás do conceito de vídeo 4D é a construção incremental da geometria estruturada da cena, ou seja, a geração de informação 3D completa acumulada com o passar do tempo ( $4 \mathrm{D}=3 \mathrm{D}+$ tempo). Esta idéia representa um passo além do tradicional vídeo de profundidade (range video) no qual cada quadro fornece informação de profundidade a partir do ponto de vista da câmera (ou seja, imagens range). $\mathrm{O}$ conceito de vídeo 4D abre novas possibilidades interessantes e que foram muito pouco exploradas até agora. Até onde se sabe, ainda não há método algum que tenha resolvido completamente este problema.

A maior dificuldade é como integrar a informação $2 \frac{1}{2} \mathrm{D}$ de cada quadro ao longo do tempo. Um passo intermediário necessário, tratado no Capítulo 4, é o rastreamento e o casamento da estrutura de objetos 3D presentes no decorrer do vídeo. $\mathrm{O}$ fato de os objetos poderem ser deformáveis (ou seja, não-rígidos) representa uma dificuldade adicional de todo o processo.

Neste trabalho, a pesquisa vem sendo feita em conjunto com outros dois pesquisadores do Instituto Nacional de Matemática Pura e Aplicada (IMPA): Luiz Velho e Marcelo Bernardes Vieira. 


\section{Trabalhos Relacionados}

Chamamos de vídeo 3D a uma imagem que varia com o tempo e que possui informação de cor e profundidade. O primeiro desafio do vídeo 3D é o projeto e o desenvolvimento de um dispositivo de aquisição.

Em geral, métodos de aquisição 3D em visão computacional dependem fortemente de correspondência e calibração. Estes métodos podem ser classificados baseando-se nos tipos de dados de entrada que são usados e em como correspondências são obtidas para triangulação de profundidade.

A escolha mais comum para aquisição 3D seria um sistema baseado em um par de câmeras e o uso de métodos estéreo passivos. Contudo, estéreo geral completo é um problema de inversão mal-posto, o qual é muito difícil de resolver-e as requisições de tempo real tornam as coisas ainda mais difíceis. A literatura sobre métodos estéreo passivos é muito extensa e, por esta razão, a discussão aqui será restrita apenas a sistemas de tempo real. Muitos dos algoritmos propostos não podem ser executados em tempo real sem que façam uso de algum tipo de aceleração por hardware. Neste contexto, uma tendência recente é tirar vantagem de GPUs programáveis [Yang \& Pollefeys, 2003]. Outra opção é o uso de múltiplas câmeras fixas seguida por uma análise da cena, de modo a obter a decomposição da cena em fundo e frente. Esta é a base para métodos de casco visual e fotográfico [Gross et al., 2003; Matusik et al., 2000].

Uma alternativa a algoritmos estéreo passivos é um sistema baseado em câmera e projetor e em estéreo ativo. Esta opção possui a vantagem de fazer uso de algoritmos estéreo restritos mais simples e robustos, mas o preço é que um padrão de luz deve ser projetado sobre a cena. Trabalhos recentes nesta área investigam diferentes configurações de câmeras e projetores [Huang et al., 2003; Zhang et al., 2004]. Em geral, o padrão de luz projetado define as características da captura. O método proposto em Koninckx et al. [2003] usa um padrão de uma tomada, auto-adaptativo, para captura 3D em tempo real a 20 qps. Usando métodos mais simples, o sistema do IMPA fornece vídeo 3D a 30 qps.

O sistema desenvolvido no IMPA também é baseado em um par câmera/projetor e em estéreo ativo (vide Figura 3.1). O dispositivo de aquisição é construído com 


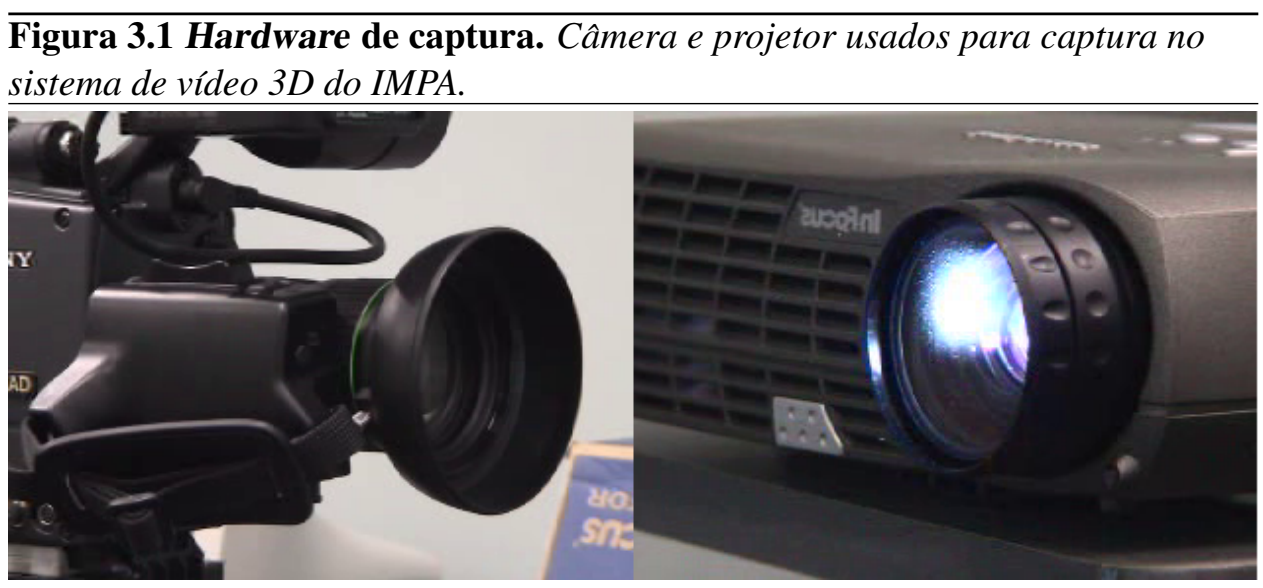

equipamento de vídeo NTSC facilmente encontrado no mercado. Isso traz diversas vantagens como uma boa relação custo-benefício, facilidade de sincronização, compatibilidade e muitas opções de canais de distribuição. A configuração atual do sistema é similar à proposta em Rusinkiewicz et al. [2002]. No entanto, o sistema do IMPA é mais eficiente devido ao uso do código de cores $(6,2)$-BCSL. Este reduz o número de imagens necessárias para a detecção de geometria e de fotometria.

\section{O Método (b, s)-BCSL}

Para detectar componentes geometricamente conexas em uma cena, o sistema de captura 3D deve fornecer imagens e geometria de alta qualidade em tempo real. Qualidade é crucial para a obtenção de análises e sínteses precisas. O tempo real é necessário para a exploração de coerência no tempo e para a captura de movimentos sutis de componentes conexas, bem como para a redução de problemas de casamento durante a análise espaço-temporal.

A reconstrução da profundidade da cena é obtida por meio de triangulação das correspondências entre a câmera e o projetor. A chave de todo o processo de modelagem 3D do sistema usado pelo IMPA é baseada em uma extensão do método (b, s)-BCSL de cores [Sá et al., 2002] para trabalhar com cenas dinâmicas, por meio da combinação com um vídeo sincronizado. 
No desenvolvimento de um código de cores para luz estruturada, os principais parâmetros a serem considerados são o número de diferentes cores (i.e., o comprimento da base $b$ do código de cores) e o número $s$ de slides projetados a cada passo da aquisição de geometria. Um número maior de palavras de código pode ser obtido se as transições entre as faixas são codificadas no lugar das faixas por si mesmas. Para um esquema de codificação de fronteiras, assumindo que $s$ slides e $b$ cores são usados no código, o número de diferentes palavras de código é $[b(b-1)]^{s}$ (assume-se que duas faixas sucessivas não podem ter a mesma cor, de modo a evitar fronteiras fantasmas). O código resultante será referenciado como (b, s)-BCSL, conforme proposto em Sá et al. [2002].

O objetivo no desenvolvimento de um esquema BCSL é ser capaz de prover resolução satisfatória sem, no entanto, tornar o reconhecimento de faixas muito complexo e sem impor fortes restrições de coerência na cena.

O código (b, s)-BCSL fornece um eficiente esquema de correspondência câmera/projetor. Trata-se de um código para fronteira de luz colorida estruturada, consistindo de uma seqüência de $s$ padrões de faixas a serem projetados, cada um com $b$ cores. O uso de padrões complementares é necessário para detectar, de forma robusta, transições de faixas e cores. O sistema do IMPA utiliza 6 cores que podem ser detectadas, sem ambigüidades, por meio de cruzamentos com zero: vermelha, verde, azul, ciano, magenta e amarela. Este conjunto de cores é geralmente referenciado pela sigla RGBCMY, aludindo às iniciais dos nomes destas na língua inglesa.

Esquemas que possuam $s=1$ são códigos puramente espaciais, que não impõem restrição alguma ao movimento de objetos. Para $s>1$, temos códigos espaço-temporais. Dentre estes, o caso $s=2$ reduz a necessidade de coerência no tempo a um mínimo. Um aumento no número de slides permite usar um número maior de faixas, aumentando portanto a resolução que pode ser obtida usando-se o código. Aumentando a base de cores $b$ também aumenta o número de faixas possíveis. Contudo, a distinção de faixas na fase de decodificação torna-se difícil de fazer e as restrições sobre propriedades refletivas da cena passam a ser mais severas.

Nos experimentos do IMPA, foi adotado um código $(6,2)$-BCSL, ou seja, 2 padrões compostos pelas 6 cores citadas, o que caracteriza mais de 900 combi- 
nações de faixas possíveis. Dois padrões é o mínimo permitido. A configuração escolhida fornece a melhor razão entre a coerência espaço-temporal e o comprimento do código.

O que o sistema emprega, na realidade, é uma seqüência de pares de padrões complementares: $S_{1} \overline{S_{1}} S_{2} \overline{S_{2}}$. Toda faixa colorida é projetada e seguida pela projeção de uma outra faixa que possua uma cor complementar, a fim de facilitar a detecção, de forma robusta, das fronteiras das faixas. Este cálculo é feito a partir da diferença das duas imagens resultantes. As fronteiras das faixas tornam-se cruzamentos com zero nas imagens consecutivas e podem ser detectadas com precisão sub-pixel.

Um padrão $S_{1}$ é uma imagem composta por diversas faixas verticais coloridas, de forma que o padrão $\overline{S_{1}}$ é uma outra imagem, também composta por faixas verticais de mesma largura e posição que as faixas do padrão $S_{1}$, só que com cores complementares. Este esquema faz com que a identificação do código seja muito robusta e a localização das fronteiras mais precisa. A reconstrução completa de uma geometria é obtida após a projeção de um padrão $S_{1}$ e seu complemento $\overline{S_{1}}$ seguida pela projeção de um padrão $S_{2}$ e seu complemento $\overline{S_{2}}$.

Há uma outra vantagem no uso de padrões complementares: foi verificado, empiricamente, que pares de padrões de cores complementares, quando projetados a $120 \mathrm{~Hz}$, são percebidos como luz branca constante. Assim, o código (b, s)-BCSL complementado torna possível fazer a captura simultânea tanto da geometria quanto da textura da cena 3D. Ele também faz com que a construção de máscaras de sombra seja uma tarefa trivial.

O código $(6,2)$-BCSL pode ser facilmente combinado com vídeo. Cada quadro de vídeo com resolução $640 \times 480$ no padrão NTSC é composto por dois campos $640 \times 240$ entrelaçados. Cada campo é exposto/capturado em 1/60 de segundo. A câmera e o projetor são sincronizados usando-se genlock (do inglês generator lock), que se trata de uma técnica comumente usada para fazer a sincronização da saída de vídeo de um equipamento com a captura de vídeo de outro. Para a projeção, é gerada uma seqüência de quadros intercambiando os dois padrões que são codificados com seus correspondentes complementos com campos em um único quadro. Este sinal de vídeo é enviado ao projetor e conectado à entrada genlock da câmera. A soma dos dois campos fornece uma imagem de textura e sua 
diferença resulta nas cores e fronteiras das faixas projetadas.

Este sistema é adequado para o rastreamento de componentes porque mantém um bom balanço entre a detecção de textura, geometria e movimento. Os vídeos foram obtidos por meio da projeção de 70-90 faixas sobre as cenas, com diferentes escalas.

\subsubsection{Codificação}

Voltemo-nos agora para o problema da geração de uma particular sequiência de faixas $b$-coloridas para cada um dos $s$ slides. Esta seqüência deve ser gerada de tal forma que, dadas as transições de faixas em um determinado pixel para os $s$ slides, possa-se recuperar, de modo eficiente, a posição da fronteira projetada correspondente.

O problema de geração de um conjunto de seqüências de faixas pode ser modelado como o problema de encontrar um caminho euleriano em um determinado grafo $G$. As arestas de $G$ correspondem às possíveis transições entre duas posições de faixas consecutivas. A fim de rejeitar fronteiras fantasmas, são consideradas transições proibidas aquelas que repetem a mesma cor no mesmo slide. $G$ possui $b^{s}$ vértices, cada um correspondendo a uma possível atribuição das $b$ cores em uma dada posição para cada um dos $s$ slides. O grafo $G$ usado para gerar a codificação $(3,2)$-BCSL é mostrado na Figura 3.2.

Para o caso $(3,2)$, a estrutura de vizinhança é mostrada na Figura 3.2(b), com cada vértice possuindo 4 possíveis vizinhos. Para o esquema $(b, s)$ geral, há $(b-1)^{s}$ possíveis vizinhos para cada vértice, resultando em um grafo regular no qual cada um dos $b^{s}$ vértices possui grau $(b-1)^{s}$. É mais apropriado, no entanto, pensar em $G$ como um grafo direcionado em que cada vértice possui $(b-1)^{s}$ arcos de entrada e $(b-1)^{s}$ arcos de saída, já que o mesmo par de vértices corresponde a duas transições distintas, uma para cada direção.

Possíveis esquemas de faixas coloridas correspondem a caminhos com arestas não repetidas (significando que cada transição multi-slide ocorre somente uma vez) no grafo dirigido $G$. O máximo número de faixas é obtido por um caminho euleriano, i.e., um caminho que visita uma vez cada aresta de $G$. Esse caminho certamente existe, uma vez que todo vértice em $G$ possui grau par e $G$ é conexo 
Figura 3.2 Grafo (3, 2)-BCSL e seu esquema de vizinhança. G possui 9 vértices, cada um rotulado com um número de 2 dígitos na base $b$.

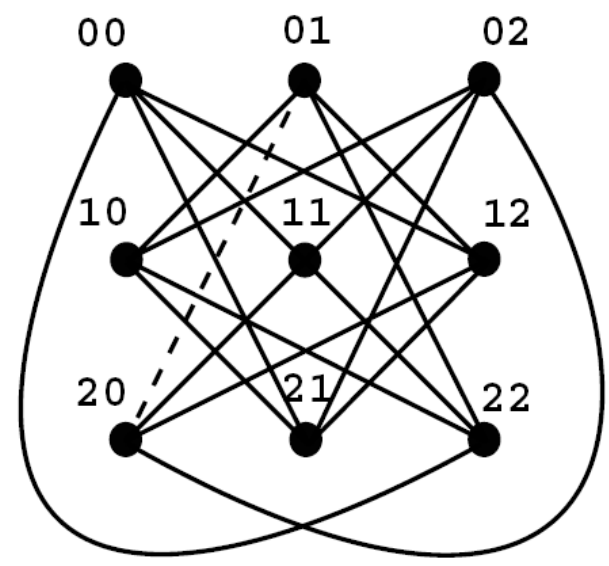

(a)

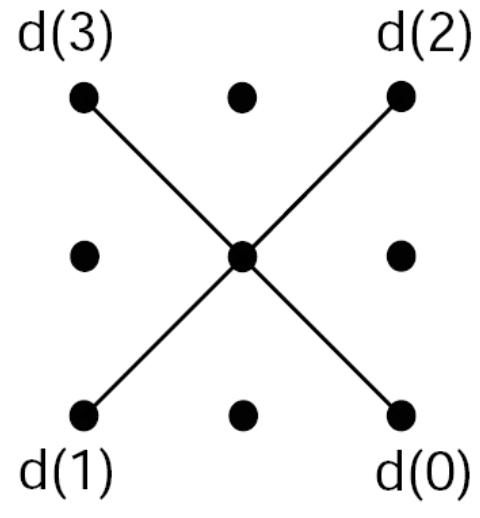

(b)

(para $b \geq 3$ ). A Figura 3.3 mostra um (3,2)-BCSL particular. A aresta conectando o vértice 20 ao vértice 01 está destacada tanto na Figura 3.2 quanto na Figura 3.4.

$\mathrm{Na}$ verdade, há um grande número de diferentes caminhos eulerianos em $G$ e um problema de otimização pode ser formulado para procurar pelo melhor caminho de acordo com algum critério desejado. Poderíamos adotar uma perspectiva de processamento de imagens, usando informações sobre as propriedades fotométricas da cena a ser varrida como um critério para gerar um melhor código adaptativo.

Em muitos casos, não há necessidade de usar o caminho euleriano completo, já que é suficiente usar um caminho de comprimento igual à máxima resolução que a câmera ou o projetor usados podem lidar.

No trabalho atual, o caminho completo é gerado, dados uma base $b$ e o número desejado $s$ de slides, sem considerar qualquer critério de otimização. Para atingir o número desejado de faixas, simplesmente trunca-se o caminho.

\subsubsection{Decodificação}

Considere agora o problema de recuperar a posição da borda dada a transição de cor em cada slide. Isso é equivalente a encontrar a posição de uma dada aresta em um 
Figura $3.3(3,2)$-BCSL usando R, G e B como base. A fronteira destacada possui código 20|01 (vide Figura 3.3).

slide1

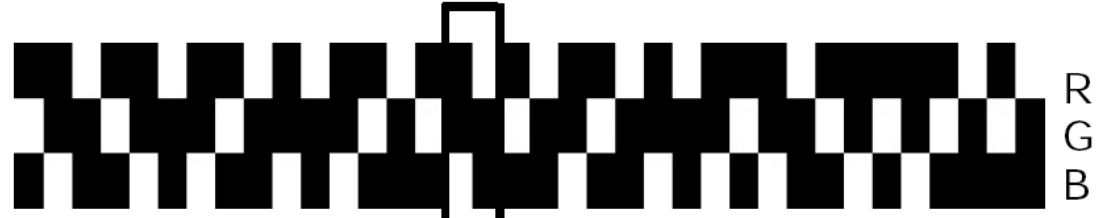

slide2

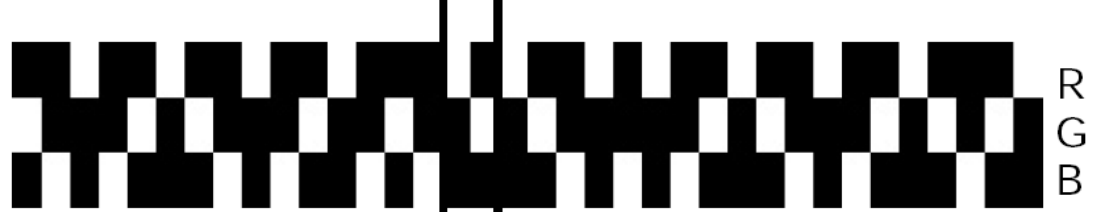

Figura 3.4 Exemplo de código de fronteira. Exemplo de código de fronteira para a aresta tracejada na Figura 3.2. Na mesma posição de transição, vai-se da cor 2 para a cor 0 no primeiro slide e da cor 0 para a cor 1 no segundo.

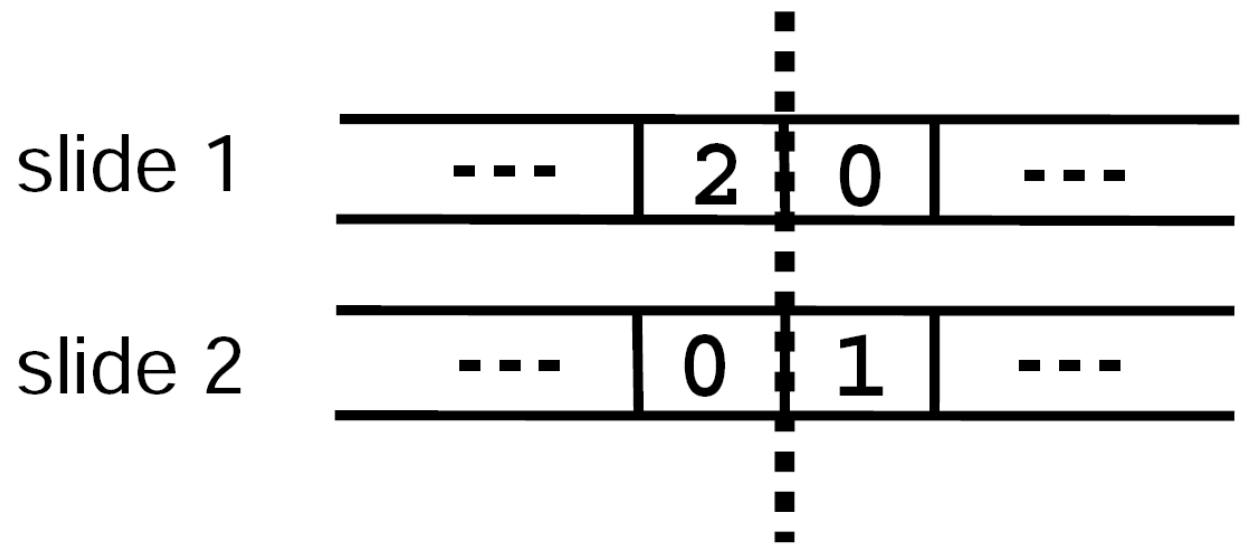


Tabela 3.1 Tabela de decodificação para (3,2)-BCSL. A entrada da tabela na posição $(V(20), d(0))$ é 16, o que significa que a transição encontrada corresponde à 16a borda, destacada na Figura 3.3.

\begin{tabular}{c|cccc}
\hline vértices & $\mathrm{d}(0)$ & $\mathrm{d}(1)$ & $\mathrm{d}(2)$ & $\mathrm{d}(3)$ \\
\hline $\mathrm{V}(00)$ & 0 & 3 & 6 & 9 \\
$\mathrm{~V}(01)$ & 14 & 17 & 19 & 11 \\
$\mathrm{~V}(02)$ & 28 & 34 & 22 & 24 \\
$\mathrm{~V}(10)$ & 26 & 29 & 18 & 21 \\
$\mathrm{~V}(11)$ & 1 & 31 & 33 & 35 \\
$\mathrm{~V}(12)$ & 15 & 4 & 8 & 13 \\
$\mathrm{~V}(20)$ & $\mathbf{1 6}$ & 23 & 32 & 12 \\
$\mathrm{~V}(21)$ & 27 & 5 & 7 & 25 \\
$\mathrm{~V}(22)$ & 2 & 10 & 20 & 30 \\
\hline
\end{tabular}

caminho euleriano encontrado no algoritmo anterior. Em nosso caso, identificar a palavra de código significa encontrar as cores em ambos os lados da borda projetada que é refletida pelo objeto.

O algoritmo de decodificação emprega uma tabela de decodificação que permite o cálculo, em tempo constante, da posição no projetor de uma dada borda de faixa encontrada nas imagens. As informações de decodificação para o caso $(3,2)$ são mostradas na Tabela 3.1. Cada linha da tabela corresponde a um vértice $v$ de $G$ (i.e., à atribuição de uma cor de faixa para todos os slides), representado na base b. Cada coluna corresponde a um de seus vizinhos, ordenado de acordo com o padrão mostrado na Figura 3.2. Cada um dos vizinhos pode ser convenientemente expresso por meio de operações aritméticas módulo $b$, explorando a regularidade das relações de adjacência, como mostrado em Hsieh [2001].

A entrada em uma determinada linha e coluna da tabela fornece a posição, no caminho euleriano, do arco correspondente à transição do vértice associado à linha ao vizinho associado com a coluna. Por exemplo, o arco que começa no vértice 11 e termina no vértice 02 , que é vizinho $d(2)$ de 11 , é o $33^{\circ}$ arco no caminho e a $33^{\text {a }}$ transição de faixa no padrão.

Suponha agora que uma determinada transição do vértice $v_{i}$ ao vértice $v_{j}$ foi detectada. Para encontrar sua posição no caminho, é suficiente determinar a loca- 
lização de $v_{j}$ na vizinhança de $v_{i}$ e recuperar a entrada para aquela coluna na linha correspondente a $v_{0}$. Para encontrar a coluna a ser inspecionada, precisamos saber qual vizinho possui a cor dada, o que pode ser obtido usando operações módulo $b$.

Considerando o algoritmo de codificação e decodificação apresentado, o problema de correspondência entre pixeis da câmera a pixeis do projetor reduz-se a uma tarefa de processamento de imagens, responsável pela identificação, em imagens da câmera, das transições e cores das faixas projetadas.

Como foi adotado um código de bordas de faixas verticais, as linhas de varredura podem ser tratadas independentemente.

\section{Características do Sistema}

Propõe-se a combinação do padrão NTSC de vídeo com o código (b, s)-BCSL a fim de obter um fluxo de vídeo 3D em tempo real. As configurações da câmera e do projetor devem ser específicas para este código com o objetivo de obter uma melhor reconstrução colorimétrica e geométrica.

Esta seção apresenta a geração do código de cores e os requisitos e a calibração para o sistema câmera/projetor para uso com o código $(6,2)$-BCSL.

\subsubsection{Geração de padrões de cores $(b, s)$-BCSL}

Padrões de cores do código (b, s)-BCSL podem ser gerados usando uma placa de aceleração gráfica padrão com controle de sincronia vertical e saída de vídeo.

O uso de um sinal de vídeo analógico para a projeção de um padrão de cores torna a sincronização mais fácil com equipamentos facilmente encontrados no mercado. Outra vantagem é que ele pode ser gravado em mídias de vídeo padrão, como fitas. O padrão de cores é então reproduzido pelo player correspondente.

Contudo, o sinal de vídeo analógico é muito restrito e ruidoso para os propósitos em questão. Em primeiro lugar, a resolução máxima é de 640 × 240 pixeis por campo, limitando consideravelmente o número de faixas que podem ser projetadas. Muito da resolução da cor é perdida já que o vídeo padrão foi projetado para possuir uma pequena banda de cores. Um problema ainda mais difícil é a perda de definição próximo às bordas de transição de faixas. Isso implica na estimação de 
uma profundidade ruidosa, uma vez que esta depende de uma detecção de transição precisa.

\subsubsection{Requisitos do Projetor}

Um requisito para o uso de padrões de cores complementares, como o (b, s)-BCSL, é que o projetor precisa ser capaz de trocar rápido entre duas cores diferentes. Nem todos os projetores possuem essa característica. Projetores LCD, por exemplo, têm uma longa latência na alternância de cores. Assim, eles são incapazes de reproduzir faixas coloridas em grandes áreas da imagem. Projetores que filtram o fluxo de entrada de vídeo também podem fornecer resultados indesejáveis com faixas coloridas (b, s)-BCSL como, por exemplo, alguns modelos projetados para entretenimento que tentam realçar cores entre os campos de vídeo. Modelos com tecnologia DLP (processamento digital de luz, do inglês Digital Light Processing) desprovidos de filtros de vídeo são recomendados em nosso caso.

A taxa de contraste do projetor deve ser tão grande quanto possível, uma vez que precisamos detectar de forma robusta transições de cores nas bordas de faixas. $\mathrm{O}$ brilho do projetor depende da aplicação. Ele definirá o quão forte e longe o padrão de cores será imposto sobre os objetos. Na configuração do sistema adotado, um brilho de 1100 lumens é o mínimo para a captura de cenas internas.

\subsubsection{Requisitos da Câmera}

A sincronização câmera/projetor é necessária para garantir que um determinado slide será projetado pelo projetor e capturado pela câmera ao mesmo tempo. Isto pode ser obtido usando uma câmera que possua um pino genlock de modo que um sinal de vídeo de um slide é enviado simultaneamente ao projetor e ao genlock da câmera. Ele força a captura do campo de vídeo a ser iniciada exatamente quando a projeção do campo de um slide é iniciada. Portanto, o sensor da câmera será exposto às cores do slide durante todo o tempo de projeção do campo.

A reconstrução é melhor feita em áreas bem expostas da imagem capturada. Uma câmera com exposição automática é recomendada a fim de tornar o sistema flexível a materiais, profundidades, iluminações e movimentos arbitrários.

O sistema de captura 3D funciona somente onde os frustrums da câmera e do 
projetor se interceptam. Lentes ajustáveis são altamente recomendadas a fim de aumentar a flexibilidade da configuração da área de trabalho.

\subsubsection{Calibração de Cores}

Em geral, a curva de resposta do sensor da câmera e a curva de resposta da reprodução do projetor possuem um comportamento completamente distinto. Isto significa que cores concebíveis possuem diferentes coordenadas em ambos os sistemas de cores. Não obstante, cada material que compõe a cena processa a luz do projetor e a luz ambiente de forma diferente, o que torna complexo um método de calibração ótimo.

A chave para a correspondência usando o código (b, s)-BCSL é saber onde uma transição de faixas ocorre e quais as cores em ambos os lados. Logo, uma transformação entre o espaço de cores do projetor e da câmera precisa ser feita. Dada uma cor na imagem capturada, precisamos saber exatamente que cor foi projetada. Uma transformação linear simples fornece aproximações muito boas na forma:

$$
\left[\begin{array}{lll}
r_{p} & g_{p} & b_{p}
\end{array}\right]^{T}=\mathrm{M} \cdot\left[\begin{array}{lll}
r_{c} & g_{c} & b_{c}
\end{array}\right]^{T}
$$

em que $\left[\begin{array}{lll}r_{p} & g_{p} & b_{p}\end{array}\right]^{T}$ é a cor projetada estimada, $\left[\begin{array}{lll}r_{c} & g_{c} & b_{c}\end{array}\right]^{T}$ é a cor capturada e $\mathrm{M}$ é uma matriz $3 \times 3$ que transforma o espaço de cores da imagem para o espaço de cores do projetor, restrita às cores usadas para codificação. Note que esta transformação pode ser executada muito rapidamente, o que é essencial para sistemas de tempo real.

O procedimento de calibração inicia-se com a projeção de cada cor $S_{i}, i=$ $1,2, \ldots, s+2$, em que $s$ é o número de cores no código, em um alvo branco, não especular e com a captura da imagem resultante $I_{i}$. As imagens para projeções pretas $\left(S_{s+1}=\left[\begin{array}{lll}0 & 0 & 0\end{array}\right]^{T}\right)$ e branca $\left(S_{s+2}=\left[\begin{array}{lll}1 & 1 & 1\end{array}\right]^{T}\right)$ também são obtidas. Nenhuma luz ambiente deve estar presente neste estágio. A exposição da câmera deve ser corrigida e sua resposta precisa coincidir com o intervalo preto e branco projetados.

Uma cor de resposta $C_{i}, i=1,2, \ldots, s+2$, pode ser calculada a partir de imagens capturadas $I_{i}$ por meio da média dos pixeis refletidos pelo alvo branco. 
Portanto, a matriz de calibração de cores $\mathrm{M}$ deve minimizar o erro no sistema

$$
\left[\begin{array}{llll}
S_{1}^{T} & S_{2}^{T} & \ldots & S_{s+2}^{T}
\end{array}\right]=\mathrm{M} \cdot\left[\begin{array}{llll}
C_{1}^{T} & C_{2}^{T} & \ldots & C_{s+2}^{T}
\end{array}\right]
$$

e pode ser calculada usando o método de mínimos quadrados. A resposta da câmera para as cores preta e branca fornece limites inferior e superior nesta minimização.

Note que se $\mathrm{M}$ fosse uma transformação afim, o vetor de translação deveria levar em conta a luz ambiente. Como resultado, a calibração dada pela equação (3.1) deveria ser muito restritiva já que uma translação nos vetores de cor $\left[\begin{array}{lll}r_{c} & g_{c} & b_{c}\end{array}\right]^{T}$ deveria sempre ser aplicada. Uma transformação linear mantém a origem em $\left[\begin{array}{lll}0 & 0 & 0\end{array}\right]^{T}$. Como resultado, a equação (3.1) é menos sensível a mudanças na iluminação ambiente.

\section{Pipeline do Processamento do Fluxo}

O sistema atual do IMPA é composto por um projetor Infocus LP-70, uma câmera de vídeo Sony Hyper HAD, um PC $1.9 \mathrm{GHz}$ com uma placa gráfica baseada no chip Nvidia GForce 3 TI para a geração de padrões e um PC $2.4 \mathrm{GHz}$ com uma placa de captura Pinnacle Studio DC10plus para processar os quadros de entrada da câmera (Figura 3.5).

Um único computador poderia ser usado para gerar os padrões de cores, capturar o vídeo e processar o fluxo. No entanto, a alta carga de processamento pode resultar na perda de quadros.

As próximas subseções apresentam em detalhe como o fluxo de vídeo é processado no sistema apresentado.

\subsubsection{Projeção e Captura dos Padrões de Cores}

O objetivo é capturar cores e geometria de uma cena projetando tão poucos slides de padrão colorido quanto for possível. Dois slides é o mínimo usando o código (b, s)-BCSL.

O uso de padrões complementares é necessário para detectar transições de faixas e cores de forma robusta. A robustez da detecção de cores aumenta se forem 
Figura 3.5 Hardware do vídeo 3D. Diagrama do hardware do sistema de captura $3 D$.

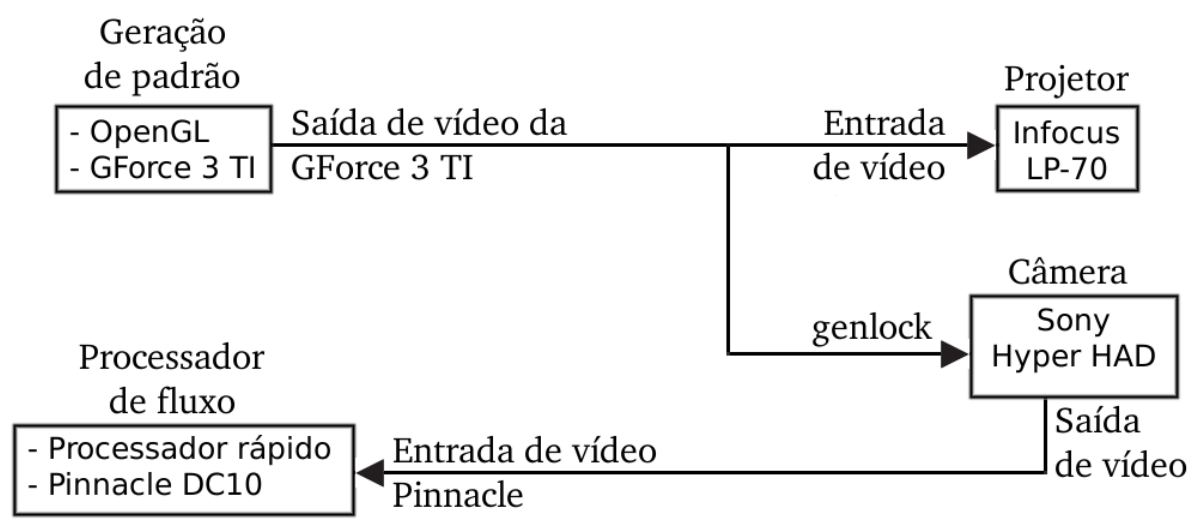

usadas apenas cores primárias, embora o código tenha sido limitado para usar as seis cores primárias que podem ser detectadas de forma não-ambígua por meio da detecção de cruzamentos com zero: vermelho, verde, azul, ciano, magenta e amarelo.

Estas duas suposições nos levam ao uso do código $(6,2)$-BCSL caracterizado por dois slides de um máximo de 900 faixas. O número máximo de faixas é muito maior do que precisamos usando vídeo analógico. A implementação atual permite que o usuário escolha o número total de faixas e onde começar na seqüência de um total de 900 faixas. Os dois slides de padrão colorido serão referidos como $P^{1} \mathrm{e}$ $P^{2}$. As respectivas imagens de cor complementar são $P^{1^{\prime}}$ e $P^{2^{\prime}}$.

Cada quadro de vídeo 640 x 480 no padrão NTSC é composto por dois campos 640 x 240 entrelaçados. Cada campo é exposto/capturado em 1/59.54s.

A sincronização câmera/projetor garante que um quadro projetado corresponderá a um quadro capturado. Assim, os padrões de cores $P^{1,2}$ podem ser codificados com seus correspondentes complementos $P^{1^{\prime}, 2^{\prime}}$ como campos em um único quadro. O fluxo de vídeo projetado resultante é então $\left(P_{t}^{1}, P_{t}^{1^{\prime}}\right),\left(P_{t+1}^{2}, P_{t+1}^{2^{\prime}}\right)$, $\left(P_{t+2}^{1}, P_{t+2}^{1^{\prime}}\right)$ e assim por diante.

O quadro capturado no instante $t$ é referenciado por $\left(I_{t}, I_{t}^{\prime}\right)$ ou por $\left(I_{t}^{k}, I_{t}^{k \prime}\right)$ quando o padrão projetado correspondente $k \in\{1,2\}$ é conhecido. Os fluxos projetados e capturados são ilustrados na Figura 3.6. 
$\overline{\text { Figura 3.6 Padrões coloridos. A seqüência de quadros de padrões coloridos e as }}$ imagens capturadas como um resultado de sua projeção sobre uma cena.

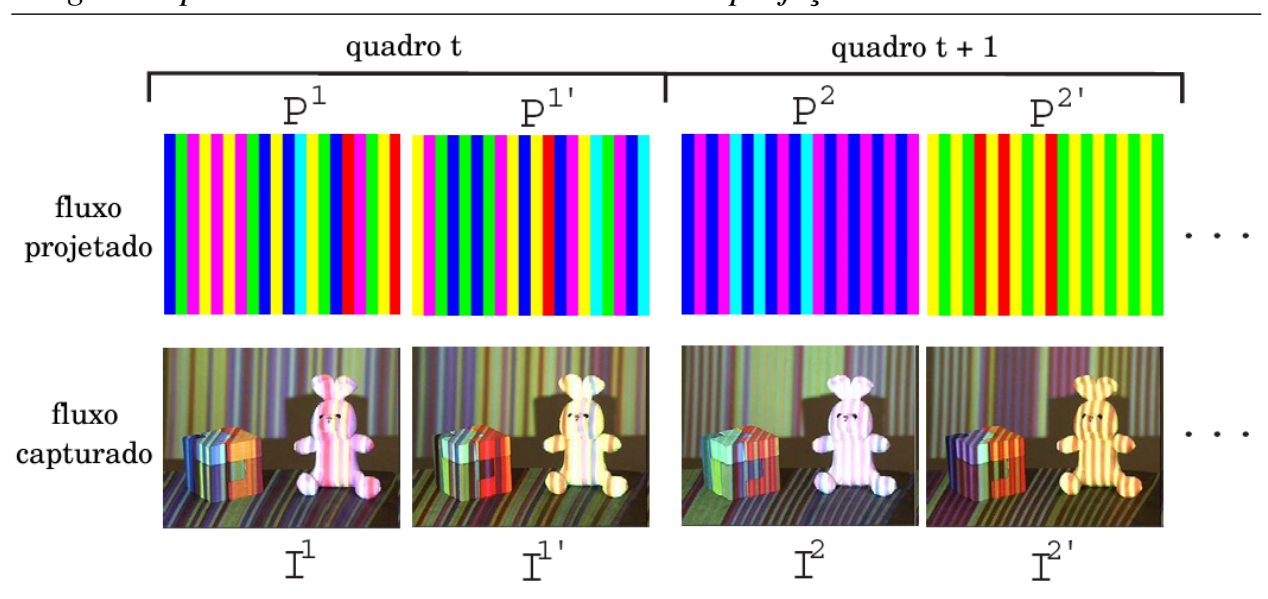

\subsubsection{Detecção de Bordas das Faixas e Cores}

A projeção dos padrões de cores complementares é a chave para encontrar onde ocorrem transições de faixa e que cores foram projetadas. A detecção inicia-se com uma filtragem passa-baixas em cada campo de entrada $I_{t}$ e $I_{t}^{\prime}$ no instante $t$, a fim de reduzir ruído.

As faixas de cores projetadas são facilmente observáveis, como mostrado na Figura 3.7(a). Contudo, como as cores projetadas são moduladas pela iluminação ambiente, pelas propriedades refletivas dos materiais e pelos sensores da câmera, um processamento direto dos quadros de entrada poderia não ser robusto.

O procedimento de casamento de cores câmera/projetor reduz consideravelmente este problema (Subseção 3.4.4). A calibração proposta transforma uma cor arbitrária em uma outra cor que está mais próxima das cores usadas para projeção. As imagens calibradas usadas para detecção são definidas como

$$
C_{t}(i, j)=\mathrm{M} \cdot I_{t}(i, j) \quad \text { e } \quad C_{t}^{\prime}(i, j)=\mathrm{M} \cdot I_{t}^{\prime}(i, j)
$$

em que M é a matriz de calibração (equação (3.1)) e $(i, j)$ são coordenadas de pixel. A Figura 3.7(b) mostra uma imagem calibrada. Note que as cores projetadas são 


\section{Figura 3.7 Exemplo de calibração de cor. (a) Campo de entrada. (b) Imagem} calibrada.

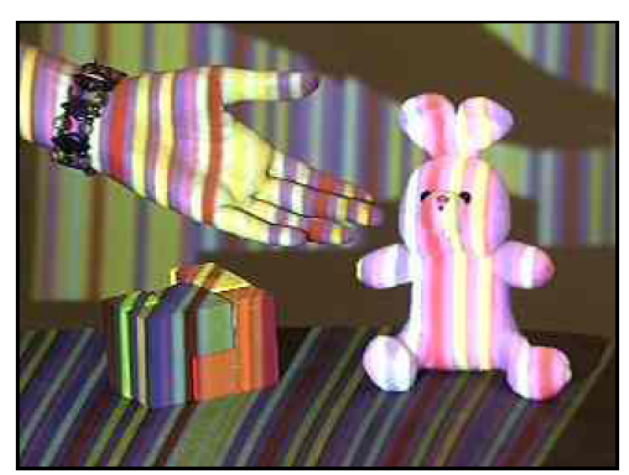

(a)

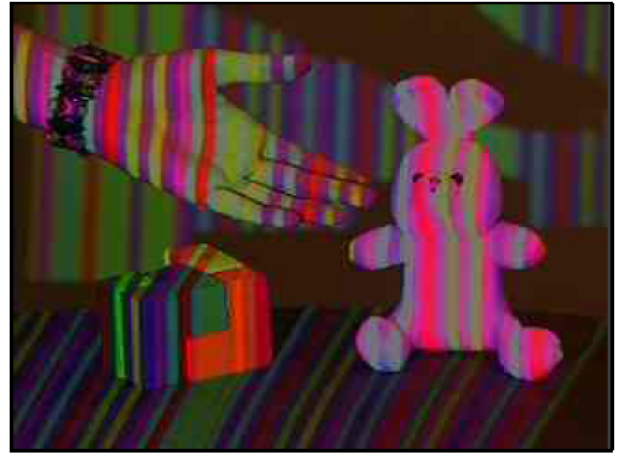

(b)

melhores quando comparadas com as da Figura 3.7(a).

As imagens deveriam ser normalizadas a fim de tornar o processo menos sensível a valores limiares. Na implementação adotada, a faixa de normalização é definida por zero e pela intensidade máxima global checando todos os canais.

\section{Detecção de Bordas de Faixas}

Sejam $D_{t}^{R}, D_{t}^{G}$ e $D_{t}^{B}$ os canais de cores da diferença de imagens calibradas $D_{t}=$ $C_{t}-C_{t}^{\prime}$.

Uma vez que cores complementares são projetadas na mesma posição, as bordas são dadas pelas localizações $P$ que satisfazem:

$$
D_{t}^{R}(P)=0 \quad \text { ou } \quad D_{t}^{G}(P)=0 \quad \text { ou } \quad D_{t}^{B}(P)=0,
$$

ou seja, cruzamentos com zero de pelo menos um canal de cores da imagem diferença (Figura 3.8(b, c)). No entanto, essa forma geral é altamente suscetível a ruído. Com o intuito de reduzir falsas detecções, os cruzamentos com zero deveriam ser examinados somente na direção $X$ e devem possuir uma alta inclinação, i.e., alta variação de intensidade local. Portanto, para um linha j fixa, o conjunto de bordas de faixa $S B_{t}$ é o conjunto de localizações subpixel $(i, j)$ para as quais

$$
D_{t}(i, j)=0 \quad \text { e } \quad\left|D_{t}(i-\delta, j)-D_{t}(i+\delta, j)\right| \geq t s
$$


Figura 3.8 Detecção de cor e fronteira. (a) Código de cores projetado. (b) Transições de faixas. (c) Visualização da imagem diferença no nariz do coelho. Linhas verticais são transições de faixa detectadas.

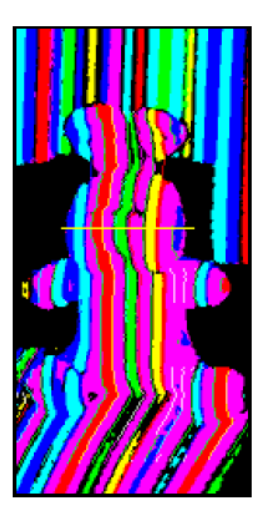

(a)

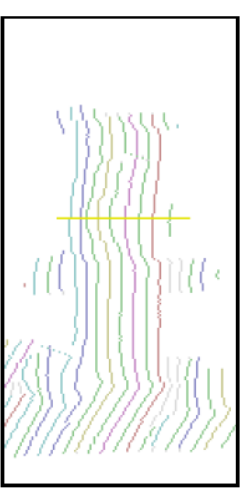

(b)

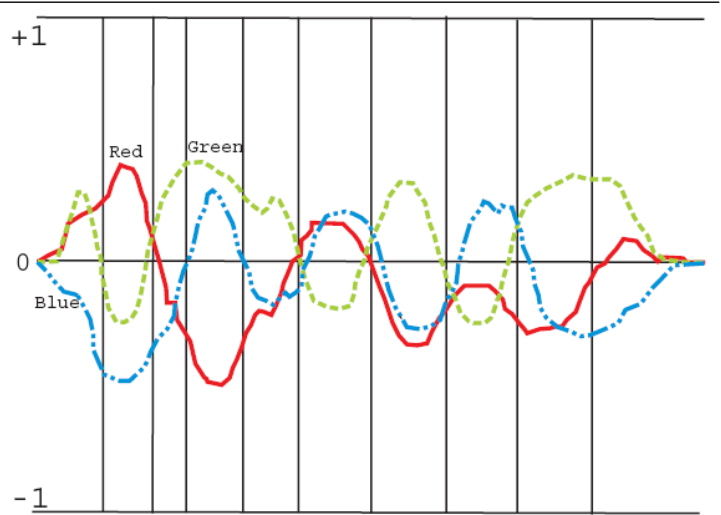

(c)

para pelo menos um canal de cor, em que $\delta$ determina vizinhos em ambos os lados e $t s$ é o limiar de inclinação. O parâmetro $\delta$ é geralmente pequeno e depende do número de faixas usado e do quão precisa é a transição na imagem. Para vídeo analógico, de 3 a 6 pixeis são adequados para mascarar a região ruidosa em torno da borda.

O limiar $t s$ pode ser fixado em 5 se a imagem for normalizada após a calibração. Este procedimento é muito robusto na detecção de bordas de faixas (Figura 3.8(c)).

\section{Detecção de Cores Projetadas}

As imagens de cores projetadas $P C_{t}$ podem ser recuperadas segundo o sinal da diferença em cada canal de cor [Sá et al., 2002]:

$P C_{t}^{R}(i, j)=0$, se $D_{t}^{R}(i, j)$ for positivo, 1 em caso contrário;

$P C_{t}^{G}(i, j)=0$, se $D_{t}^{G}(i, j)$ for positivo, 1 em caso contrário, e

$P C_{t}^{B}(i, j)=0$, se $D_{t}^{B}(i, j)$ for positivo, 1 em caso contrário.

Claro, nem todos os objetos são bem iluminados pelo projetor, devido a propriedades dos materiais, iluminação ambiente, oclusão, distância do projetor, etc. Para evitar erros na decodificação, somente pixeis contendo pelo menos dois canais 
com diferença absoluta maior que um limiar $t_{c}$ são usados. Pixeis de $P C_{t}$ que não satisfaçam a essa condição ou que tenham o valor branco $\left[\begin{array}{lll}1 & 1 & 1\end{array}\right]^{T}$ são alterados para preto $\left[\begin{array}{lll}0 & 0 & 0\end{array}\right]^{T}$ e assim invalidados (Figura 3.8(a)). No sistema em uso, o limiar $t c$ foi fixado em 20.

Para a borda de uma faixa $P=(i, j) \in S B_{t}$, as cores das faixas da direita e da esquerda são:

$$
P_{l}=P C_{t}(i-\delta, j) \quad \text { e } \quad P_{r}=P C_{t}(i+\delta, j),
$$

respectivamente. O deslocamento $\delta$ é o mesmo usado para encontrar bordas (equação (3.5)). Note que $P_{l}$ e $P_{r}$ precisam ser duas possíveis cores projetadas distintas. Caso contrário, um outro par de cores deveria ser procurado para além de $\delta$. Se não há cores válidas, então a borda $P$ é removida.

\section{Detecção de Quadros Perdidos (dropped)}

Alguns quadros de entrada podem ser perdidos devido a atrasos no sistema de captura. Isso resultará em dois quadros consecutivos com o mesmo padrão projetado. Logo, a correspondência câmera/projetor, usando esses quadros, não é possível.

Se $P C_{t}(P)=P C_{t+1}(P)$ para um grande número de pixeis válidos $P$, então o mesmo padrão de cores foi usado. Isso significa que alguns quadros foram perdidos nos fluxos de projeção ou captura. O último quadro $P C_{t+1}$ deve ser mantido para correspondência com o próximo quadro. Este é um método muito robusto para sempre correlacionar quadros com padrões diferentes no pipeline.

\subsubsection{Correspondência Câmera/Projetor}

A correspondência câmera/projetor é obtida usando as bordas das faixas e as cores projetadas de dois quadros consecutivos. O primeiro passo é correlacionar todas as bordas de faixas $P \in S B_{t}$ detectadas no quadro $t$ com as bordas $Q \in S B_{t-1}$ detectadas no quadro $t-1$.

Nesse ponto, uma posição de faixa projetada $p_{t}(P)$ é atribuída a cada borda $P$ no espaço de imagem da câmera. Se não houver um $Q$ que case, $P$ deve ser mantido para a correlação do próximo quadro. 

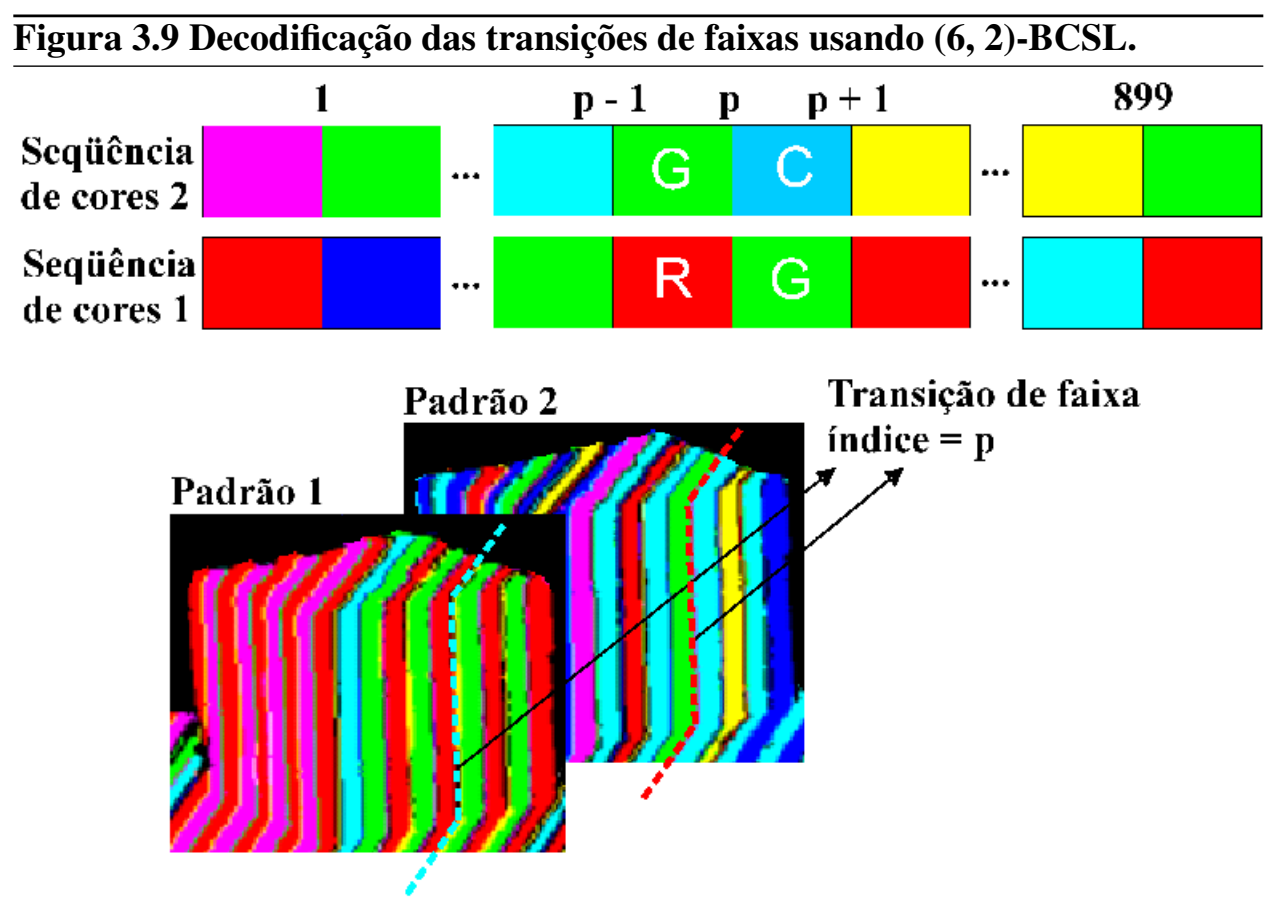

Para a construção da correspondência câmera/projetor, projeta-se uma subseqüência de dois padrões na cena e detectam-se as cores e as fronteiras das faixas projetadas a partir da imagem obtida por uma câmera de alta velocidade. As quatro cores projetadas, duas para cada padrão, detectadas próximas a qualquer fronteira, são unicamente decodificadas para a faixa projetada de índice $p$ (Figura 3.9). A coluna correspondente no espaço do projetor é detectada em $O(1)$ usando o processo de decodificação $(6,2)$-BCSL. A profundidade é então calculada pelos parâmetros intrínsecos do par câmera/projetor e pela transformação rígida entre seus sistemas de referência.

Precisamos encontrar o ponto $Q$ mais próximo que, combinado com $P$, fornece uma posição de faixa $(6,2)$-BCSL válida por meio da decodificação das tuplas coloridas $\left(P_{l}, P_{r}, Q_{l}, Q_{r}\right)$ ou $\left(Q_{l}, Q_{r}, P_{l}, P_{r}\right)$. Cada quadro é decodificado usando a tupla mais posições de faixas válidas. Esta tupla pode ser facilmente prevista a partir da anterior.

Note que a ordem de decodificação de cor depende da última seqüência de 
padrões projetados: $\left(P_{t-1}^{1}, P_{t-1}^{1^{\prime}}\right),\left(P_{t}^{2}, P_{t}^{2^{\prime}}\right)$ ou $\left(P_{t-1}^{2}, P_{t-1}^{2^{\prime}}\right)\left(P_{t}^{1}, P_{t}^{1^{\prime}}\right)$.

A borda $Q$ é procurada em uma vizinhança $7 \times 7$ de $P$. Surpreendentemente, isto é suficiente até mesmo para movimentos razoavelmente rápidos. A razão é que, enquanto objetos se movem, a faixa permanece estacionária. Já que descontinuidades altas em profundidade são raras de ocorrer na maioria dos objetos, as bordas $P$ e $Q$ geralmente estão próximas uma à outra.

\subsubsection{Reconstrução da Colorimetria e da Geometria}

Possuindo as bordas $P \in S B_{t}$ e sua posição de faixa projetada estimada $p_{t}(P)$, é possível obter o ponto 3D real no sistema de referência da câmera. Isto é feito usando os parâmetros intrínsecos da câmera e do projetor e a transformação rígida que casa seus sistemas de coordenadas.

A colorimetria pode ser recuperada simplesmente adicionando ambos os campos de entrada, uma vez que a soma de cores complementares resulta em branco. Contudo, esta operação depende da qualidade do sistema de projeção e captura. No sistema em questão, o vídeo analógico corrompe cores em torno de bordas de faixas. Como resultado, as cores nestas regiões não são bem reconstruídas.

Note que os padrões são intercalados no tempo (Subseção 3.5.1). Neste esquema, cada quadro de entrada resulta em uma imagem colorida, por meio da adição dos campos, e é correlacionada com o quadro anterior para obtenção da geometria (Figura 3.10). Portanto, o pipeline pode reconstruir tanto a colorimetria quanto a geometria a 30 quadros por segundo usando NTSC.

\subsubsection{Tradeoffs de Qualidade}

O pipeline proposto não é a única combinação possível de fluxo de vídeo e código $(6,2)$-BCSL. Outros esquemas podem ser implementados dependendo da aplicação. No entanto, nenhum esquema pode fornecer ao mesmo tempo textura, geometria e taxa de quadros de alta qualidade. Assim, há um tradeoff que precisa ser balanceado para cada aplicação. Os seguintes esquemas ilustram este fato:

textura boa a 30 qps e geometria pobre a 60 qps: isto é possível projetando a seguinte sequiência como campos de vídeo: padrão de cores 1 , branco completo e padrão de cores 2. O campo branco é usado para detecção de cruzamentos 
Figura 3.10 Esquema de captura. Quadros do vídeo de entrada e a seqüência de saída da textura e da geometria. A taxa de saída também é de 30 quadros por segundo.

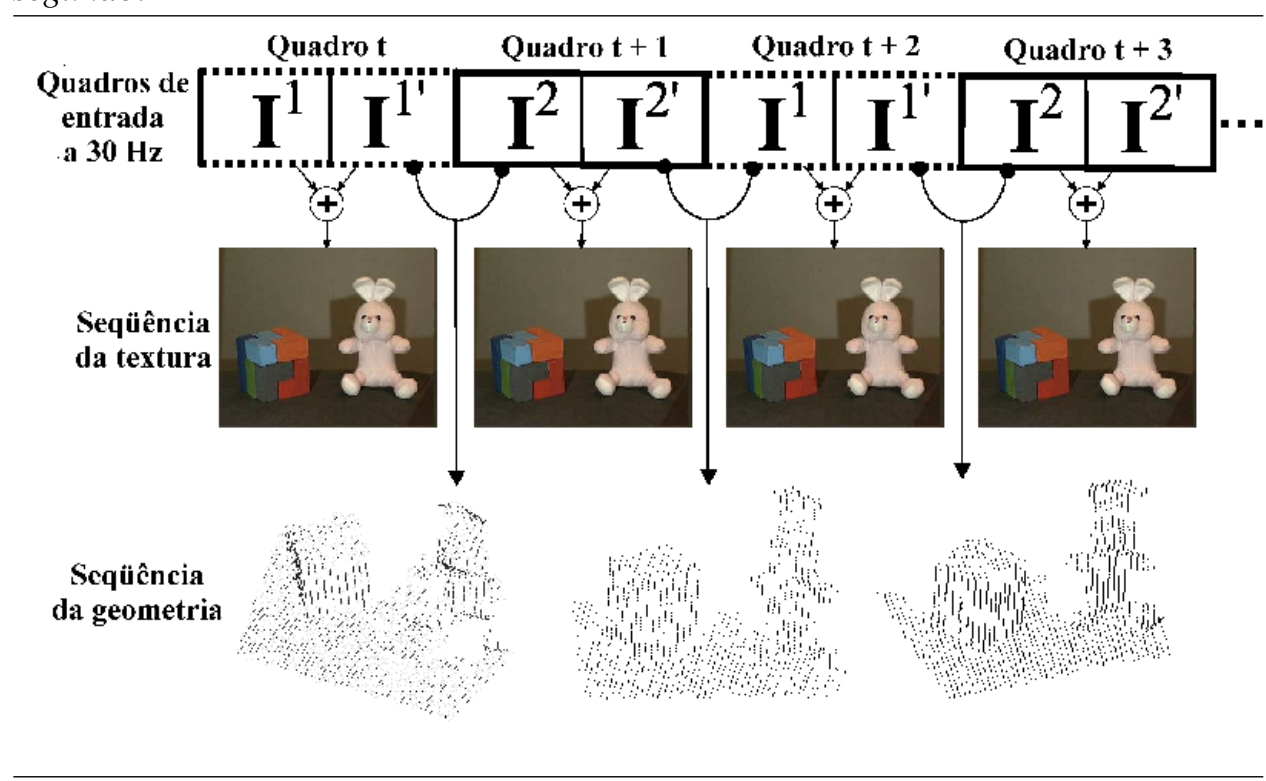

com zero e das cores projetadas. A diferença entre o branco completo e os padrões coloridos fornece o slide complementar que falta. Contudo, isto não é robusto a variações na luz ambiente, resultando em baixa precisão geométrica, $\mathrm{ou}$

excelente textura a $10 \mathrm{~Hz}$ e excelente geometria a $20 \mathrm{~Hz}$ : padrões complementares são projetados como proposto, mas a textura não é obtida pela adição de campos. Em vez disso, um quadro completamente branco é projetado. São obtidas textura e geometria de alta qualidade mas suas taxas de quadro são baixas e não balanceadas. Movimentação rápida pode ser um problema.

Esquemas híbridos também são possíveis usando as estratégias de projeção acima. O pipeline proposto fornece texturas razoáveis e geometria de alta qualidade ambos a 30 qps. Este é o melhor compromisso entre possuir uma boa geometria e textura de qualidade, registro interquadros e correspondência com movimento. 


\subsubsection{Pipeline do Sistema}

A Figura 3.11 fornece uma visão geral do pipeline do processamento 3D. A seqüência $S_{1} \overline{S_{1}} S_{2} \overline{S_{2}}$ de padrões de faixas é projetada sobre a cena (Figura 3.11(a)). Para cada par $S_{k} \overline{S_{k}}$, são inferidas as cores das faixas (Figura 3.11(b)) e as respectivas fronteiras (Figura 3.11(c)). Na seqüência, códigos de fronteira são derivados a partir de padrões $S_{i j}$ que se casam. Textura e máscara de sombra são obtidas pela combinação das imagens $S_{k} \overline{S_{k}}$ (Figura 3.11(d)). A profundidade é calculada por meio da triangulação das correspondências de fronteira na câmera e no projetor, seguida por interpolação (Figura 3.11(e)). Finalmente, o vídeo 3D é montado, transmitido e visualizado (Figura 3.11(f)).

A observação chave que explica porque a codificação (b, s)-BCSL funciona bem para cenas dinâmicas é que as fronteiras das faixas projetadas alteram muito pouco de um quadro para outro, mesmo quando objetos da cena movem-se rapidamente. A obstrução de fronteiras ocorre somente devido ao movimento dos objetos na frente da câmera.

A geometria e a textura obtidas pelo pipeline proposto são bem registradas. A Figura 3.12 mostra uma malha recuperada combinada com a respectiva textura para obter uma visão 3D virtual. Esse modelo foi reconstruído com 90 faixas. A conectividade é dada pelas bordas mais próximas no espaço da imagem.

A Figura 3.13 mostra um exemplo de reconstrução em pequena escala projetando 70 faixas em uma cena composta por um cubo $10 \times 10 \times 10 \mathrm{~cm}$ e por um coelho de pelúcia. As curvaturas suaves da superfície do coelho são recuperadas de forma acurada. As normais mostradas na Figura 3.13(b) foram obtidas usando os vizinhos mais próximos no espaço 3D.

Uma reconstrução de média escala é ilustrada na Figura 3.14. Este exemplo mostra os movimentos finos da boca e da face detectados com 70 faixas. Informações 3D de faces podem ser usadas em muitas aplicações tais como sistemas de segurança, métodos de reconhecimento, biometria, etc.

A sequiência na Figura 3.15 mostra uma pessoa caminhando em frente a um plano. Fica evidente a performance do sistema com um cenário complexo e movimento razoavelmente rápido. A reconstrução em larga escala foi feita com 67 faixas. 
Figura 3.11 Seqüência de passos do sistema do IMPA. (a) Projeção de slides sobre objetos; (b) Padrões projetados; (c) Fronteiras das faixas identificadas;

(d) Captura da textura; (e) Cálculo da profundidade; $(\boldsymbol{f})$ Modelagem 3D.

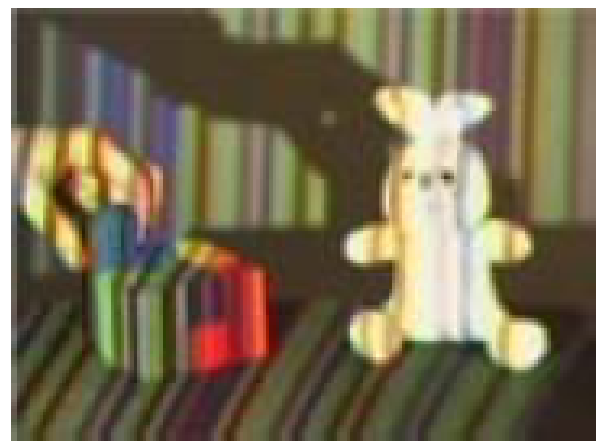

(a)

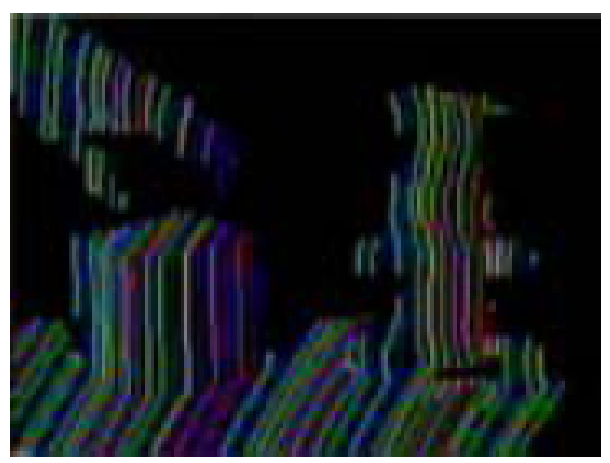

(c)

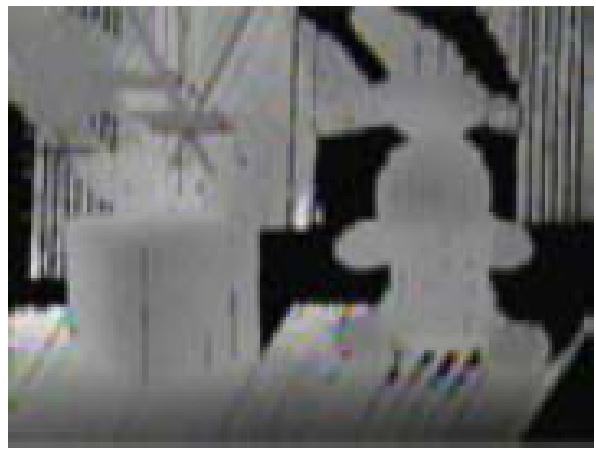

(e)

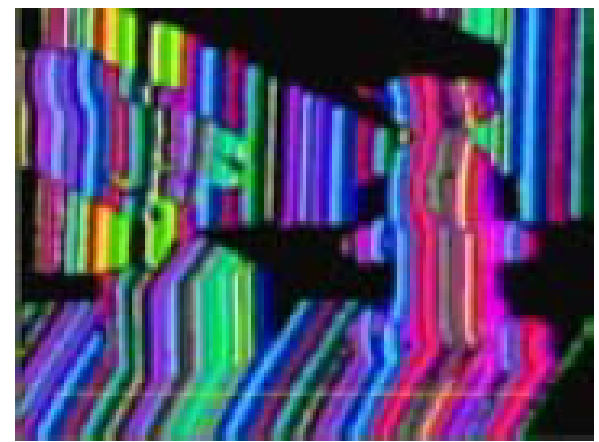

(b)

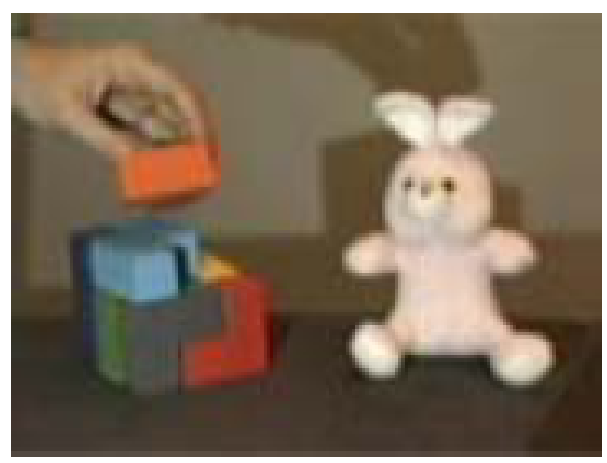

(d)

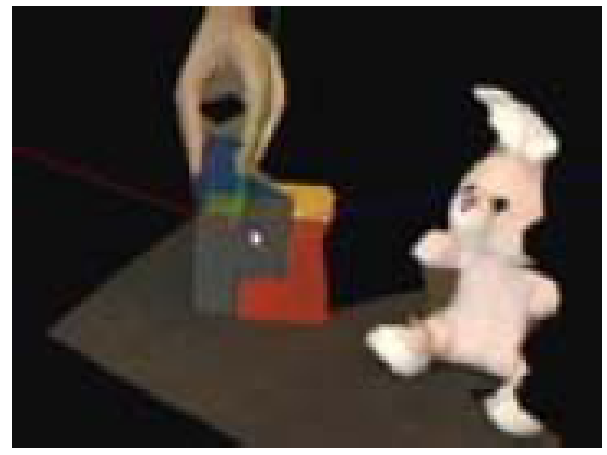

(f) 
Figura 3.12 Composição de cena virtual. (a) Geometria. (b) Textura. (c) Cena composta.

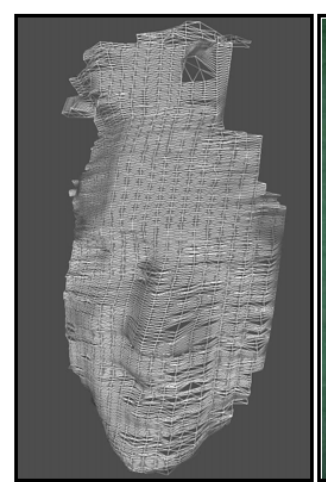

(a)

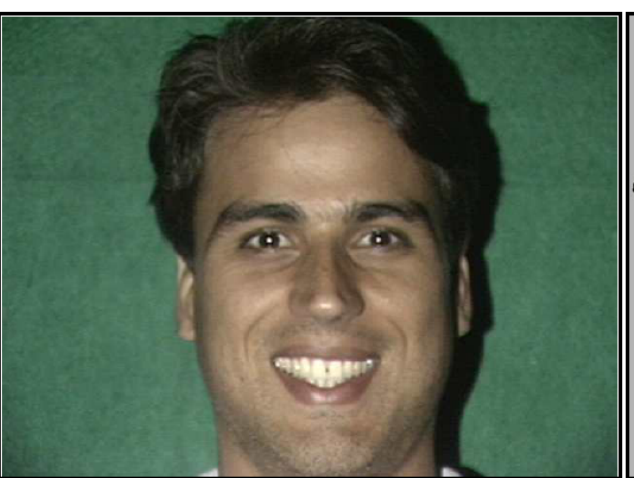

(b)

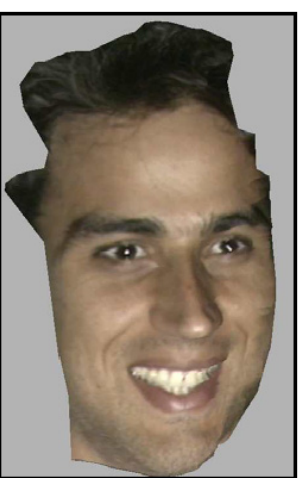

(c)

$\overline{\text { Figura 3.13 Reconstrução de coelho e caixa. (a) Pontos detectados. (b) Normais }}$ inferidas.

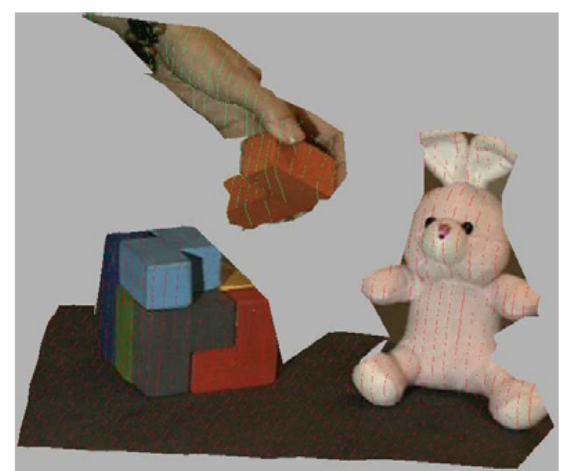

(a)

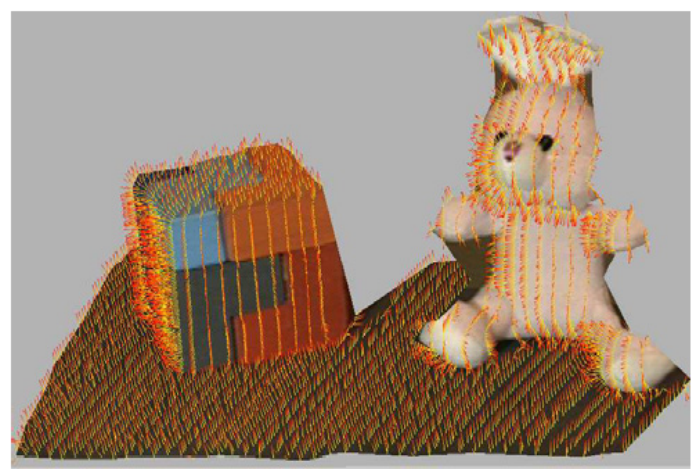

(b)

\section{Figura 3.14 Movimento de face e boca.}
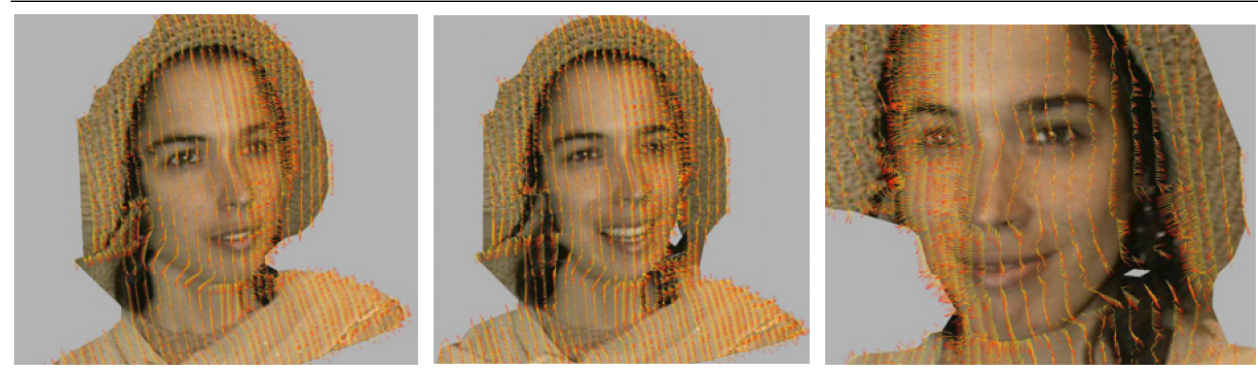


\section{Figura 3.15 Pessoa caminhando em frente a um plano.}

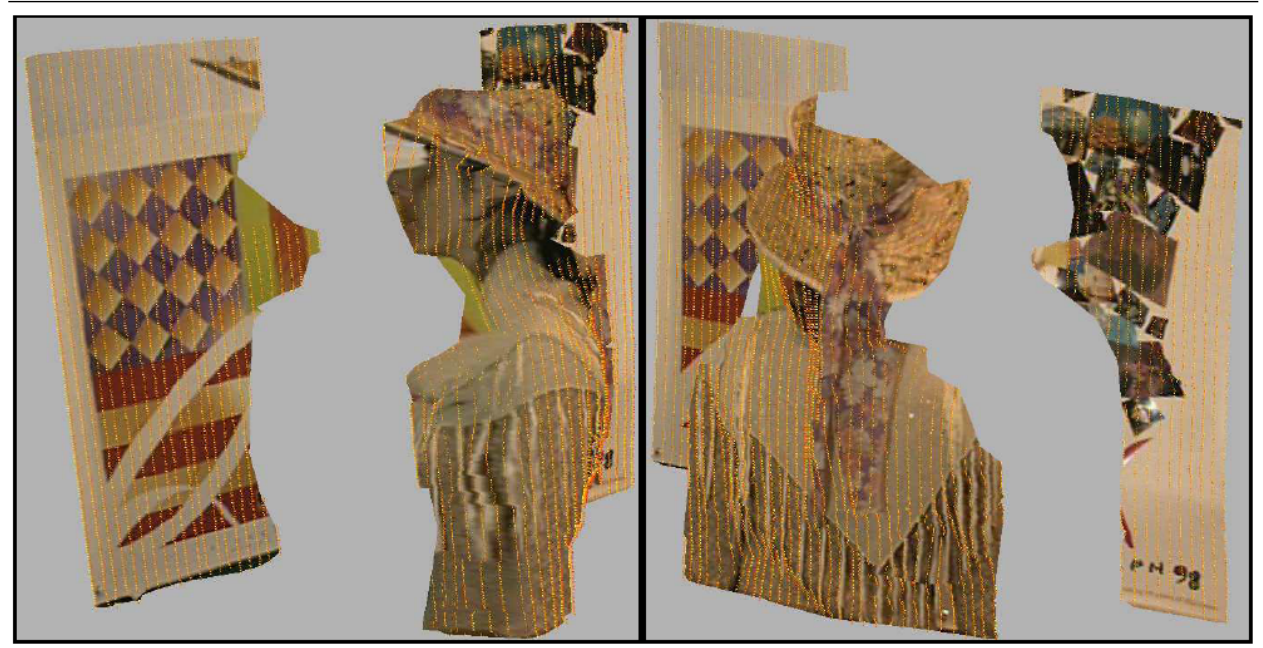

Maiores informações e vídeos de exemplo contendo textura e geometria completas podem ser baixados juntamente com um visualizador específico para o formato de vídeo 4D a partir de http: / / www . impa.br/ mbvieira/video $4 \mathrm{~d}$.

\section{Sumário e Conclusões}

Concluindo, foi apresentado nesta seção o projeto de um sistema câmera/projetor, desenvolvido no IMPA, para vídeo 3D em tempo real. Ele fornece tanto a textura quanto a geometria de objetos com movimentos razoáveis a 30 qps, tendo sido explorado para gerar os dados usados nesta dissertação. Conforme é usual em sistemas câmera/projetor, a principal limitação refere-se a objetos altamente especulares. O sistema endereça as necessidades que podem ser inerentes à próxima geração de vídeo digital e é a primeira fase do projeto Vídeo de Quarta Geração. 


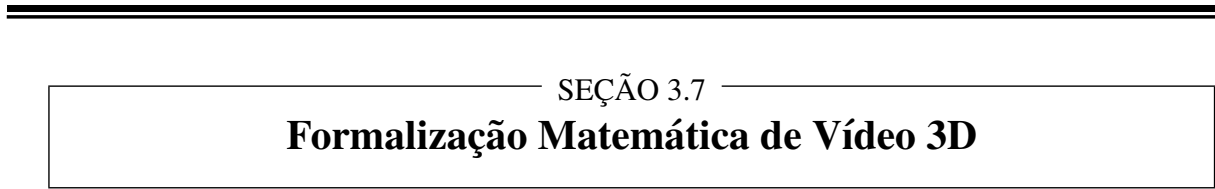

Para se lidar com o vídeo 3D de um modo mais formal, deve-se definir uma função para o mesmo. Isso permitirá uma abordagem menos qualitativa e mais matemática dos aspectos da metodologia. Conforme a definição adotada na Seção 1.2, podemos considerar que o vídeo 3D é uma sequiência de fotografias $3 D$. Entende-se por fotografia 3D o conjunto de técnicas usadas para a aquisição de dados gráficos que permitam a recriação no computador do modelo digital de um objeto 3D real [Carvalho et al., 2005].

Visando o desenvolvimento do vídeo 3D em direção ao vídeo de 4⿳亠丷⿵冂丶 geração, podemos considerar que a cada voxel na posição $(x, y, z)$ no tempo $t$ está associada uma intensidade $i: \mathbb{R}^{4} \longrightarrow \mathbb{R}^{3}$, de modo que:

$$
i(x, y, z, t)=(r, g, b)
$$

Para aplicações em que os únicos voxeis que interessam são os capturados pela câmera, pode-se levar em conta a função $f: \mathbb{R}^{3} \longrightarrow \mathbb{R}^{4}$, a qual possui como domínio o espaço paramétrico $(u, v)$ da textura e o tempo $t$ de aquisição do quadro:

$$
f(u, v, t)=(r, g, b, p)
$$

Desta forma, fica evidenciado que tal função fornece-nos, para cada ponto na textura, tanto as três componentes RGB do pixel quanto a profundidade do voxel pertencente à superfície $2 \frac{1}{2} \mathrm{D}$ capturada associado a esse pixel. 


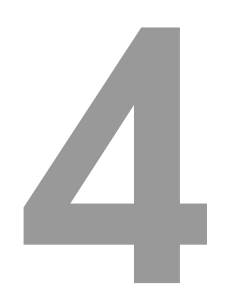

\section{Rastreamento e Registro de Componentes Conexas 3D}

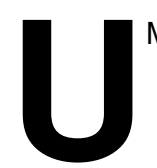

M DOS PROBLEMAS IMPORTANTES em aberto nas áreas de visão computacional e computação gráfica é o rastreamento e o casamento de componentes conexas geometricamente em um vídeo 3D. Passemos então para a definição de componente conexa que será adotada:

Definição. Uma componente conexa $(C C)$ é um conjunto de pontos no espaço oriundos de um vídeo $3 D$ de tal modo que dois pontos, $P_{a}$ e $P_{b}$, pertencem a uma mesma $C C$ se existe uma seqüência $P_{a}, \ldots, P_{b}$ de pontos adjacentes (segundo uma vizinhança de 4) tais que, tomados dois a dois nesta seqüência, sua distância é menor que um limiar pré-determinado.

Desta forma, pela definição adotada, cada quadro de um vídeo 3D possui de uma a diversas CCs. Estas são constituídas por um grupo de pontos próximos entre si ou por apenas um ponto, isolado de todos os outros, dependendo do limiar adotado. É este que decide a pertinência de um ponto qualquer a uma $\mathrm{CC}$ em questão. Uma vez que o número de pontos da geometria capturada e a distribuição destes num quadro de vídeo 3D são fixos, a escolha do valor do parâmetro de distância que estabelece as CCs também indica a quantidade destas:

se o limiar é muito baixo, têm-se muitas CCs formadas por poucos pontos cada uma; no extremo, o número de CCs coincide com o número de pontos; 
tá já no caso de o limiar ser muito alto, o número de CCs diminui e cada uma é constituída por muitos pontos; no extremo, têm-se uma só CC que contém todos os pontos.

Portanto, o conceito de proximidade entre os pontos é dado por este limiar. É importante salientar que, neste trabalho, o limiar é mantido constante em todos os quadros de um mesmo vídeo 3D.

O presente capítulo descreve uma nova solução para o problema de rastreamento e registro de componentes conexas em um vídeo 3D, a qual é obtida por meio da integração das informações de geometria e de textura fornecidas pelo mesmo.

É relatada aqui a solução desenvolvida, a qual consiste em uma contribuição original do presente trabalho. As técnicas introduzidas não só são passos intermediários fundamentais para a implementação do sistema de vídeo 4D como também permitem a filtragem de ruído, culminando numa melhora na qualidade dos dados.

Este capítulo está organizado como se segue: a Seção 4.1 fornece uma visão geral da solução proposta, a qual é tratada com mais detalhes nas seções seguintes. A detecção e o rastreamento de CCs são tratados nas Seções 4.2 e 4.3, respectivamente. Já o problema do registro de CCs é abordado na Seção 4.4. Por fim, na Seção 4.5 são apresentadas duas aplicações que foram desenvolvidas tomando como base as componentes conexas detectadas.

\section{SEÇÃO 4.1}

\section{Visão Geral da Abordagem Proposta}

O rastreamento de objetos em seqüências de vídeo é um importante problema de visão computacional e tem recebido muita atenção por parte da comunidade científica. Métodos de rastreamento têm diversas aplicações tais como detecção e extração de características, além de casamento, alinhamento e costura de imagens para a geração de panoramas.

No presente trabalho, a atenção é voltada para o rastreamento de componentes conexas tridimensionais [Meier \& Ade, 1998] obtidas a partir de cada quadro de um vídeo 3D. Este é um problema diferente do de rastrear objetos $2 \mathrm{D}$ em tradicionais sequiências de vídeo em níveis de cinza ou colorido justamente por incorporar a 
informação de profundidade da cena gravada. A saída do processo de rastreamento é uma relação inter-quadros de cada componente conexa.

Para abordar o problema de rastreamento e registro de componentes conexas em um vídeo 3D e fazer a integração dos dados geométricos, primeiramente é preciso detectar as componentes conexas tridimensionais presentes em cada quadro. Tal necessidade deve-se ao fato de que o casamento entre todas as CCs (casamento global) é melhor feito quando cada uma delas é registrada individualmente, uma vez que é eliminada a influência do movimento relativo entre elas. As CCs podem representar objetos completos ou partes de objetos presentes na cena gravada.

A Figura 1.7, já discutida na Seção 1.4, ilustra a abordagem adotada. Dois quadros subseqüentes são esquematicamente exibidos (denotados como quadro $t-$ 1 e quadro $t$ ). Após a detecção das CCs, os próximos passos necessários são:

(1) rastreamento das componentes conexas por meio da identificação de qual CC no quadro $t-1$ corresponde a qual no quadro $t$ ou da verificação de tratar-se de uma nova $\mathrm{CC}$;

(2) identificação de uma translação que melhor aproxime as texturas dos dois quadros consecutivos;

(3) aplicação da translação calculada no passo anterior aos dados de geometria;

(4) identificação de pontos salientes no quadro $t$;

(5) identificação de pontos correspondentes no quadro $t-1$ por meio de interpolação dos dados de geometria, e

(6) aplicação do algoritmo ICP para registro tridimensional das componentes conexas.

É importante notar que o sistema de aquisição de vídeo 3D usado provê tanto informação de textura quanto de geometria da cena em cada quadro, ou seja, os dados são fornecidos como uma superfície de Monge (imagem de profundidade) com textura. Em outras palavras, trata-se de um gráfico em $\mathbb{R}^{3}$ de uma função $f: U \longrightarrow$ $\mathbb{R} \times c(u, v)$, em que $U$ é um aberto de $\mathbb{R}^{3}$ e $c(u, v)=(R(u, v), G(u, v), B(u, v))$ é a cor da textura, no sistema de cores RGB, do pixel de coordenadas $(u, v)$. Além 
Figura 4.1 Taxa de Nyquist. O teorema de Nyquist afirma que, para se obter uma representação precisa de um sinal analógico, a amplitude do mesmo deve ser amostrada a uma taxa igual ou superior a duas vezes a freqüencia da componente senoidal de mais alta freqüência do sinal.
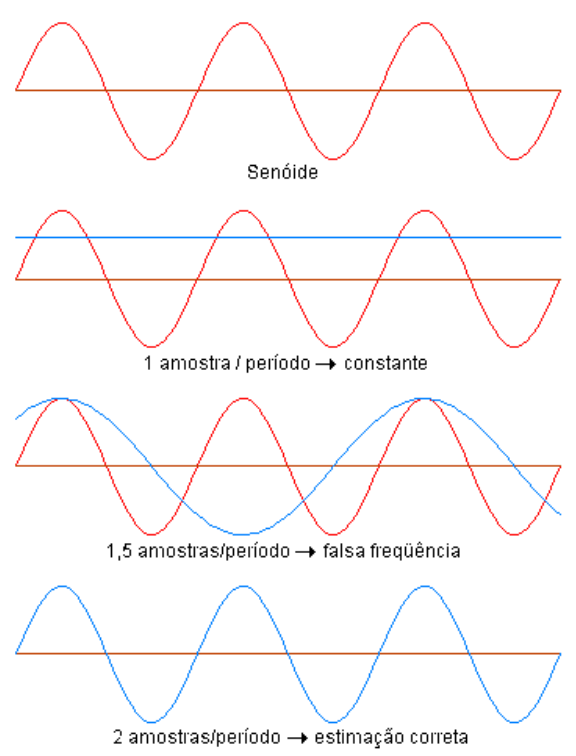

da informação geométrica de cada CC 3D, essa abordagem também aproveita-se da textura da imagem, a fim de melhorar os resultados de uma forma eficiente. A taxa de aquisição, por ser em tempo real, implica em uma alta consistência temporal, a qual é explorada pelos procedimentos de rastreamento e alinhamento.

Sistemas de vídeo 3D geralmente adquirem a textura da cena com uma resolução maior que a da geometria da mesma. Este fato é verificado no sistema de captura de vídeo 3D do IMPA, uma vez que foi adotado estéreo ativo (luz estruturada) para obtenção de informação de geometria 3D. Baseado no conceito da taxa de Nyquist (vide Figura 4.1), a resolução da textura precisa ser pelo menos duas vezes a da geometria. Nos experimentos feitos, ela é mais que o dobro. Desta forma, uma abordagem razoável é usar a textura para melhorar o casamento da geometria. A imagem da textura provê características visuais a serem exploradas enquanto a geometria fornece características geométricas (forma) dos objetos na cena. Ambas são exploradas de maneira complementar. Trata-se de um passo intermediário e este documento contém o estudo que já foi desenvolvido nesse sentido. 
Figura 4.2 Sistemas de coordenadas. Para a captura de vídeo $3 D$ e o rastreamento e registro de CCs, são usados três sistemas de coordenadas: o da textura ( $u$, v e d $(u, v)$ ), o da câmera ( $p$, v e d $(p, v)$ ) e o do mundo ( $x$, y e $z)$. Os dados de cada um destes sistemas são alterados de acordo com o valor no eixo $t$, do tempo.

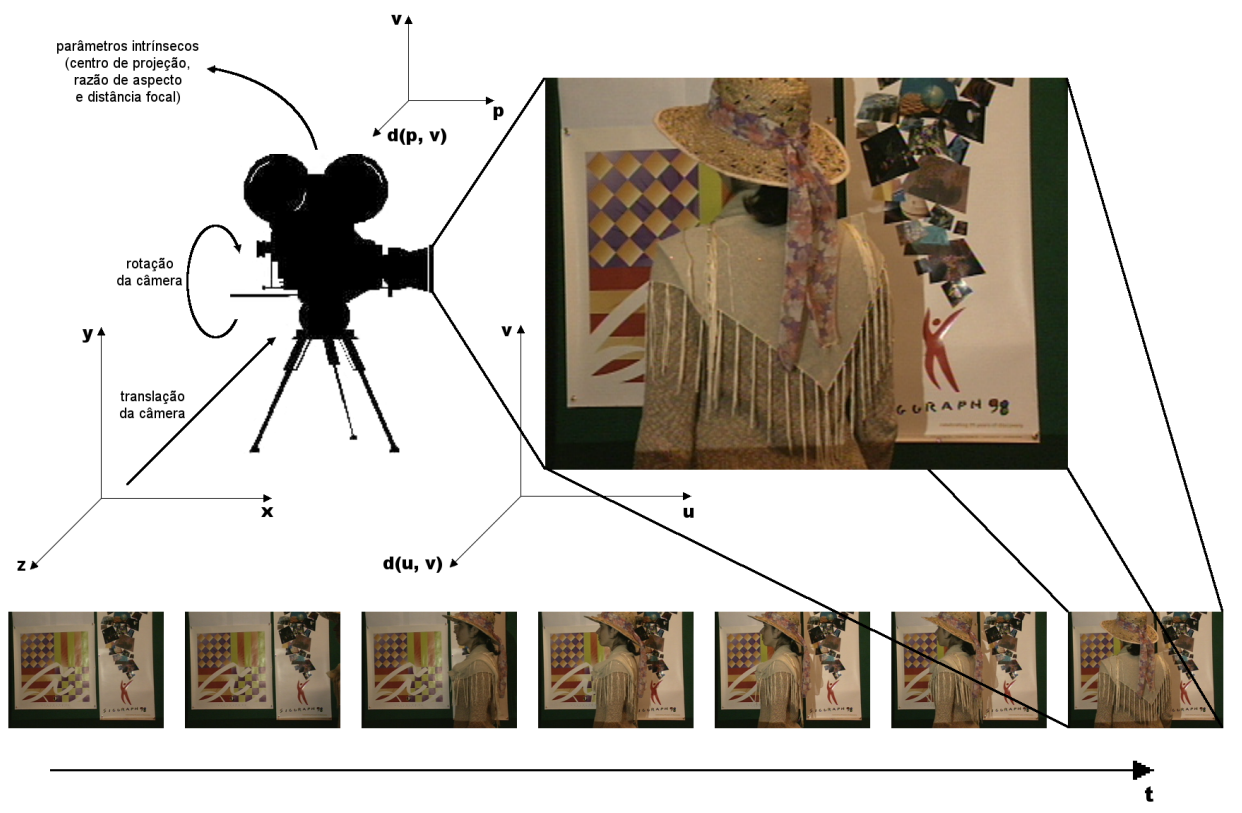

Pode-se usar diferentes sistemas de coordenadas para descrever os objetos modelados em um sistema de vídeo 3D. O sistema de coordenadas serve para dar uma referência em termos de medidas do tamanho e posição dos objetos dentro da área de trabalho [Azevedo \& Conci, 2003]. O sistema de captura de vídeo 3D envolve três sistemas de coordenadas diferentes (ilustrados na Figura 4.2):

Sistema de coordenadas da textura: é o domínio paramétrico da imagem da textura, o qual é usado também para a imagem de profundidade (isto é, geometria). Para cada ponto $(u, v)$ na imagem é associada uma função de cor $c(u, v)=(R(u, v), G(u, v), B(u, v))$ além da informação de profundidade $d(u, v)$. Conforme explicado na Seção 3.5, a informação de profundidade não é calculada pelo sistema para todos os pontos $(u, v)$, mas ela pode ser 
obtida por interpolação dos pontos de amostragem. Comete-se o abuso de usar a notação $c(u, v, t)$ e $d(u, v, t)$ para denotar, respectivamente, a textura e a profundidade do pixel de coordenadas $(u, v)$ do quadro no tempo $t$. Alguns autores preferem chamar este sistema de coordenadas de sistema de referência do dispositivo, já que neste tipo de sistema faz-se uso de coordenadas que podem ser fornecidas diretamente por um dispositivo específico. Assim, os limites dos valores das coordenadas são dados pelo número máximo de pixeis que compõem o vídeo $(640 \times 240)$. No entanto, este não é o caso, uma vez que considera-se o sistema de coordenadas da câmera como sendo um outro, que é descrito a seguir.

Sistema de coordenadas da câmera: este sistema de coordenadas é dado pelos parâmetros intrínsecos (e.g., distância focal, razão de aspecto e centro de projeção) e extrínsecos (translação e rotação) da câmera. Baseando-se na parametrização $(u, v)$ da imagem, é possível calcular a posição de um ponto da cena visto pela câmera: consideremos um ponto $P$ amostrado na imagem de profundidade e associado ao pixel $p=(u, v)$, com profundidade $w_{P}=$ $d(u, v)$. Podemos calcular o vetor direção de $P$ como $\boldsymbol{v}=(P-O) /\|P-O\|$, em que $O$ é a origem do centro de projeção. Todos os pontos pertencentes ao raio de visão determinado por $O$ e $P$ são da forma $r(w)=O+w \boldsymbol{v}$, em que o parâmetro $w$ indica a distância até a origem $O$. Então, a coordenada do ponto $P$ da superfície é dada, no sistema de coordenadas da câmera, por $P=r\left(w_{P}\right)=O+w_{P} \boldsymbol{v}$, conforme exemplificado na Figura 4.3. Para fins de rastreamento e registro, considera-se o sistema de coordenadas da câmera como sendo constituído pelos eixos $p, v$ e $d(p, v)$. O eixo $v$ equivale ao eixo das ordenadas no sistema de coordenadas da textura. Por sua vez, o eixo $p$ indica o número da faixa colorida que é projetada sobre a cena gravada, incorporando assim informação que é enviada pelo projetor.

Sistema de coordenadas do mundo: é o sistema de coordenadas global da cena, no qual elementos da câmera e da cena estão embutidos. Também é chamado de sistema de referência do universo. Uma vez que tanto a câmera pode ter seus parâmetros alterados quanto os objetos na cena podem se mover, suas posições e orientações são dependentes do tempo. Na Figura 4.2, esse 
Figura 4.3 Cálculo da posição de um ponto da cena. $O$ ponto $P$ está localizado na ponta do nariz do modelo tridimensional da face exibida. A reta que liga o ponto $P$ ao centro de projeção $O$ da câmera, passa pelo pixel de coordenadas $(u, v)$ na textura, a qual é representada como um retângulo em perspectiva em frente ao modelo $3 D$.

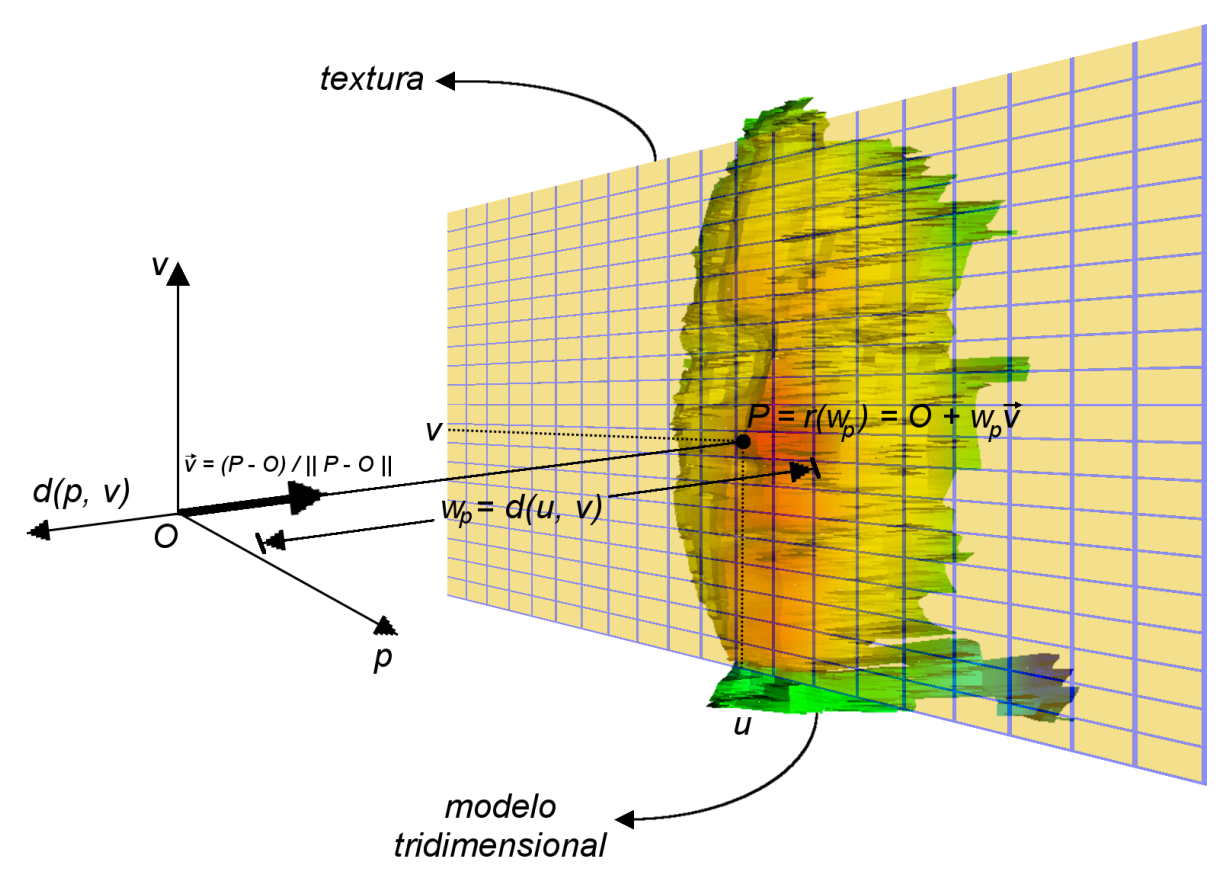

sistema é representado pelos eixos $x, y$ e $z$.

Todos esses sistemas de coordenadas são explorados na abordagem adotada, cada um sendo escolhido convenientemente, a fim de permitir a criação de uma solução mais eficaz. O rastreamento de CCs é feito no sistema de coordenadas da imagem. A detecção de características visuais e o alinhamento de textura para a identificação de pontos salientes e seus correspondentes no decorrer dos diferentes quadros também são executados no sistema de coordenadas da imagem e permitem o mapeamento da informação entre as coordenadas da câmera de diferentes quadros. Finalmente, a detecção de características de forma e o alinhamento da geometria são feitos no sistema de coordenadas da câmera e permitem o mapeamento 
Figura 4.4 Proximidade no espaço discreto $(p, v)$. O quadriculado à esquerda mostra pontos vizinhos ao ponto central de coordenadas $(p, v)$ no espaço da câmera. O exemplo à direita ilustra como esta proximidade pode ser usada para reduzir o espaço de busca por pontos que estejam próximos também na geometria dos objetos gravados.

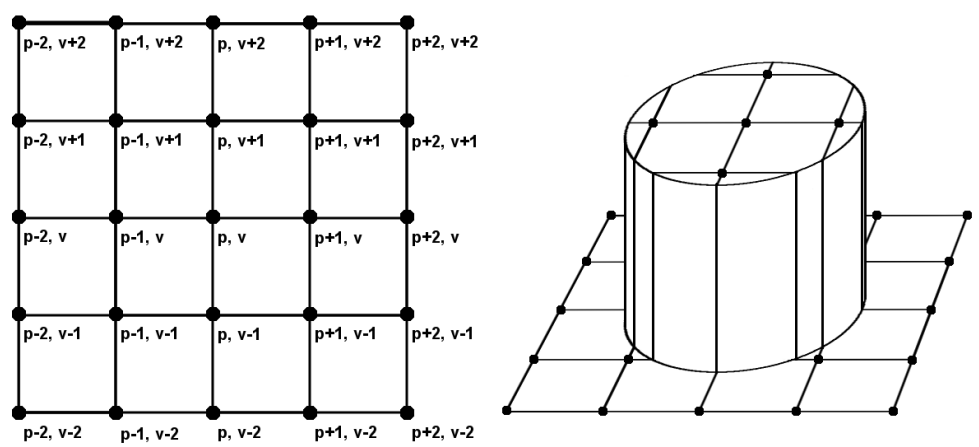

de informação de posição no sistema de coordenadas global. Cada um desses passos é detalhado nas seções que seguem.

SEÇÃO 4.2

\section{Detecção de Componentes Conexas}

O primeiro passo para a detecção de componentes conexas é a construção de um grafo de conexão de pontos 3D. De modo simples, pontos cuja proximidade seja menor que um determinado limiar $l$ são ditos conexos. Uma componente conexa é um grafo isolado de pontos conexos. Abordagens ingênuas para a construção de tais grafos podem possuir um tempo de complexidade muito alto.

Os métodos de decodificação usados em sistemas estéreo ativos fornecem automaticamente informação local que pode ser usada para a detecção de componentes conexas. As coordenadas $p$ e $v$ (coluna e linha, respectivamente, no espaço da câmera) de um ponto 3D definem uma topologia intrínseca.

Deste modo, pontos que estão próximos no espaço discreto $(p, v)$ são fortes candidatos a estarem próximos no espaço 3D (vide Figura 4.4). Isto nem sempre é verdade devido a descontinuidades na profundidade da cena. Por outro lado, pontos distantes no espaço $(p, v)$ também estão distantes no espaço 3D. Portanto, o uso 
de uma tabela $(p, v)$ reduz significativamente o espaço de busca para o cálculo do grafo de conexão e das diferentes componentes conexas.

Neste esquema, dois pontos estão conectados se eles forem $k$-vizinhos na tabela $(p, v)$ e se a distância que os separa no espaço 3D for menor que o limiar $l$. É necessário ter cuidado porque a resolução de $v$ é tipicamente muito maior que a resolução de $p$ e, conseqüentemente, suas unidades são diferentes.

As componentes conexas de uma cena são identificadas de acordo com rótulos que lhes são atribuídos. Para fins de visualização, tais rótulos são mapeados em cores num número máximo de 1024.

\section{SEÇÃO 4.3}

\section{Rastreamento de Componentes Conexas}

Com a detecção de cada CC em mãos, pode-se obter a segmentação das mesmas. Sendo $r_{i}$ o rótulo da CC de interesse, para segmentá-la basta percorrer os dados pertencentes às linhas de profundidade, realizando uma nova rotulação:

se o rótulo do ponto é $r_{i}$, deve-se mantê-lo;

caso contrário, deve-se alterá-lo para um rótulo de fundo $r_{f}$.

Tal procedimento pode ser usado inclusive para fazer a segmentação da textura correspondente. O único fato adicional a ser levado em conta é a diferença nas resoluções. Para tanto, pode-se considerar, por exemplo, que a textura correspondente ao intervalo entre dois pontos de profundidade adjacentes com o mesmo rótulo $r_{i}$ refere-se à $\mathrm{CC}$ de rótulo $r_{i}$. Essa informação é levada em conta no alinhamento de texturas (a ser visto adiante).

Uma vez que as CCs são segmentadas quadro a quadro independentemente, é necessário implementar um procedimento de rastreamento para identificar qual CC no quadro $t-1$ corresponde a qual no quadro $t$. Diferentes eventos importantes precisam ser tratados pelo procedimento de rastreamento, tais como: CCs móveis que mudam de forma, novas CCs que aparecem na cena, CCs antigas que desaparecem (por exemplo, movendo-se para fora da cena), CCs que se unem (por exemplo, dois objetos diferentes que se tocam em algum instante) e CCs que se dividem (por 


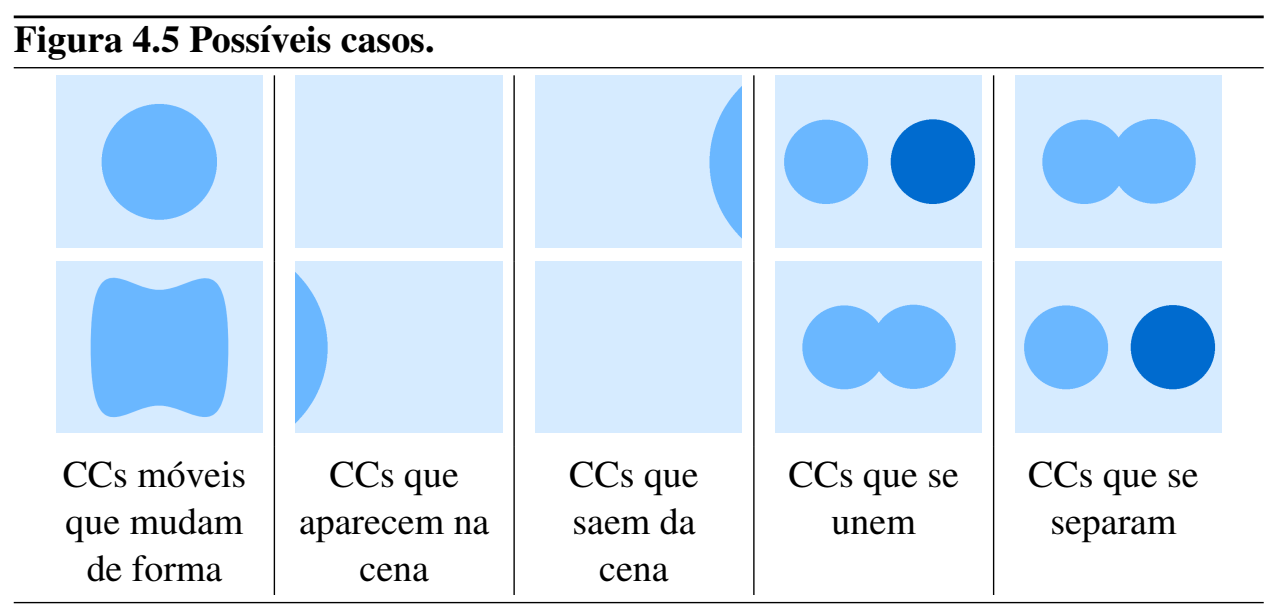

Figura 4.6 Área de sobreposição em quadros subseqüentes. (a) e (b) ilustram duas componentes conexas correspondentes em quadros subseqüentes; (c) Devido à alta taxa de aquisição, as duas CCs tendem a possuir uma grande área de sobreposição.

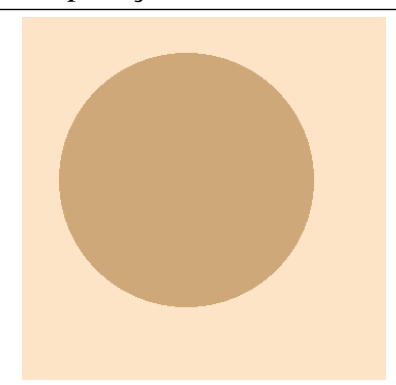

(a)

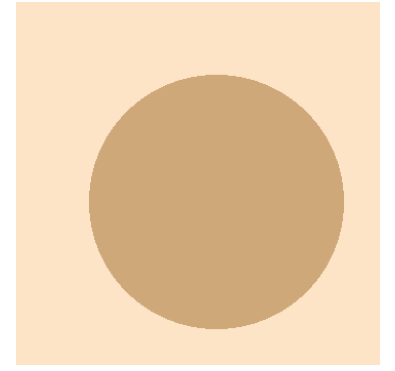

(b)

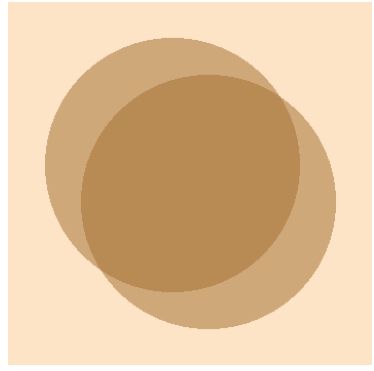

(c)

exemplo, objetos que se tocavam e que separam-se movendo-se cada um para um lado). Uma coletânea destes possíveis casos é mostrada na Figura 4.5.

$\mathrm{O}$ procedimento de rastreamento proposto considera quadros consecutivos de modo que possamos explorar o fato de que cada $\mathrm{CC}$ faz pequenos movimentos entre quadros subseqüentes devido à alta taxa de aquisição (30 quadros por segundo). Em tais casos, espera-se que a intersecção de uma $\mathrm{CC}$ em um quadro $t$ com sua correspondente CC no quadro $t-1$ seja grande. A intersecção entre as CCs em quadros subsequientes é usada para rastrear as CCs (veja a Figura 4.6). O processamento do primeiro quadro é especial, uma vez que não há quadro anterior para que 
as intersecções entre as componentes conexas sejam calculadas.

Seja $L=\left\{l_{1}, l_{2}, \ldots, l_{r}\right\}$ um conjunto de $r$ rótulos de CCs em cada quadro. O rastreamento de uma componente conexa pode ser visto como a determinação de um mapeamento $M: L \rightarrow L$ tal que, para cada quadro no tempo $t$, se uma mesma CC possuir rótulo $l_{x}$ em um quadro no tempo $t-1$ e rótulo $l_{y}$ no quadro no tempo $t$, então $M\left(l_{y}\right)=l_{x}$. A imagem de profundidade $d(u, v, t)$ é usada para construir $M$. Para cada CC $c$ no tempo $t$, é calculada a intersecção entre $c$ e todas as CCs no tempo $t-1$. Somente as componentes conexas no tempo $t-1 \mathrm{com}$ uma intersecção maior que um limiar definido previamente são consideradas como candidatas. Nesse ponto, a heurística usada é que intersecções muito pequenas freqüentemente advêm como resultado da presença de ruídos nos dados de entrada.

Sejam $c_{1}, c_{2}, \ldots, c_{n}$ essas CCs candidatas no quadro $t-1$. A diferença média entre as coordenadas de profundidade de $c$ e $c_{1}, c_{2}, \ldots, c_{n}$ é dada por:

$$
m\left(c, c_{i}\right)=\frac{1}{\left|c \cap c_{i}\right|} \sum_{(u, v) \in c \cap c_{i}}|d(u, v, t)-d(u, v, t-1)|,
$$

para $i=1,2, \ldots, n$. O termo $\min _{i} m\left(c, c_{i}\right)$ é chamado de erro normalizado mínimo. A CC em $t-1$ que minimiza a média de diferenças $m\left(c, c_{i}\right)$ é escolhida como a candidata final. É essa $\mathrm{CC}$ que melhor casa com a componente conexa $c$ no quadro $t$.

Determina-se um limiar de distância máxima $d_{\max } \cdot \operatorname{Se} \min _{i} m\left(c, c_{i}\right)>d_{\max }$, então nenhum mapeamento entre os quadros $t$ e $t-1$ é criado para $c$. Neste caso, $c$ é considerada como sendo uma nova CC surgida no quadro $t$, ou seja, que não estava presente no quadro $t-1$. Um novo rótulo é então atribuído a $c$.

Nos experimentos feitos, adotou-se $d_{\max }=1.5$ e a intersecção mínima aceitável foi de $30 \%$ da área da componente conexa sendo analisada. Ambos os parâmetros são determinados empiricamente. Se a intersecção for grande o suficiente, a componente não pode ser considerada ruído e é candidata ao rastreamento. Se a intersecção máxima de uma componente no quadro $t$ com todas as componentes no quadro $t-1$ for menor que a constante de intersecção mínima aceitável adotada, então deve-se ser mais flexível, passando a aceitar uma intersecção mínima menor ainda. Caso contrário, sempre que uma nova $\mathrm{CC}$ surgisse na cena próximo 
$\overline{\text { Figura 4.7 Rastreamento de componentes conexas que são divididas. }(\boldsymbol{a}) e(\boldsymbol{b})}$ ilustram dois quadros consecutivos, $t-1$ e t. O quadro $t-1$ contém três objetos e o fundo, os quais são tomados como sendo 4 CCs. A CC do fundo é indicada por A. Conforme a CC do meio move-se e atinge a borda da imagem, o fundo é dividido em duas CCs, como mostrado em (b). O procedimento de rastreamento de CCs é capaz de lidar com tais situações, identificando que ambas as CCs Be $C$ no quadro t correspondem à CC A no quadro $t-1$.

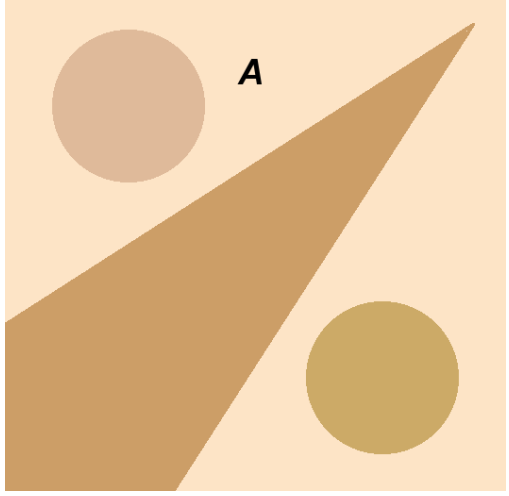

(a) Quadro $t-1$

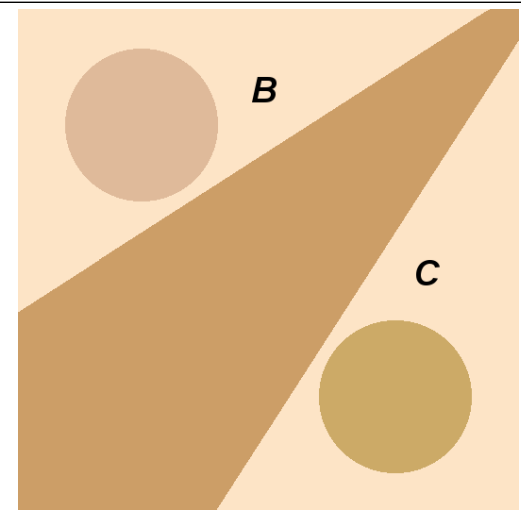

(b) Quadro $t$

a uma grande variedade de $\mathrm{CCs}$, ela teria um novo rótulo atribuído. Isso ocorreria por vários quadros, até que um rótulo se estabilizasse, devido à maior porção no cálculo da intersecção conforme a nova CC ganha mais espaço em cena.

Visualmente, o rastreamento dá-se pelas cores de cada CC, as quais estão estritamente ligadas aos rótulos que são atribuídos. É importante notar que este algoritmo de rastreamento também lida corretamente com o caso em que uma componente conexa simples divide-se de um quadro para o próximo: espera-se que as duas novas CCs criadas no quadro $t$ sejam mapeadas na mesma CC no quadro $t-1$. Um exemplo é exibido na Figura 4.7.

\section{Registro de Componentes Conexas}

Uma vez que as CCs são rastreadas ao longo da seqüência de vídeo, cada par de CCs correspondentes em quadros subseqüentes deve ser alinhado. Isto é feito por meio da aplicação do algoritmo iterativo de pontos mais próximos (ICP) [Besl \& 
McKay, 1992] a um conjunto de pontos salientes selecionados a partir das CCs. O algoritmo ICP é amplamente usado para o alinhamento de modelos tridimensionais baseando-se somente na geometria ${ }^{1}$ das superfícies.

É importante salientar que esse tipo de registro não pode ser feito pelo método de mínimos quadrados, uma vez que este deve ser aplicado a conjuntos que contenham a mesma quantidade de pontos, o que nem sempre é o caso.

Quatro passos são seguidos a fim de selecionar os pontos que alimentam o algoritmo ICP:

(1) Alinhamento das texturas: As regiões retangulares relativas às texturas das CCs consideradas são extraídas. Para cada uma destas regiões retangulares, os pixeis que não pertencem à $\mathrm{CC}$ em questão têm seu valor alterado para a cor preta. As duas novas imagens são casadas por meio de correlação cruzada. Para o cálculo da correlação cruzada, faz-se uso do teorema da correlação. Desta forma, sendo $f(x, y)$ e $h(x, y)$ funções que representam as duas imagens a serem correlacionadas, temos que:

$$
f(x, y) \circ h(x, y) \Leftrightarrow F^{*}(u, v) H(u, v),
$$

ou seja, a correlação cruzada no domínio do espaço pode ser obtida tomando-se a transformada inversa de Fourier do produto ponto-a-ponto entre o conjugado complexo da transformada de Fourier da primeira função e a transformada de Fourier da segunda função. O ponto máximo de correlação das duas regiões de textura $c(u, v, t) \circ c(u, v, t-1)$ indica a translação que uma região deveria sofrer a fim de ocorrer um casamento com a outra. Uma correspondência ponto a ponto entre as duas regiões $c(u, v, t)$ e $c(u, v, t-1)$ é então estabelecida. A principal vantagem de se usar textura para criar esta correspondência entre dois quadros, em vez da geometria, é a alta resolução apresentada pela primeira.

\section{(2) Aplicação da translação calculada no passo anterior aos dados de geome-}

tria (quadro $t$ ): A translação que é calculada para um melhor alinhamento das texturas é aplicada aos dados de geometria do quadro $t$. Essa translação é feita

\footnotetext{
${ }^{1}$ Há versões modificadas do algoritmo ICP que também se utilizam da cor presente em uma
} textura que é mapeada sobre a superfície a ser registrada. 
ignorando-se o eixo $d(p, v)$ de profundidade da câmera, levando-se em conta apenas os eixos $p$ e $v$ (vide esquema do sistema de coordenadas da câmera na Figura 4.2).

(3) Identificação de pontos salientes nos dados da geometria (quadro $t$ ): Os dados $d(p, v)$ da geometria representam a informação de profundidade medida ao longo dos padrões de luz projetados na cena. Ao se tentar fazer o registro de duas nuvens de pontos originárias de um vídeo 3D, o algoritmo ICP tem a tendência de alinhá-las, ficando uma linha range alinhada com outra. A solução encontrada para este problema é fazer uma seleção de pontos salientes. Para a seleção destes, considera-se cada linha que demarca a fronteira entre duas faixas de luz como sendo um sinal unidimensional. São tomados como pontos salientes o conjunto de pontos máximos e mínimos locais, os quais são identificados por meio de diferenciação numérica de $d(p, v, t)$. Neste momento (antes do cálculo da primeira derivada do sinal), é importante usar um filtro de borramento do sinal, tal como o filtro da gaussiana, a fim de evitar a seleção de ruídos como pontos salientes. Os ruídos aparecem na geometria como picos no sinal $d(p, v, t)$, sendo portanto identificados como máximo ou mínimo local caso uma filtragem passa-baixas não seja aplicada.

(4) Identificação de pontos correspondentes por meio de interpolação dos dados de geometria (quadro $t-1)$ : A posição na textura $c(u, v, t)$ de cada ponto saliente de $d(u, v, t)$ é identificada. Devido ao procedimento de alinhamento por correlação da textura, usa-se como heurística que esta também seja a posição dos pontos salientes na imagem alinhada da textura $c(u, v, t-1)$. É importante notar que, devido à resolução da imagem da textura ser maior que a da geometria, a posição de um ponto saliente no quadro $t-1$ pode não ter um ponto correspondente amostrado nos dados da geometria do quadro $t-1$. Portanto, o ponto saliente no quadro $t-1$ é obtido por interpolação linear simples dos pontos da geometria deste mesmo quadro.

O procedimento acima leva a dois conjuntos de pontos salientes correspondentes dos dados da geometria dos quadros $t$ e $t-1$. Esses dois conjuntos de pontos são então registrados por meio da aplicação do algoritmo ICP, enfim produzindo o resultado desejado: o casamento das componentes conexas. 


\section{SEÇÃO 4.5 \\ Aplicações Desenvolvidas}

Uma vez tendo as componentes conexas detectadas, rastreadas e registradas, uma miríade de aplicações pode ser desenvolvida. De fato, a maior aplicação que se tem em mente é a que dará origem ao vídeo de $4^{\mathrm{a}}$ geração, no qual modelos tridimensionais seriam obtidos, melhorados e aperfeiçoados a partir de cada modelo $2 \frac{1}{2} \mathrm{D}$ existente em cada quadro de um vídeo 3D.

Até que este objetivo final seja atingido, diversas outras aplicações precisam ser desenvolvidas. Duas destas tarefas intermediárias foram concluídas durante este trabalho: (1) aplicação de uma malha às CCs detectadas e (2) módulo de visualização das mesmas.

A malha usada para os modelos tridimensionais das CCs identificadas foi a A48, uma malha dinâmica adaptativa baseada em operadores estelares já comentada na Seção 2.4. Essa malha possui a capacidade de adaptar-se à geometria da superfície conforme esta evolui. De posse de tais malhas, pode-se por fim fazer a integração das mesmas, tomando-as duas a duas na seqüência de quadros do vídeo $3 \mathrm{D}$ e gerando uma malha final que acomode melhor as componentes conexas casadas. Esse é um tópico que será abordado na continuação deste trabalho.

Para facilitar o experimento de novos algoritmos com os dados oriundos do vídeo 3D, deu-se início à implementação de um sistema de visualização do mesmo. Neste sistema, foi desenvolvida uma interface que permite a aplicação de:

decimação quádrica, com a possibilidade de se escolher a percentagem de redução dos dados;

suavização da superfície da malha;

cálculo das normais à superfície, para maior fidelidade à iluminação;

mapeamento de cores segundo a profundidade, facilitando a visualização dos modelos $2 \frac{1}{2} \mathrm{D}$ ao serem renderizados pela placa gráfica;

renderização estéreo vermelho-azul, permitindo experimentações com óculos de visão estéreo vermelho-azul (celofane), e 
efeito de borramento por movimento da câmera. 


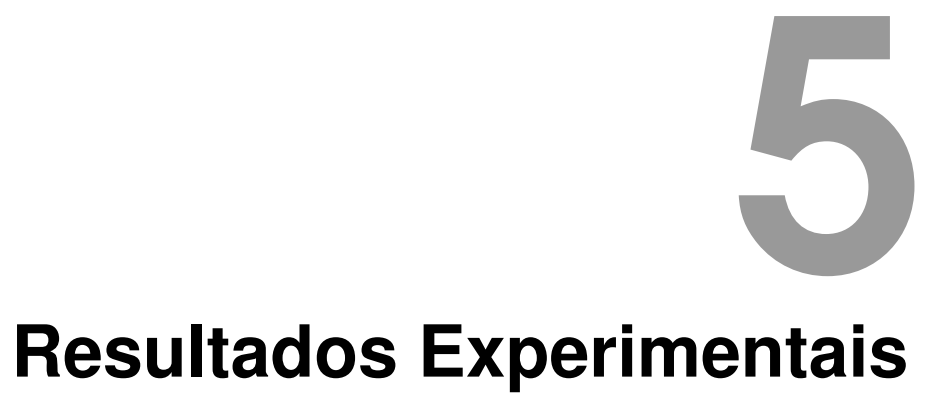

$\mathbf{N}$ ESTE CAPÍTULO, são apresentados resultados experimentais usando seqüências de vídeo 3D fornecidas pelo IMPA. Tais resultados evidenciam a vantagem do uso da textura para um melhor casamento da geometria, já que a resolução daquela é maior que a desta.

Primeiramente são mostrados resultados referentes ao rastreamento e casamento de componentes conexas. Na seqüência, há imagens que ilustram a aplicação da malha dinâmica adaptativa aos dados de vídeo 3D e o sistema de visualização desenvolvido.

Todos os cálculos computacionais foram feitos usando-se a infra-estrutura descrita na ficha técnica na página xxv.

\section{Rastreamento e Casamento de Componentes Conexas}

A Figura 5.1 mostra a informação de textura de três quadros de uma sequiência de vídeo (linha do topo) juntamente com os correspondentes dados de geometria segmentada (linha do meio). No primeiro quadro (coluna da esquerda) há uma pessoa em frente a um fundo plano, portanto definindo duas componentes conexas no espaço da geometria. As CCs são codificadas por meio de cores diferentes. À medida que a pessoa se move, as CCs correspondentes são rastreadas conforme esperado (linha da base). A estrutura do fundo que está atrás da pessoa no primeiro quadro aparece como uma terceira $\mathrm{CC}$, de acordo com o que é mostrado na segunda coluna. É importante notar que essa terceira $\mathrm{CC}$ não é identificada como 
Figura 5.1 Rastreamento de componentes conexas em vídeo 3D. Exemplo de três quadros de vídeo com suas correspondentes componentes conexas sendo rastreadas. A informação de textura é mostrada na linha do topo enquanto a de geometria (CCs identificadas) é mostrada na linha do meio. Na linha da base é exibido o rastreamento das CCs. Estes não são quadros consecutivos no vídeo $3 D$.
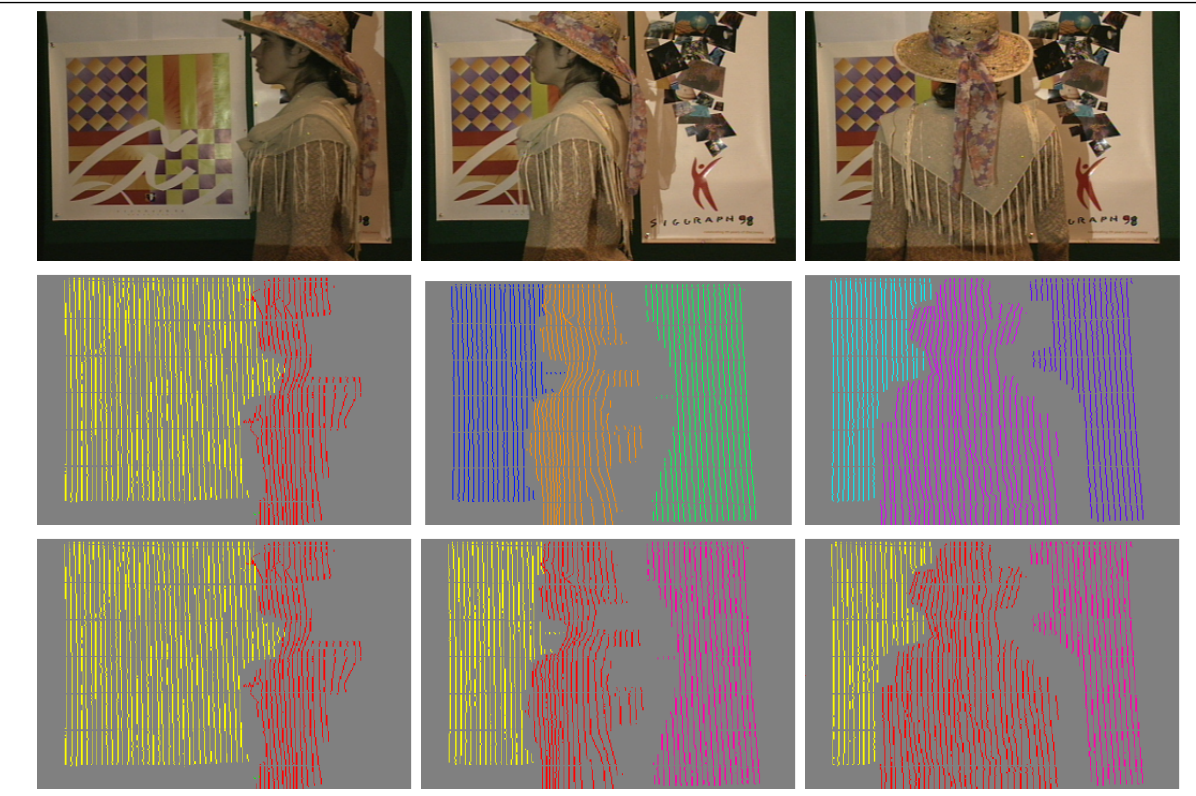

sendo a primeira $\mathrm{CC}$ do fundo porque ela não foi vista inicialmente como uma $\mathrm{CC}$ nos dados de geometria (primeira coluna) e porque a $\mathrm{CC}$ da pessoa divide completamente a $\mathrm{CC}$ do fundo, da base ao topo. Esta terceira $\mathrm{CC}$ que aparece também é corretamente rastreada, conforme exibido na terceira coluna.

Um exemplo da informação de textura e da segmentação correspondente usando a geometria da CC é mostrado na Figura 5.2. Essa textura segmentada é usada pelo procedimento de alinhamento da mesma para criar um mapeamento entre as texturas de quadros subseqüentes, como mostrado na Figura 5.3. Nesse exemplo, usamos uma diferença de dez quadros apenas com o propósito de uma melhor visualização. Em quadros consecutivos, a translação geralmente é pequena.

Os pontos salientes calculados para o quadro mostrado na Figura 5.4(a) são mostrados na Figura 5.4(b) na cor branca. As linhas em vermelho representam o 
Figura 5.2 Segmentação da textura. (a) Textura completa de um quadro. (b) Textura de apenas uma componente conexa, usada para calcular o casamento de texturas.

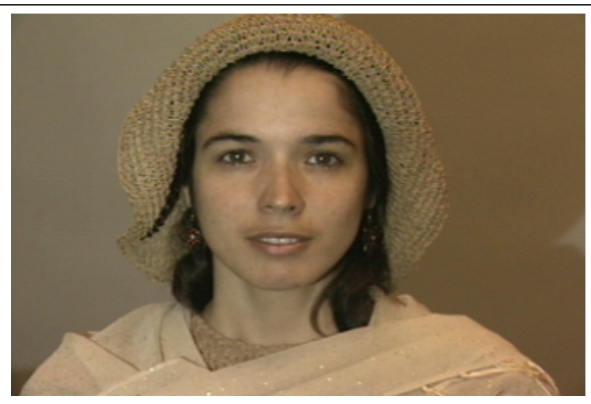

(a)

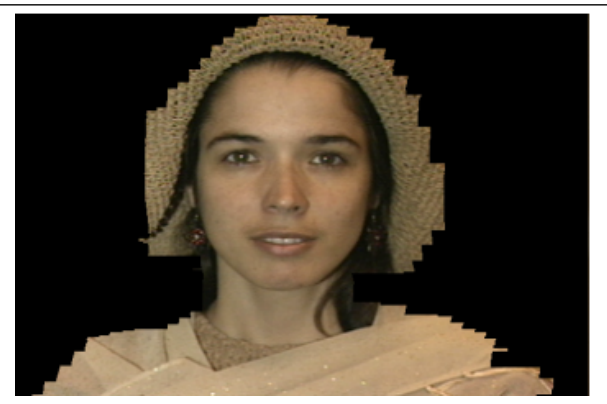

(b)

Figura 5.3 Translação baseada no casamento de textura. (a) Textura de uma componente conexa em um quadro $t-10$. (b) Textura da mesma componente conexa no quadro t. (c) Quadro t transladado em $(u, v)=(1,71)$ com relação ao quadro $t-10$ e sobreposto a este último. O quadro té mostrado com $50 \%$ de transparência.

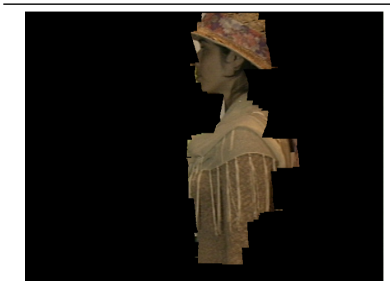

(a)

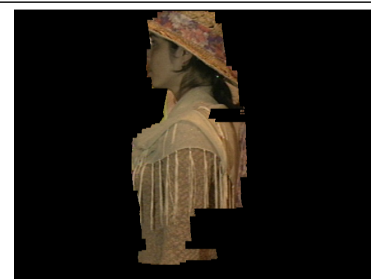

(b)

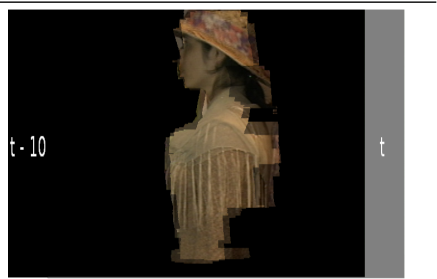

(c)

restante dos dados de profundidade. Na mesma figura, é mostrada a textura da componente conexa em questão no quadro anterior, juntamente com seus pontos salientes interpolados correspondentes (Figuras 5.4(c) e 5.4(d)).

Os pontos salientes são selecionados como entrada para o algoritmo ICP (o programa Scanalyze tem sido usado em nossos experimentos-http: / graphics . stanford.edu/software/scanalyze/). O casamento resultante é mostrado na imagem (a) da Figura 5.5. Uma nuvem de pontos é exibida na cor laranja e a outra na cor azul. A imagem na Figura 5.5(b) mostra um outro conjunto de pontos alinhados de acordo com a Figura 5.3. Ambos os resultados corroboram o método introduzido. 
Figura 5.4 Dados de profundidade e pontos salientes. Dois quadros consecutivos contendo apenas uma componente conexa são mostrados em (a) e (c). Cada quadro é acompanhado por seus dados de profundidade correspondentes em $(b) e$ (d). Os pontos salientes (máximos e mínimos locais) são os brancos.

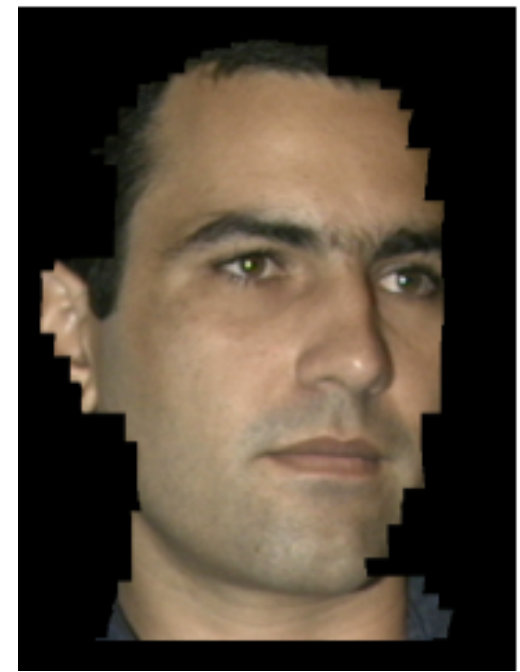

(a)

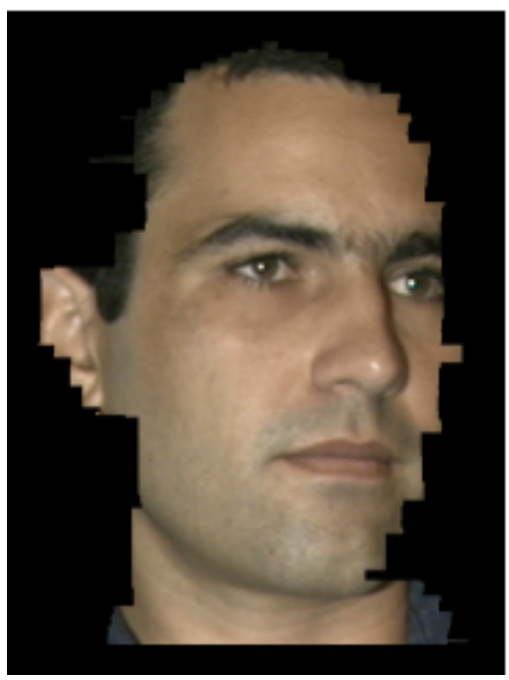

(c)

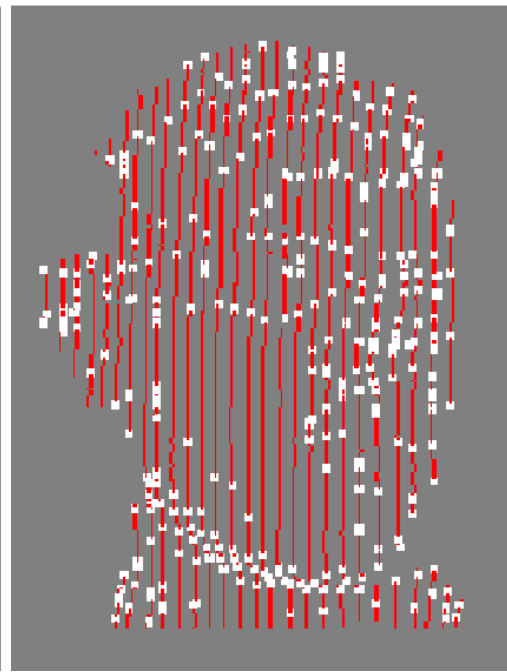

(b)

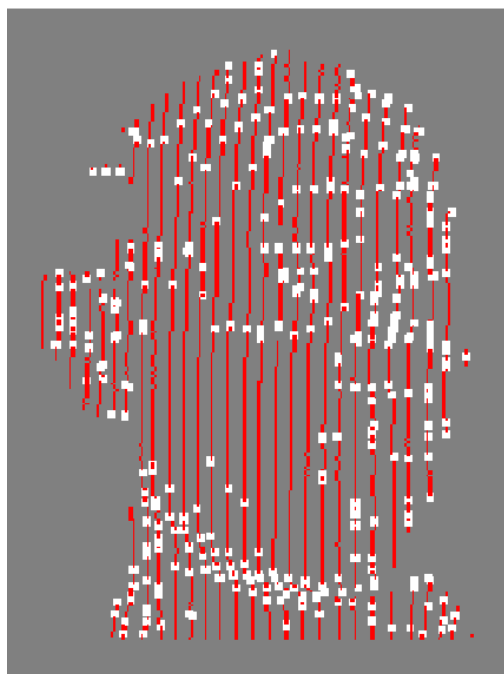

(d) 
Figura 5.5 Casamento feito pelo algoritmo ICP. A imagem (a) mostra os pontos salientes da Figura 5.4 casados usando o algoritmo ICP. A imagem (b) mostra um outro conjunto de pontos alinhados.

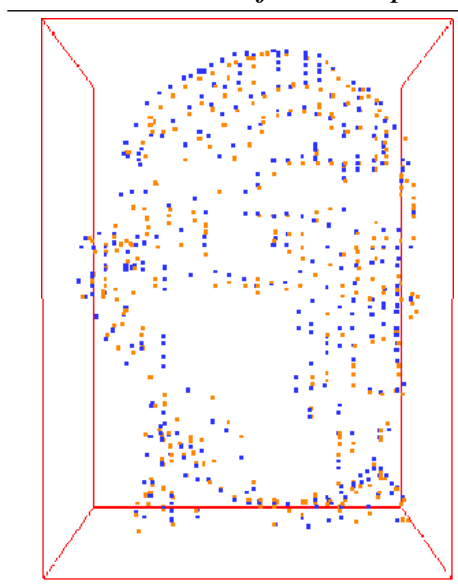

(a)

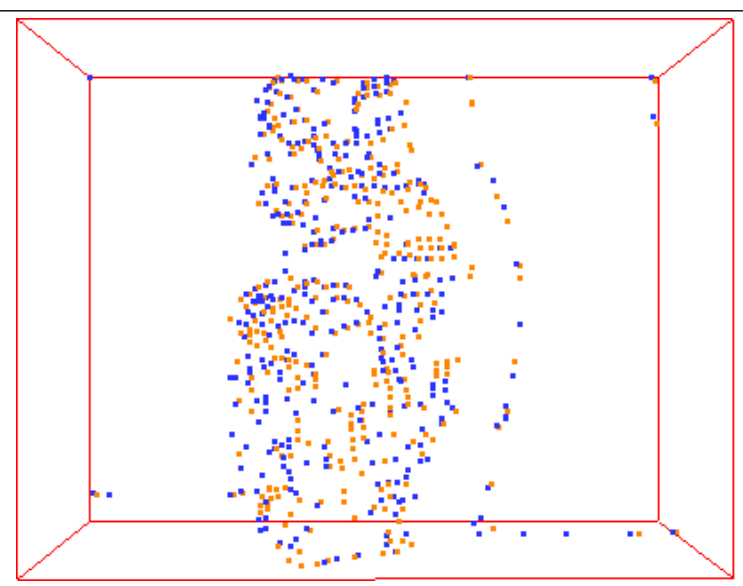

(b)

Os procedimentos de identificação e o rastreamento das componentes conexas foram desenvolvidos na linguagem $\mathrm{C}$, com restrições de tempo real em mente. Assim, podem ser executados em tempo de taxa de vídeo de acordo com a alteração de parâmetros. Quanto maior a velocidade de processamento, menor a qualidade do rastreamento. $\mathrm{O}$ alinhamento de textura foi escrito em uma linguagem de programação diferente $\left(\mathrm{MATLAB}^{\circledR}\right)$ e ainda não foi integrado ao restante do código.

SEÇÃO 5.2

\section{Aplicação da Malha e Sistema de Visualização}

A Figura 5.6 exemplifica a aplicação da malha dinâmica adaptativa A48 em dados oriundos de um vídeo 3D. À esquerda temos a malha aplicada a uma face e à direita é mostrada em detalhe a região do nariz e da boca da face exibida.

A interface gráfica do sistema de visualização que vem sendo desenvolvido é exibida na Figura 5.7. Parte dos diversos modos de visualização já implementados é mostrada na Figura 5.8. São ilustrados exemplos de decimação quádrica com $80 \%$ de redução dos dados, mapeamento de cores segundo a profundidade, renderização estéreo vermelho-azul e efeito de borramento por movimento da câmera. 
Figura 5.6 Aplicação da malha dinâmica adaptativa. Malha aplicada a uma face e detalhe da região do nariz e da boca. Em cima temos uma visualização da face de cada triângulo. Embaixo são exibidas apenas as arestas. Fica evidente a quadrangulação triangulada, necessária para a construção da malha.

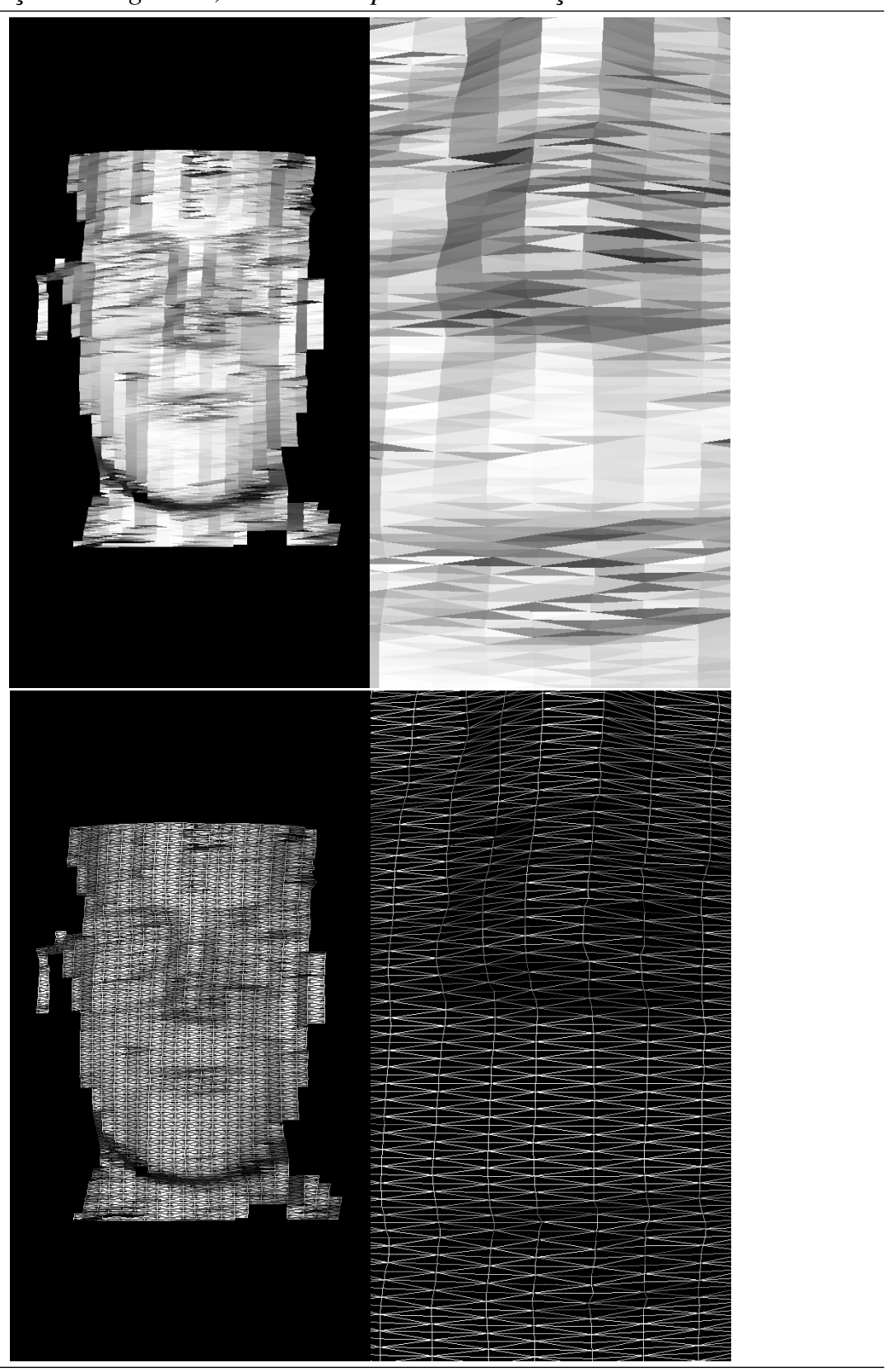


Figura 5.7 Sistema de visualização. Interface gráfica do sistema de visualização que está sendo desenvolvido.

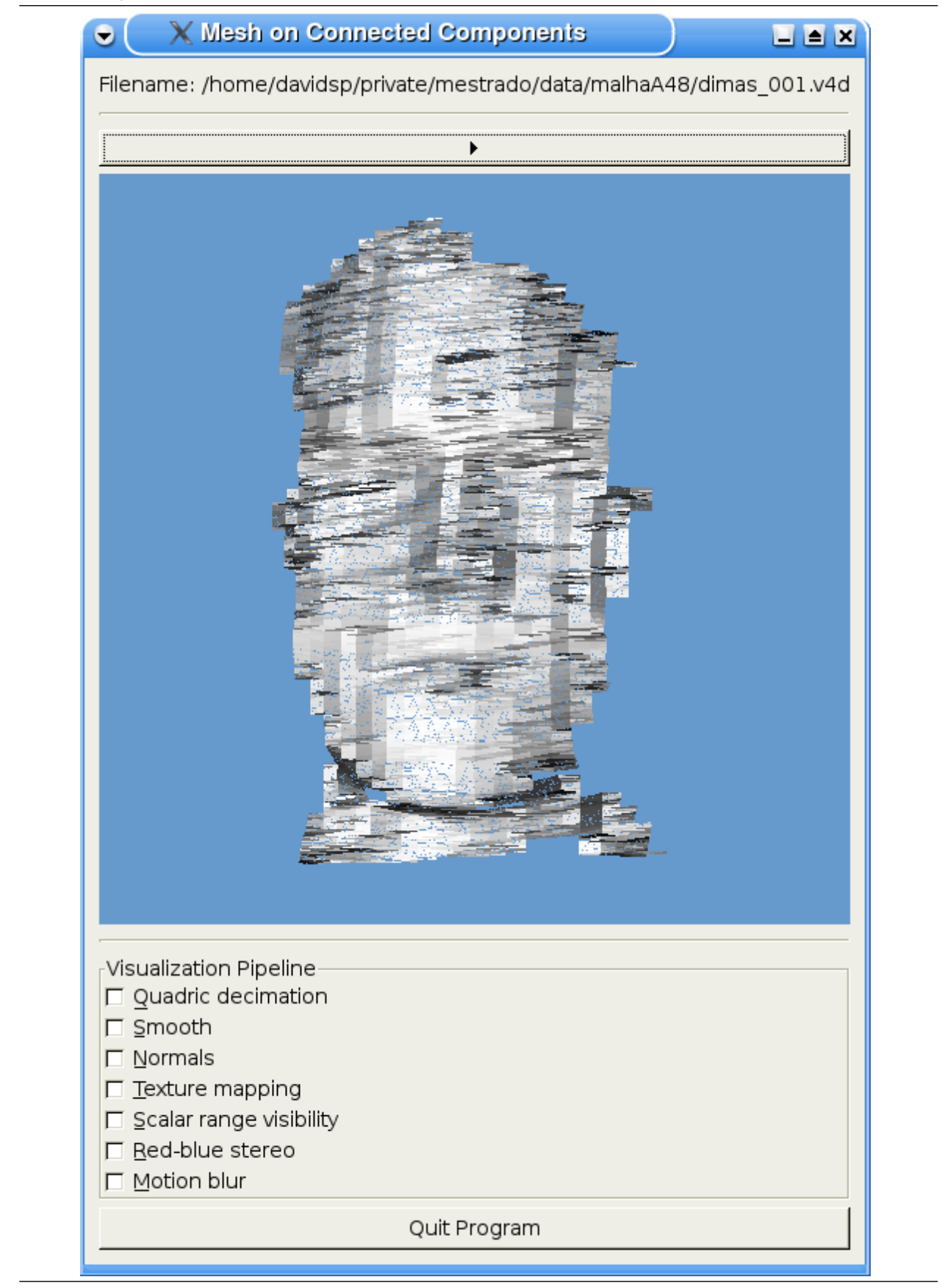


Figura 5.8 Visualizações do vídeo 3D. Decimação quádrica com $80 \%$ de redução dos dados, mapeamento de cores segundo a profundidade, renderização estéreo vermelho-azul e efeito de borramento por movimento da câmera.

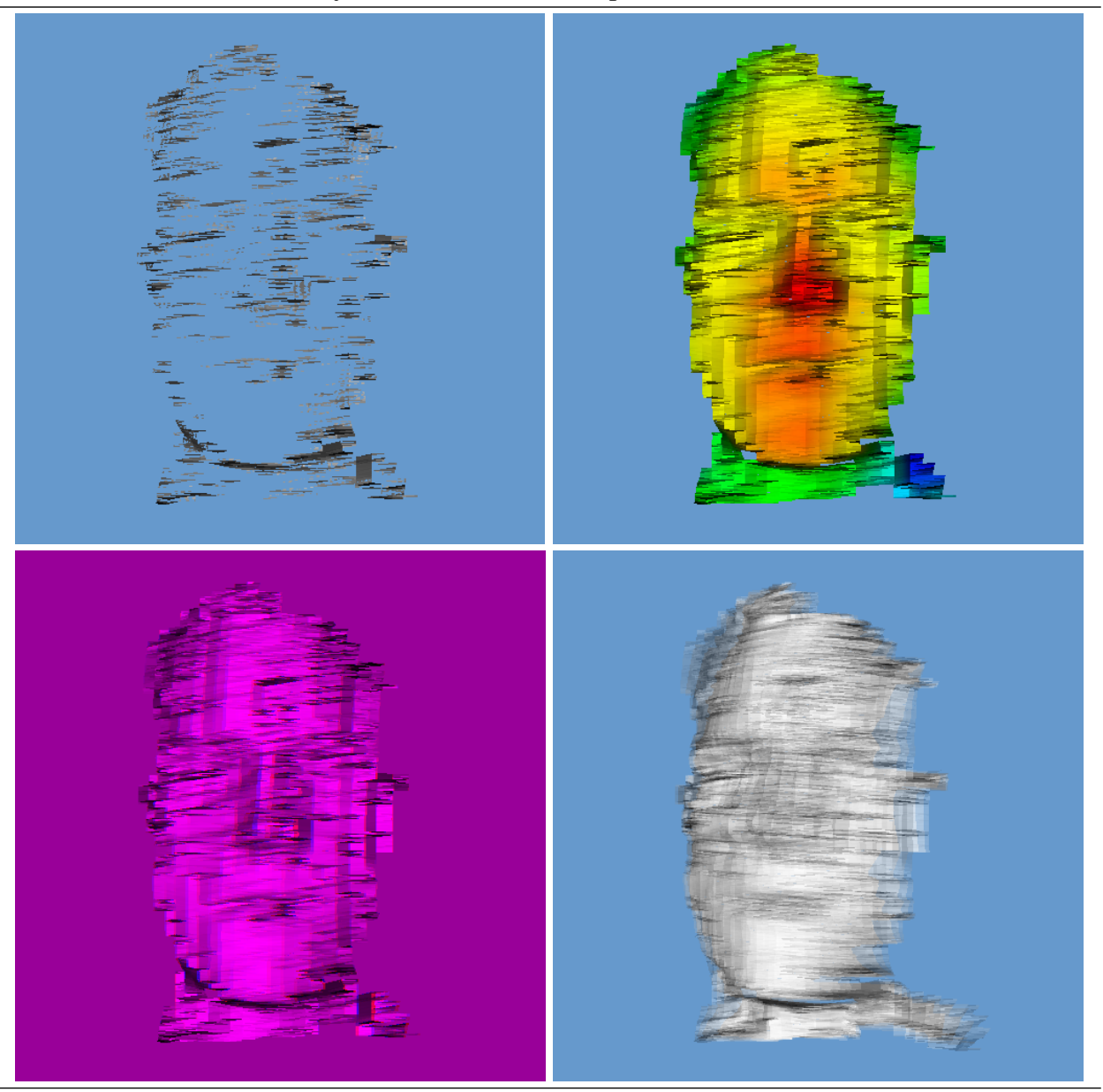




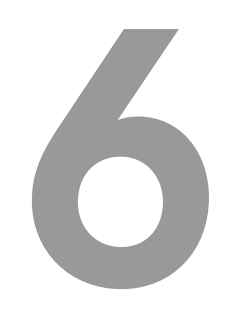

\section{Conclusão}

A

PRINCIPAL MOTIVAÇÃO no andamento deste trabalho tem sido a reconstrução tridimensional dos objetos presentes em uma cena de vídeo 3D por meio do casamento de diversas imagens $2 \frac{1}{2} \mathrm{D}$. Para tanto, a detecção, o rastreamento e o registro das componentes conexas presentes em um vídeo 3D são passos intermediários importantes.

Este projeto de mestrado envolveu a aplicação e a extensão de um método já desenvolvido e apresentado no SIGGRAPH (International Conference and Exhibition on Computer Graphics and Interactive Techniques) sob o título Real Time 3D Video [Velho et al., 2004]. Foi concluída uma fase de implementação e aplicação dos conceitos estudados. Em particular, testes com o algoritmo ICP foram feitos por meio do uso do programa Scanalyze, da Universidade de Stanford. Isso foi possível graças ao livre acesso que se tem ao código que manipula os arquivos de formato $\mathrm{v} 4 \mathrm{~d}$, criado no IMPA.

Uma outra fase deste trabalho envolveu a geração de malhas para cada componente conexa. Para esse fim, foi usada a biblioteca de malha dinâmica adaptativa A48 desenvolvida pelo professor Luiz Velho [Velho, 2004].

Durante a escolha e a redação do conteúdo dos capítulos anteriores, não se teve, de forma alguma, a pretensão de tornar este documento auto-contido, pois isto implicaria num texto demasiado extenso e tiraria o foco da metodologia introduzida. No entanto, fez-se necessária a inclusão de uma explicação detalhada sobre o sistema de aquisição de vídeo 3D do IMPA, que, apesar de não ter sido fruto do trabalho desenvolvido nesse mestrado, é a base para os avanços obtidos. 
Com tais objetivos em mente, os seguintes assuntos foram abordados neste documento: definição de vídeo 3D, métodos estereoscópicos, explicação básica de modelagem 3D, codificação por luz estruturada, o algoritmo ICP, malha dinâmica adaptativa, sistema de vídeo 3D do IMPA, sistema de visualização desenvolvido e rastreamento e casamento de CCs.

Este capítulo conclui a apresentação do trabalho desenvolvido com uma discussão acerca dos avanços obtidos e das limitações encontradas (Seção 6.1). Na seqüência, sugestões para trabalhos futuros são apresentadas na Seção 6.2, incluindo o uso do filtro de Kalman para acelerar o processo de rastreamento e o uso do caráter adaptativo da malha dinâmica.

\section{SEÇÃO 6.1 \\ Discussão}

O novo método para rastreamento e casamento de CCs apresentado tem se mostrado efetivo em nossos experimentos, sendo conveniente para diversas aplicações envolvendo vídeos 3D. O método lida corretamente com diferentes eventos que podem ocorrer, tais como o surgimento, o desaparecimento, a união e a divisão de CCs móveis e maleáveis.

A principal contribuição deste trabalho é a integração das informações de geometria e textura fornecidas por um vídeo 3D. A originalidade mostra-se tanto na reunião inédita de técnicas já conhecidas como no uso do algoritmo ICP a dados oriundos de um vídeo 3D, com o fim de rastrear e registrar CCs, objetivando a modelagem tridimensional. Este é um passo importante, pois trata-se de um avanço inicial em direção ao conceito de vídeo de 4⿳a geração [Vieira et al., 2005], por meio da acumulação da geometria no tempo.

O uso do casamento da textura melhora o casamento da geometria justamente porque a resolução daquela é maior que a desta, fato que é comum em sistemas de captura de vídeo 3D.

Vale a pena enfatizar o fato de que todo o processamento é feito individualmente sobre as componentes conexas de um vídeo 3D, em oposição a um casamento que fosse realizado com todos os dados de geometria de uma cena de uma só vez (o que equivaleria a considerar que todo quadro contivesse apenas uma CC). 
Tal procedimento resulta na obtenção de um melhor casamento global. A melhora obtida com a união dos casamentos individuais com relação a um único casamento por quadro deve-se à eliminação do movimento relativo entre as CCs.

Não foi desenvolvido nenhum método de avaliação que fornecesse uma medida de erro para validação do casamento efetuado. A avaliação do resultado foi apenas visual, por meio de comparação entre os casamentos da geometria com e sem o uso do casamento da textura.

Conforme foi dito no capítulo sobre a metodologia introduzida, o código ainda não foi unificado. Além do uso de três linguagens (C, C++ e Matlab $\left.{ }^{\circledR}\right)$, a comunicação entre as partes do código ainda é feita por meio da leitura e da escrita de arquivos em disco em vez de a transferência de dados ocorrer toda em memória. Em particular, esta falta de integração entre o código desenvolvido inviabiliza uma avaliação técnica sobre a interferência causada na execução em tempo real, que era uma característica do sistema original.

É importante notar que os resultados obtidos neste trabalho levaram em conta um casamento de texturas que foi feito apenas com o uso de translações. Certamente, o uso de métodos mais complexos que resultem num melhor casamento de texturas também resultará num melhor casamento da geometria.

Também deve-se notar que o caráter de adaptação da malha A48 ainda não foi usado. Até então, o que se fez foi aplicar a malha a cada uma das CCs presentes no vídeo. Graças à grande similaridade existente entre as geometrias de uma mesma $\mathrm{CC}$ em quadros consecutivos, tem-se uma grande expectativa com relação ao uso desta característica da malha dinâmica adaptativa. Algumas idéias já foram desenvolvidas neste sentido conforme pode ser visto na descrição presente na seção seguinte.

\section{Trabalhos Futuros}

Para finalizar, são apresentados alguns problemas em aberto bem como algumas linhas de pesquisa que surgem conforme considerações relacionadas aos resultados obtidos nesta dissertação. São propostos possíveis caminhos para a resolução dos mesmos. A partir de uma pesquisa bibliográfica feita, pretende-se dar continuidade 
ao estudo aprofundado tanto dos algoritmos a serem usados quanto do estado da arte na área.

Algoritmos para lidar com objetos fixos e rígidos já foram desenvolvidos. Assim, objetiva-se tanto estudar o comportamento de tais algoritmos nos objetos especificados, determinando as maiores falhas e estipulando as melhorias a serem feitas, quanto pretende-se também estudar os efeitos do uso de tais algoritmos para fazer o casamento de objetos móveis e maleáveis, apontando eventuais falhas nos métodos atuais.

Em uma fase mais avançada do projeto, pretende-se explorar as características do sistema em aplicações práticas tais como detecção, rastreamento, segmentação, reconhecimento e reconstrução 3D de faces, dentre outras.

O desenvolvimento futuro visa um conteúdo áudio-visual baseado em objetos e contempla o conteúdo da cena 3D aumentada obtida com a incorporação da informação de geometria ao fluxo de vídeo. O desafio final é a reconstrução tridimensional de objetos móveis e maleáveis a partir de vídeo 3D em tempo real, por meio da integração dos dados finais obtidos após o registro. Esse passo consistirá na integração das imagens de profundidade registradas em um único modelo de superfície conectada. Tal processo primeiro tira vantagem das porções de sobreposição para determinar como as diferentes imagens de profundidade podem ser combinadas e então eliminar as redundâncias nas áreas de sobreposição. Esse problema ainda não foi resolvido completamente. Outra preocupação é a aceleração do processo de rastreamento via filtro de Kalman que, aliado ao algoritmo ICP, permitirá uma exploração da coerência espaço-temporal.

Faz-se necessária a utilização de medidas para avaliação de o quanto a suposição de pouco movimento entre os quadros afeta os resultados. Até então, as melhorias foram notadas por meio de supervisão visual por parte dos pesquisadores. Após ser dada como finalizada a solução de toda a parte teórica, nossa preocupação recairá sobre a otimização do código.

Parte do trabalho futuro consistirá na determinação de quais tipos de problemas 2D podem ser solucionados através do uso de dados 3D obtidos. Tais questões poderiam constituir uma aplicação do vídeo $3 \mathrm{D}$ em problemas de visão computacional, e.g., oclusão de objetos, segmentação, reconhecimento, etc.

Conforme discutido, a integração de dados envolve muitas idéias e técnicas, 
nas quais o essencial é usar a informação temporal de quadros passados em uma determinada representação e adaptá-la ao que se tem no presente para que seja feita uma integração volumétrica. Técnicas de reamostragem podem ser usadas para a eliminação de ruídos. Além disso, toda a teoria desenvolvida para fotos 3D estáticas pode ser usada desde que seja passível de extensão para vídeos.

Um exemplo de trabalho ainda a ser feito é a utilização da coerência temporal em conjunto com a geometria e com a textura. A idéia é aproveitar o casamento da textura em quadros consecutivos para "preencher" partes da geometria, melhorando assim sua qualidade. Observe que, além de haver uma junção entre informações 2D e 3D, há também um caráter de memória envolvido, já que partes da geometria vista em quadros passados passam a compor a geometria no modelo correspondente ao quadro corrente.

Finalmente, um procedimento para a união de formas usando a informação de registro das CCs está atualmente em desenvolvimento. Com a conclusão de todas as atividades propostas, o sistema culminará num trabalho mais robusto e completo, com a possibilidade de atender a diversas aplicações. Para tanto, pretende-se logo de início criar uma interface gráfica que permita e facilite a interação do usuário com os dados. Juntamente com este desenvolvimento, uma nova plataforma de software será desenvolvida, tudo em um único ambiente e linguagem.

\subsubsection{ICP}

Embora o programa ICP adotado leve a resultados satisfatórios, parte de nosso trabalho atual está focado no aperfeiçoamento da implementação deste algoritmo de modo a permitir o registro de CCs em tempo real [Dalley, 2000; Gupta et al., 2002; Johnson \& Kang, 1996; Masuda \& Yokoya, 1995; Rusinkiewicz \& Levoy, 2001].

Conforme visto na revisão bibliográfica, o ICP é um algoritmo para rastreamento que converge para um máximo local e que pode ser muito bem aplicado a casos em que ocorre a intersecção de objetos, fazendo-se uma união na região comum. Um desafio deste estágio é a parte topológica, caso que trata, por exemplo, do que ocorre numa esfera quando, a partir de componentes que são desconexas no $\mathbb{R}^{2}$ se passa para componentes que são conexas no $\mathbb{S}^{2}$. 
O resultado do algoritmo ICP e o erro calculado por ele também podem ser usados para corroborar e avaliar diversos passos do método apresentado, como por exemplo a correlação. Isso pode ser feito por meio do uso de todos os pontos salientes ou variando a quantidade destes.

O recente trabalho de Mitra et al. [2007] envolve a aplicação do ICP para o registro dinâmico de geometria, assunto diretamente relacionado com a presente pesquisa.

Em breve, pretende-se alterar e aperfeiçoar o código do ICP a partir de alguma biblioteca já implementada e disponível e, juntamente com o código do filtro de Kalman, desenvolver uma interface para trabalhar com os dados fornecidos pelo IMPA, culminando numa maior robustez para o sistema.

\subsubsection{Kalman}

O filtro preditivo de Kalman [Stenger et al., 2001; Welch, 2007] combina todos os dados de medida disponíveis, além do conhecimento prévio sobre o sistema e os dispositivos mensuradores, a fim de produzir uma estimativa dos valores das variáveis desejadas de tal modo que o erro seja minimizado estatisticamente.

Neste trabalho, o intuito de seu uso é acelerar todo o processo de registro de vídeo 3D por meio da combinação de diferentes fontes de dados disponíveis, a fim de predizer a posição e a pose das CCs em um quadro do vídeo em questão. Para tanto, o algoritmo deve basear-se nas posições verificadas em quadros anteriores, inferindo assim o movimento. Esse passo seria dado como um pré-processamento dos dados de entrada do algoritmo ICP.

A busca de uma aceleração do processo de rastreamento evidencia uma preocupação com a performance, o que vai ao encontro da manutenção da característica de execução em tempo real que o sistema possuía originalmente.

\subsubsection{A Malha Dinâmica Adaptativa A48}

Conforme foi visto no capítulo sobre a metodologia introduzida, a biblioteca de malha dinâmica adaptativa baseada em operadores estelares [Velho, 2004] já vem sendo usada para a geração de uma malha tridimensional em separado para cada CC identificada. 
Para que a malha seja considerada boa para as aplicações que podem surgir no avanço do vídeo 3D, ela deve possuir as seguintes características: adaptação à geometria dos objetos, independência com relação à câmera, capacidade de adaptação de um quadro a outro do vídeo e possuir triângulos gordos ${ }^{1}$.

\section{Triangulação}

Os dados do vídeo 3D são muito particulares: eles são estruturados segundo as linhas range em que temos a profundidade. Pode-se aproveitar esta mesma estrutura para a criação da triangulação a ser usada na malha 4-8, segundo uma quadrangulação regulada (triangulada de acordo com um critério para decisão de qual diagonal tomar). Logo, não se faz necessário aplicar um algoritmo de triangulação já conhecido, pois assim perde-se a estrutura que já se tem.

Apesar de a triangulação presente no visualizador de vídeo 3D possuir a vantagem de aproveitar (e manter) a estrutura dos dados, ela ainda não é a mais indicada para a geração da malha pelos seguintes motivos:

吼 é dependente da câmera;

a malha seria adaptada de acordo com a estrutura da câmera e não segundo a complexidade dos objetos na cena;

não há um controle referente ao número de polígonos usados para representar um objeto, e

mevido à grande diferença de resolução na horizontal e na vertical dos dados de geometria, os triângulos formados seriam muito "finos", ou seja, um dos ângulos seria agudo demais.

\section{Operações Sobre a Malha 4-8}

A biblioteca A48 fornece uma malha com estrutura semi-regular 4-8. Essa malha é baseada em operadores estelares, os quais permitem alterações na resolução e na estrutura de conectividade da mesma.

A malha pode sofrer dois processos básicos de transformação:

${ }^{1}$ Informalmente, diz-se que um triângulo é gordo quando nenhum de seus ângulos internos é agudo demais. O triângulo mais gordo possível é o equilátero. 
simplificação: Pode-se simplificar a malha em regiões do objeto em que a superfície é mais suave, em que não haja grandes complexidades ou detalhes na geometria.

refinamento: Pode-se refinar a malha fazendo uma interpolação dos dados amostrados. Contudo, isso não é interessante, pois não implica em ganho de informação. O que realmente vale a pena, e que está ligado à adaptação da malha no decorrer do vídeo, é o aproveitamento de informação de partes diferentes da geometria, a qual surge a partir de novas aquisições, de um quadro para outro.

\section{Em Busca da Triangulação e da Malha Ideais}

Como obter uma malha boa, com as características descritas acima, a partir dos dados do vídeo 3D? Uma maneira ingênua (e computacionalmente cara) seria aumentando a resolução da geometria na horizontal até que houvesse uma eqüidade com a resolução na vertical.

Um modo mais esperto é descrito nos passos a seguir:

(1) Analisar cada curva de faixa para saber o quanto se pode simplificar cada uma delas por meio da retirada de pontos. Parar quando o erro de Hausdorff (medida de erro entre dois conjuntos) total tornar-se inaceitável (segundo um limiar a ser adotado e testado empiricamente).

(2) Com a retirada de pontos, os dados não serão mais estruturados. Para obter a estrutura de volta, devemos fazer um refinamento de modo que todas as curvas possuam o mesmo número de pontos. Para tanto, pode-se usar como parâmetro um grau de aproximação dado pela distância mínima entre dois pontos em uma mesma curva.

(3) Baseando-se neste grau de aproximação, aumentar a resolução horizontal da geometria por meio da inserção de novas curvas obtidas por interpolação linear.

(4) Num novo espaço paramétrico $(u, j)$, em que $u$ é o número da linha na textura e $j$ é o número da transição entre faixas coloridas, fazer uma quadrangulação regular com os pontos $(u, j),(u+1, j),(u, j+1)$ e $(u+1, j+1)$. A decisão 
sobre qual das duas direções a diagonal da triangulação irá tomar deve basear-se em um de seus vizinhos já calculados.

(5) Criar a malha com a triangulação obtida.

(6) Partir para a simplificação. A malha A48 possui duas filas de prioridade. Retirar pontos destas filas e ir acumulando o erro quádrico. Somar um quarto da quádrica para cada vizinho. Parar quando o erro quádrico total tornar-se inaceitável ou quando o número de polígonos passar a ser pequeno demais para representar satisfatoriamente a superfície do objeto.

\section{Casamento e Adaptação de Malhas}

No decorrer do vídeo, é de se esperar que a malha torne-se cada vez melhor, representando com mais fidelidade os objetos presentes na cena. A exigência que é feita neste ponto é que a malha seja boa para sofrer adaptações conforme o surgimento de novas partes dos objetos, bem como o aumento de informação de geometria no intervalo entre as faixas.

De início, a idéia era gerar uma malha para cada quadro e fazer um casamento entre as malhas, gerando assim a adaptação. Todo este trabalho pode ser evitado se as duas nuvens de pontos de uma mesma $\mathrm{CC}$ em quadros consecutivos sofrerem um registro com o algoritmo ICP e a mesma transformação (rotação e translação) for aplicada aos pontos da malha. Na seqüência, calcula-se a projeção dos pontos da nuvem do quadro corrente sobre a malha transformada (rotacionada e transladada). Isso pode ser feito da seguinte forma:

para pontos da geometria do quadro corrente que, após sofrerem a projeção, caírem sobre polígonos da malha obtida até o quadro anterior, decidir se é necessário fazer um refinamento da malha (caso típico: movimentos de zoom, em que os objetos aproximam-se ou distanciam-se da câmera).

os outros pontos constituirão o crescimento da malha pelas bordas (caso típico: movimento lateral, em que os objetos movem-se em um plano paralelo ao plano da imagem capturada pela câmera).

Para lidar com o crescimento da malha, deve-se dar atenção especial às suas bordas. Mais especificamente, pode-se limitar-se a apenas dois dos quatro lados 
possíveis da borda: (em cima ou embaixo) e (esquerda ou direita). A escolha é definida pelo movimento feito pelos objetos.

Dar atenção especial às bordas pode ser entendido como manter a resolução da malha nessas regiões como a mais fina possível, ou seja, levando em conta a distância mínima calculada no procedimento de retirada de pontos das faixas. Isso deve ser feito sempre mantendo a estrutura 4-8 da malha.

Até então, discutiu-se sobre o refinamento e o crescimento da malha por meio da agregação de novos pontos da geometria. O procedimento de simplificação pode ser aplicado às regiões da malha cujos pontos não aparecem mais, isto é, cuja superfície não é mais amostrada no vídeo.

Em suma, um melhor conhecimento da classe de objetos à qual a malha será aplicada leva à possibilidade de se usar tais dados para uma melhor especificação da malha e das demais etapas a serem aplicadas sobre ela.

\subsubsection{Uso da Textura para o Rastreamento de CCs}

A informação de textura foi usada, até agora, para melhorar o casamento da geometria, mas ela também pode ser usada para melhorar o rastreamento das CCs.

A abordagem adotada e descrita neste documento envolve o rastreamento das CCs feito com base na diferença entre os dados de profundidade das regiões das CCs no quadro anterior que possuem intersecção com a CC em questão no quadro corrente. A idéia é também usar a textura no cálculo dessa diferença, fazendo as devidas normalizações e ponderando a importância de cada uma das partes.

Considerando que $d_{z}$ representa a distância na profundidade e $d_{t}$ a distância na textura, tem-se:

$$
d\left(c, c_{i}\right)=\alpha \cdot d_{z}\left(c, c_{i}\right)+(1-\alpha) \cdot d_{t}\left(c, c_{i}\right)
$$

Uma outra abordagem que também leva em conta a textura é o cálculo do fluxo ótico na mesma. Essa informação pode ser usada em conjunto com o algoritmo ICP e com o filtro de Kalman. 


Considerações Finais

O propósito inicial e, por isso mesmo, central da investigação feita, como já anunciado na introdução, foi o rastreamento e registro das CCs presentes em um vídeo 3D. Neste texto, foram apresentados os problemas encontrados bem como as soluções adotadas foram introduzidas e debatidas. O estudo se concentrou na melhoria do casamento da geometria por meio do casamento da textura, embora também tenha havido avanços no desenvolvimento de uma interface gráfica para visualização de vídeo 3D e na aplicação de uma malha às CCs.

Os resultados apresentados aqui indicam que há muito ainda a ser feito até que o conceito de vídeo 4D seja atingido. Conforme pode-se ver na seção anterior, são diversas as idéias que podem ser aplicadas de modo a tornar realidade o vídeo 4D.

Com este trabalho, espera-se ter contribuído para o avanço da ciência. Que seu conteúdo sirva de inspiração para novas idéias e de base para a evolução do sistema discutido. 



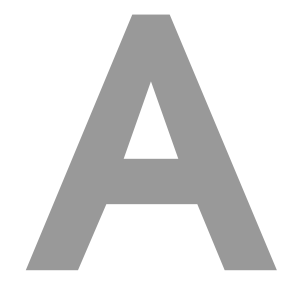

\section{Código Desenvolvido}

STE APÊNDICE trata de parte do código que foi desenvolvido durante o mestrado. Na Seção A.1 é explicado o código que faz o rastreamento de

$\mathrm{CCs}$, com ênfase nas constantes que tem influência direta no resultado e que devem ter seus valores atribuídos de forma empírica. Já na seção Seção A.2 há uma discussão acerca dos limites para armazenamento de vértices, arestas e faces necessários para a visualização da superfície de uma CC.

\section{Rastreamento de CCs}

O módulo de rastreamento de componentes conexas consiste de dois arquivos: concomp.c e concomp.h. Ele provê uma estrutura de dados boa para lidar com CCs, envolvendo armazenamento, mudança de propriedades e ações a serem feitas com elas.

Há diversas constantes que servem de parâmetros para os cálculos feitos para o rastreamento de CCs. As mais importantes são:

MAX_DIFF_Z: Indica a máxima diferença na coordenada de profundidade $z$ tal que a componente conexa seja considerada como sendo a mesma entre quadros consecutivos. É determinada empiricamente. Valores comuns: 1,5, 2.

MIN_INTERSEC: Indica a intersecção mínima que deve ocorrer para que uma componente conexa no frame anterior não seja considerada ruído. 
GRID_HEIGHT e GRID_WIDTH: O limite superior dessas constantes são a altura (em pixeis) da textura e o número de faixas projetadas. Quanto mais próximos desses valores, mais precisos e lentos são os resultados. Devem ser testados e determinados empiricamente.

MAX_LABELS: São considerados rótulos no intervalo [0, MAX_LABELS - 1], de acordo com o software que já havia sido desenvolvido. Atualmente, os rótulos são escolhidos aleatoriamente neste intervalo. $\mathrm{O}$ ideal seria que eles representassem cores que fossem facilmente distinguidas por seres humanos, implicando num intervalo com menos de 1024 possibilidades.

Duas imagens simplificadas, grid1 e grid2, são usadas para calcular a intersecção entre CCs dos quadros passado e corrente. Em cada posição é armazenado o rótulo de um ponto na geometria cujas coordenadas da textura são normalizadas para as dimensões da grade.

in t grid1 [GRID_HEIGHT][GRID_WIDTH]; in t grid2 [GRID_HEIGHT] [GRID_WIDTH] ;

As duas grades acima estão relacionadas a outras duas: grid1z e grid2z. Elas armazenam a coordenada $z$ de cada ponto geométrico. O campo usado é VIDEO4D-ZC, o qual informa a profundidade do ponto na imagem com relação à câmera.

double grid1z [GRID_HEIGHT][GRID_WIDTH]; double grid2z [GRID_HEIGHT][GRID_WIDTH];

A matriz intersection é indexada pelos rótulos das CCs. Inicialmente com todas suas posições valendo zero, ela contém o número de vezes que cada rótulo da grade 2 (índice das linhas) intersecta com cada rótulo da grade 1 (índice das colunas).

$\underline{\text { int }}$ intersection [MAXLABELS][MAXLABELS];

Já na matriz intersection_max, que também é indexada pelos rótulos das CCs armazenadas na grade 2, cada elemento contém o tamanho da máxima intersecção para cada rótulo.

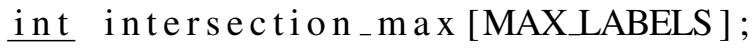


O tamanho de cada CC é armazenado na matriz intersection_total:

$\underline{\text { int }}$ intersection_total [MAX_LABELS];

A matriz error acumula a soma do valor absoluto da diferença entre as coordenadas $z$ armazenadas nas matrizes gridlz e grid2z. No final do programa, ao calcular o mapeamento, esse erro é normalizado pelo tamanho das intersecções entre os rótulos.

double error [MAXLABELS][MAXLABELS ];

$\mathrm{O}$ arquivo de cabeçalho concomp. h provê a seguinte interface:

void TrackCCsOnFrame (VIDEO4D *video4d, unsigned \ 1

$\rightarrow$ int firstFrame);

Esta função percorre todos os pontos geométricos do frame corrente de um vídeo 3D, alterando os rótulos das componentes conexas de acordo com os rótulos do quadro precedente. Ao final, o mapeamento realizado resulta no efeito de um rastreamento executado sobre as componentes conexas.

A chamada para essa função é feita no procedimento ProcesscurrentFrame do arquivo main. c da seguinte forma:

TrackCCsOnFrame (\&control $\rightarrow$ video4d, 1);

O processamento do primeiro quadro é especial no sentido de que deve-se alocar espaço na memória para todas as estruturas desenvolvidas para lidar com CCs, fazer uma verificação dos parâmetros iniciais para confirmar que estão dentro dos limites estabelecidos.

A cada novo quadro que é processado, a informação contida nas grades grid2 e grid2 z são copiadas para grid1 e grid1z, respectivamente. Na seqüência, para cada posição da grade, verifica-se o rótulo e incrementa-se as respectivas intersecção e intersecção total, além de se fazer o cálculo da diferença de profundidade. Essas informações são suficientes para calcular a intersecção máxima entre as CCs presentes na grade 2 com todas as CCs da grade 1.

Para o cálculo do mapeamento, que é o que informa o rastreamento das CCs, primeiramente é necessário verificar se a intersecção máxima de uma CC com rótulo $i$ na grade 2 com todas as componentes da grade 1 é menor que a constante 
MIN_INTERSEC. Se isso ocorrer, devemos ser mais flexíveis, passando a aceitar essa intersecção máxima para o rastreamento e não simplesmente desprezá-la, considerando que houve ruído nos dados de entrada.

Uma vez descartadas as intersecções insignificantes, pode-se selecionar a CC do quadro anterior que minimiza a somatória da diferença de profundidade para cada ponto presente na intersecção. Se após essa minimização a diferença é maior que a constante MAX_DIFF_Z, então considera-se que a CC é nova na cena. Caso contrário, ela receberá o rótulo da $\mathrm{CC}$ que minimizou a somatória, sendo assim feito o rastreamento.

O código do vídeo 3D roda em tempo real. A execução do código de rastreamento de CCs atrasa em muito o processamento. Para reduzir a quantidade de dados processados e assim obter uma maior velocidade, foi criada uma grade representativa da imagem do vídeo 3D. O número de linhas e de colunas dessa grade não deve ultrapassar o número de linhas e de colunas da textura. Quanto menor a resolução da grade, em menos tempo e com menor precisão é feito o rastreamento.

\section{Limitação do Número de Faces e de Arestas em Relação ao Número de Vértices}

Ao criar malhas para visualização dos dados oriundos de um vídeo 3D é necessário, a partir dos vértices, criar arestas e faces. Dependendo da biblioteca usada, a alocação de espaço em memória é estática, de modo que deve-se fornecer a quantidade de vértices, arestas e faces que serão necessários para a aplicação.

O número de vértices é facilmente calculado a partir dos dados do vídeo 3D. Já para o número de arestas e faces podemos encontrar limitantes inferior e superior.

Dado que a superfície fornecida para cada CC é $2 \frac{1}{2} \mathrm{D}$, pode-se tomar a projeção da mesma sobre um plano, ou seja, tais superfícies são planares. Sendo assim, podemos fazer uso da fórmula de Euler no plano:

$$
V-A+F=1
$$

Uma vez que cada aresta pode fazer parte de uma única face ou de no máximo 
duas e já que todas as faces em uma triangulação possuem três arestas, podemos afirmar:

$$
A \leq 3 F \leq 2 A
$$

Como uma superfície $2 \frac{1}{2} \mathrm{D}$ não pode representar um volume 3D fechado, podemos inclusive tirar a igualdade da segunda inequação acima, pois sempre existirão arestas de borda, as quais fazem parte de apenas uma face.

As duas inequações acima podem ser reduzidas a uma equação com um parâmetro variando em um determinado intervalo:

$$
\begin{gathered}
F=\frac{1}{3} A+\alpha A \\
F=\left(\frac{1}{3}+\alpha\right) A,
\end{gathered}
$$

com $0 \leq \alpha \leq \frac{1}{3}$

Substituindo essa expressão para $F$ na fórmula de Euler acima, temos:

$$
\begin{gathered}
n-A+\left(\frac{1}{3}+\alpha\right) A=1 \\
A=\frac{n-1}{\frac{2}{3}-\alpha}
\end{gathered}
$$

Se o interesse é por um limite superior para alocação de um vetor, os tamanhos máximos a serem necessários para armazenar as arestas e as faces são obtidos quando $\alpha$ tem seu valor máximo $\frac{1}{3}$, resultando em:

$$
\begin{aligned}
& A_{\max }=3(n-1) \\
& F_{\max }=2(n-1)
\end{aligned}
$$





\section{Referências Bibliográficas}

Agin, G. J. \& Binford, T. O. (1973). Computer descriptions of curved objects. In: Proc. Int. Joint Conf. on Artificial Intelligence.

ANJYO, K. (1997). Tour into the picture. Electronic Theater in SIGGRAPH 97 sediado em Los Angeles, Califórnia.

Asada, M., ICHIKawa, H. \& Tsuji, S. (1986). Determining of surface properties by projecting a stripe pattern. In: Proc. Int. Conf. on Pattern Recognition.

AsADA, M., ICHIKAWA, H. \& TsujI, S. (1988). Determining surface orientation by projecting a stripe pattern. IEEE Trans. Pattern Anal. Mach. Intell. 10(5), 749-754.

AsADA, M. \& Tsuji, S. (1985). Utilization of a stripe pattern for dynamic scene analysis. In: Proc. Int. Joint Conf. on Artificial Intelligence.

Azevedo, E. \& Conci, A. (2003). Computação Gráfica: Teoria e Prática. São Paulo: Editora Campus.

Barnard, S. T. \& Fischler, M. A. (1982). Computational stereo. Computing Surveys 14(4), 553-572.

Batlle, J., Mouaddib, E. \& SAlvi, J. (1998). Recent progress in coded structured light as a technique to solve the correspondence problem: A survey. Pattern Recognition 31(7), 963-982.

BECCARI, C. (1997). Typesetting mathematics for science and technology according to ISO 31/XI. TUGboat: The Communications of the $T_{E} X$ Users Group 18(1), 39-48.

Besl, P. J. (1988). Active, optical range imaging sensors. Machine Vision Applications 1, 127-152.

BESL, P. J. \& JAIN, R. C. (1986). Invariant surface characteristics for 3D object recognition in range images. Comput. Vision Graphics Image Process 33, 33-80. 
Besl, P. J. \& MCKAY, N. D. (1992). A method for registration of 3-D shapes. IEEE Transactions on Pattern Analysis and Machine Intelligence 14(2), 239-256.

Botsch, M., Steinberg, S., Bischoff, S. \& Kobbelt, L. (2002). OpenMesh - a generic and efficient polygon mesh data structure. In: OpenSG PLUS Symposium.

Bowden, R., Mitchell, T. \& Sahardi, M. (1997). Real-time dynamic deformable meshes for volumetric segmentation and visualization. In: Proc. BMVC.

Brady, J. P., Nandhakumar, N. \& Aggarwal, J. K. (1988). Recent progress in the recognition of objects from range data. In: Proceedings of International Conference on Pattern Recognition, vol. 88.

CApson, D. W. \& Eng, S. (1988). A tiered-color illumination approach for machine inspection of solder joints. IEEE Transactions on Pattern Analysis and Machine Intelligence 10(3), 387-393.

Carvalho, P. C., Velho, L., Sá, A., Medeiros, E., Montenegro, A. A., Peixoto, A. \& EscribA, L. A. R. (2005). Fotografia 3D. Luiz Velho e Paulo Cezar Carvalho (eds.).

Chen, C., Hung, Y. \& Chung, J. (1998). A fast automatic method for registration of partially-overlapping range images. IEEE Internacional Conference on Computer Vision 13(2), 119-152.

Chen, Y. \& Medioni, G. (1992). Object modeling by registration of multiple range images. Image and Vision Computing 14(2), 145-155.

DALLEY, G. (2000). A Software Test-bed for the Registration of 3D Range Images. Master's thesis, Ohio State University.

Darlin, J. S., Senthilkumaran, P., Bhattacharya, S., Kothiyal, M. P. \& SIROHI, R. S. (1996). Fabrication of an array illuminator using tandem Michelson interferometers. Opt. Commum. 123, 1-4. 
Fabri, A., Giezeman, G.-J., Kettner, L., Schirra, S. \& Schonherr, S. (2000). On the design of CGAL a computational geometry algorithms library. SP\&E 30(11), 1167-1202.

Faraco, C. E. \& Moura, F. M. (1992). Gramática Nova. Editora Ática S.A. Segunda tiragem.

Faugeras, O. (1993). Three-Dimensional Computer Vision: A Geometric Viewpoint. Cambridge, MA: MIT Press.

FAugeras, O. \& HeBert, M. (1986). The representation, recognition, and locating of 3D shapes from range data. The International Journal of Robotics Research 5(3), 27-52.

FAugeras, O. D. \& Toscani, G. (1986). The calibration problem for stereo. In: Proc. Computer Vision and Pattern Recognition.

Ferreira, A. B. D. H. (1986). Novo Dicionário da Língua Portuguesa. Rio de Janeiro: Editora Nova Fronteira S. A., segunda ed. 40a impressão.

FINCH, C. (1984). Special Effects: Creating Movie Magic. New York: Abbeville Press.

Frueh, C. \& ZAKhor, A. (2005). Capturing $2 \frac{1}{2}$ D depth and texture of timevarying scenes using structured infrared light. In: 3DIM.

GARLAND, M. (1999). Multiresolution modeling: Survey \& future opportunities. In: Eurographics'99, State of the Art Report (STAR).

GLÜCKSTAD (1995). Adaptative array illumination and structured light generated by spatial zero-order self-phase modulation in a Kerr medium. Opt. Commun 120, 194-203.

Grant, I., Zhao, Y., Smith, G. H. \& Stewart, J. N. (1995). Split-screen, single-camera, laser-matrix, stereogrammetry instrument for topographical water wave measurements. Appl. Opt. 34(19), 3806-3809. 
Gross, M., Würmlin, S., Naef, M., Lamboray, E., Spagno, C., Kunz, A., Koller-Meier, E., Svoboda, T., Gool, L. V., Lang, S., Strehlke, K., Moere, A. V. \& StAADT, O. (2003). Blue-c: A spatially immersive display and 3D video portal for telepresence. ACM Transactions on Graphics 22(3), 819-827.

Gupta, S., Sengupta, K. \& Kassim, A. A. (2002). Compression of dinamic 3D geometry data using iterative closest point algorithm. Computer Vision and Image Understanding 87, 116-130.

Hall, E., Tio, J. B. K., McPherson, C. A. \& Sadjadi, F. A. (1982). Measuring curved surfaces for robot vision. Computer, 42-54.

Haralick, R. M. \& Shapiro, L. G. (1982). Computer and Robot Vision II. Addison-Wesley, Reading, MA.

HATA, S. (1992). Shape detection of small specular surface using color stripe lighting. In: Proc. Int. Conf. on Pattern Recognition.

Hebert, M., Ikeuchi, K. \& Delingette, H. (1995). A spherical representation for recognition of free-form surfaces. IEEE Transactions on Pattern Analysis and Machine Intelligence 17(7), 681-690.

Hoffman, R. \& JAIn, A. K. (1987). Segmentation and classification of range images. IEEE Transactions on Pattern Analysis and Machine Intelligence 9(5), 608-620.

Hoppe, H. (1998). Efficient implementation of progressive meshes. Computer and Graphics 22(1), 27-36.

Hoshino, J., Uemura, T. \& MASUdA, I. (1990). Region-based reconstruction of an indoor scene using an integration of active and passive sensing techniques. In: Proc. Int. Conf. on Computer Vision.

HSIEH (2001). Decoding structured light patterns for three-dimensional imaging systems. Pattern Recognition 34(2), 343-349. 
Hu, G., Jain, A. K. \& Stockman, G. (1986). Shape form light stripe texture. In: Proc. Computer Vision and Pattern Recognition.

Hu, G. \& Stockman, G. (1989a). 3-D surface solution using structured light and constraint propagation. IEEE Transactions on Pattern Analysis and Machine Intelligence 11(4), 390-402.

Hu, G. \& Stockman, G. (1989b). Representation and segmentation of a cluttered scene using fused edge and surface data. In: Proc. Computer Vision and Pattern Recognition.

Huang, P. S., Zhang, C. \& Chiang, F.-P. (2003). High-speed 3-D shape measurement based on digital fringe projection. Optical Engineering 42(1), $163-168$.

IKEUCHI, K. \& SATO, K. (1991). Determining reflectance properties of an object using range and brightness of images. IEEE Transactions on Pattern Analysis and Machine Intelligence 13(11), 1139-1153.

JARVIS, R. (1993). Range Sensing for Computer Vision, vol. 1 of ThreeDimensional Object Recognition System, A. K. Jain and P. J. Flynn, editores, Advances in Image Communication. Amsterdam: Elsevier Science Publisher.

JARVIS, R. A. (1983). A perspective on range finding techniques for computer vision. IEEE Transactions on Pattern Analysis and Machine Intelligence 5(2), $122-139$.

Johnson, A. \& Hebert, M. (1997). Surface registration by matching oriented points. Conference on Recent Advances in 3D Digital Imaging and Modeling, $121-128$.

Johnson, A. \& KANG, S. B. (1996). Registration and integration of textured 3D data. Cambridge Research Laboratory - Technical Report Series .

Kemmotsu, K. \& Kanade, T. (1992). Sensor placement design for object pose determination with three light-stripe range finders. Research Report No. CMUCS-94-152, School of Computer Science, Carnegie Mellon University . 
Kemmotsu, K. \& Kanade, T. (1995). Uncertainty in object pose determination with three light-stripe range measurements. IEEE Trans. Robotics Automation 11(5), 741-747.

Klette, R., Schlüns, K. \& Koschan, A. (2001). Computer Vision: ThreeDimensional Data from Images. Cingapura: Springer-Verlag.

Kobbelt, L. P., Bareuther, T. \& Seidel, H.-P. (2000). Multiresolution shape deformations for meshes with dynamic vertex connectivity. Computer Graphics Forum 19(3), 127-152.

Kon, F. (2006). Notas sobre escrita de textos na área de sistemas de computação na língua de camões. http://www.ime.usp.br/ kon/ Researchstudents/traducao.html.

Koninckx, T. P., Griesser, A. \& Gool, L. V. (2003). Real-time range scanning of deformable surfaces by adaptively coded structured light. In: Fourth International Conference on 3-D Digital Imaging and Modeling (3DIM03).

LICKORISH, W. B. R. (1999). Simplicial moves on complexes and manifolds. In: Proceedings of the Kirbyfest.

MAsudA, T. \& YokoYA, N. (1995). A robust method for registration and segmentation of multiple range images. Computer Vision and Image Understanding 61(3), 295-307.

Matusik, W., Buehler, C., Raskar, R., Gortler, S. J. \& McMillan, L. (2000). Image-based visual hulls. In: Proceedings of ACM SIGGRAPH 2000, Computer Graphics Proceedings, Annual Conference Series.

MEIER, E. B. \& ADE, F. (1998). Object detection and tracking in range image sequences by separation of image features. In: Proc. IEEE International Conference on Intelligent Vehicles.

Michaelis, H. (2000). Dicionário Ilustrado Michaelis-Inglês/Português. São Paulo: Companhia Melhoramentos de São Paulo. 
Mitra, N. J., Flöry, S., Ovsjanikov, M., Gelfand, N., Guibas, L. \& Pottmann, H. (2007). Dynamic geometry registration. In: Eurographics Symposium on Geometry Processing.

Nahata, H. R. \& Murdocca, M. (1996). Decomposition of two-dimensional microlaser patterns. Appl. Opt. 35(8), 1195-1204.

Ozeki, O., Nakano, T. \& Yamamoto, S. (1986). Real-time range measurement device for three-dimensional object recognition. IEEE Trans. Pattern Anal. Mach. Intell 8(4), 550-554.

Pires, D. D. S., Cesar-JR, R. M., Vieira, M. B. \& Velho, L. (2005). Tracking and matching connected components from 3D video. In: Proceedings of 18th Brazilian Symposium on Computer Graphics and Image Processing (SIBGRAPI). Natal, Rio Grande do Norte, Brasil: IEEE Computer Society Press.

Popescu, V., Sacks, E. \& Bahmutov, G. (2004). Interactive point-based modeling from dense color and sparse depth. In: SPBG'04 Symposium on PointBased Graphics.

Popplestone, R. J., Brown, C. M., Ambler, A. P. \& Crawford, G. F. (1975). Forming models of plane-and-cylinder faceted bodies from light stripes. In: Proc. Int. Joint Conf. on Artificial Intelligence.

PULLI, K. (1999). Multiview registration for large data sets. Second International Conference on 3D Digital Imaging and Modeling , 160-168.

Rocker, F. \& KIESSLING, A. (1975). Methods for analyzing three dimensional scenes. In: Proceedings of International Joint Conference on Artificial Intelligence.

Rusinkiewicz, S., Hall-Holt, O. \& Levoy, M. (2002). Real-time 3D model acquisition. ACM Transactions on Graphics 21(3), 438-446.

RusinkiewiCZ, S. \& LEvoy, M. (2001). Efficient variants of the ICP algorithm. Third International Conference on 3D Digital Imaging and Modeling . 
Sanderson, A. C., Weiss, L. E. \& NAYAR, S. K. (1988). Structured highlight inspection of specular surfaces. IEEE Transactions on Pattern Analysis and Machine Intelligence 10(1), 44-55.

Sato, Y., Kitagawa, H. \& Fujita, H. (1982). Shape measurement of curved objects using multiple slit-ray projections. IEEE Transactions on Pattern Analysis and Machine Intelligence 4(6), 641-646.

SHIRAI, Y. \& SUWA, M. (1971). Recognition of polyedrons with a range finder. In: Proc. Int. Joint Conf. on Artificial Intelligence.

Shrikhande, N. \& Stockman, G. (1989). Surface orientation from a projected grid. IEEE Transactions on Pattern Analysis and Machine Intelligence 11(6), 650-655.

Silberschatz, A. \& Galvin, P. B. (2000). Sistemas Operacionais: Conceitos. São Paulo: Prentice Hall.

Silva, L., Bellon, O. R. P. \& Boyer, K. L. (2003). Robust multiview range image registration. In: Proceedings of SIBGRAPI, XVI Brazilian Symposium on Computer Graphics and Image Processing. CEFET - CPGEI, Curitiba/PR, Brasil.

Stenger, B., Mendonça, P. R. S. \& Cipolla, R. (2001). Model-based hand tracking using an unscented Kalman filter. In: Proceedings of British Machine Vision Conference, vol. I. Manchester, UK.

Stockman, G. \& Hu, G. (1986). Sensing 3-D surface patches using a projected grid. Comput. Vision Pattern Recognition, 602-607.

SÁ, A., Carvalho, P. C. \& Velho, L. (2002). (b, s)-BCSL: Structured light color boundary coding for 3D photography. In: Proceedings of 7th International Fall Workshop on Vision, Modeling, and Visualization.

Tanenbaum, A. S. \& Woodhull, A. S. (1997). Operating Systems: Design and Implementation. New Jersey: Prentice Hall, segunda ed. 
Velho, L. (2004). A dynamic adaptive mesh library based on stellar operators. Journal of Graphics Tools 9(2), 1-29.

VelHo, L. (2006). A48: A dynamic adaptive mesh library. http: / /w3 . impa . br/ lvelho/a $48 /$.

Velho, L. \& Gomes, J. (2000). Variable resolution 4-K meshes: Concepts and applications. Computer Graphics Forum 19, 195-212.

Velho, L., Vieira, M. B., Luz, J. L. S., SÁ, A. \& Carvalho, P. C. (2004). Real time 3D video. http://w3. impa.br/ lvelho/v3d-s 04 / $3 \mathrm{dv}$-poster.pdf.

Vemuri, B. C. \& AGgARWAL, J. K. (1986). 3-D model construction from multiple views using range and intensity data. In: Proc. Computer Vision and Pattern Recognition.

Vieira, M. B., Velho, L., SÁ, A. \& Carvalho, P. C. (2005). A cameraprojector system for real-time 3D video. In: Proceedings of IEEE International Workshop on Projector-Camera Systems (PROCAMS). San Diego, California, USA. Em conjunto com CVPR 2005.

WANG, Y. F. (1991). Characterizing three-dimensional surface structures from visual images. IEEE Transactions on Pattern Analysis and Machine Intelligence 13(1), 52-60.

WANG, Y. F. \& Cheng, D. I. (1992). Three-dimensional shape constriction and recognition by fusing intensity and structured light. Patter Recognition 25(12), $1411-1425$.

WANG, Y. F. \& LiANG, P. (1989). A new method for computing intrinsic surface properties. In: Proc. Computer Vision and Pattern Recognition.

WAng, Y. F., Mitiche, A. \& AgGarwal, J. K. (1987). Computation of surface orientation and structure of objects using grid coding. IEEE Transactions on Pattern Analysis and Machine Intelligence 9(1), 129-136. 
Welch, G. (2007). The Kalman filter. http://www.cs.unc.edu/ $\sim$ welch/kalman/.

Yamamoto, H., SATo, K. \& InOKUChi, S. (1986). Range imaging system based on binary accumulation. In: Proc. Int. Conf. on Pattern Recognition.

YANG, R. \& Pollefeys, M. (2003). Multi-resolution real-time stereo on commodity graphics hardware. In: Proceedings of Conference on Computer Vision and Pattern Recognition (CVPR 2003).

Yokoyama, A., Sato, K., Yoshigahara, T. \& Inokuchi, S. (1994). Realtime range imaging using adjustment-free phot-VLSI—silicon range finder. In: Proc. Int. Conf. on Intelligent Robots and Systems.

Zhang, L., Snavely, N., Curless, B. \& Seitz, S. M. (2004). Spacetime faces: High resolution capture for modeling and animation. ACM Transactions on Graphics 23(3), 548-558.

ZHANG, Z. (1994). Iterative point matching for registration of free-form curves and surfaces. International Journal of Computer Vision 13(2), 119-152. 


\section{Índice Remissivo}

$k$-vizinhos, 77

(b, s)-BCSL, 45-67

$2 \frac{1}{2} \mathrm{D}, \mathrm{xix}, 43$

2-D, xxiii

2D, veja 2-D

3-D, xxiii

3D, veja também 3-D, xxiii

análise, 20

animação, 4

aquisição, 17, 42

captura, 10

cena, 47

coordenadas, 20, 24

espaço, 22

manipulação, 42

mapa, 23, 32

modelagem, 7, 9, 45

reconstrução, 8

vídeo, 3-6

4-D, xxiii

4D, veja também 4-D, 43

A48, 36

adaptação

critérios de, 36

regras de, 36

algoritmo

ICP, xix, 9, 80, 82, 87

alinhamento

de geometria, xix

amostragem, 74

análise espaço-temporal, 45

analógico formato, 1

vídeo, 2

ângulo de visão, 5

animação

de corpos deformáveis, 36

animação 3D, 4

API, veja Application Program Interface

aplicações gráficas, 36

Application Program Interface, 37

aresta

bisecção, 38

inversão, 38

armazenamento, 36

balão inflável, 38

bidimensional, veja 2D

bit, 30, 31

borda

da cena, 24

de superfície, 30

detecção, 24

detecção de, 19

brilho, 30

código

comprimento, 47

de fronteira, 64

para fronteira, 46

câmera, 20

ideal, 20

parâmetros de, 19

parâmetros intrínsecos, 61

calibração, 17, 28 


\begin{tabular}{|c|c|}
\hline fotométrica, 42 & movimento, 6,10 \\
\hline geométrica, 42 & nova, 79 \\
\hline campos combinatórios, 38 & rastreamento, xix, $11-13,48,69$ \\
\hline canais de distribuição, 45 & 89 \\
\hline características & registro, 11, 14, 69-89 \\
\hline detecção, 70 & segmentação, 14 \\
\hline extração, 70 & compressão, xix, 2, 43 \\
\hline características salientes, xix & computação gráfica, 2, 36, 42, 69 \\
\hline casamento, xxiv, $6,30,45$ & consistência temporal, 72 \\
\hline casco convexo, 3 & coordenadas \\
\hline cena & $2 \mathrm{D}, 73$ \\
\hline $3 \mathrm{D}, 47$ & $3 \mathrm{D}, 24$ \\
\hline colorida, 31 & da câmera, 74 \\
\hline contínua, 31 & da imagem, 75 \\
\hline descontínua, 31 & de profundidade, 79 \\
\hline dinâmica, 19, 45 & do mundo, 8,74 \\
\hline mensuração, 31 & do projetor, 31 \\
\hline estática, 19, 29 & geral, 21 \\
\hline mensuração, 31 & global, 25, 26, 28, 74 \\
\hline centro de projeção, 74 & sistema de, 8 \\
\hline codificação, 30 & vetores de, 21 \\
\hline absoluta, 31 & cor, $3,6,18,31,45,70,85$ \\
\hline coerência espaço-temporal, 43, 47 & complementar, 47 \\
\hline coerência no tempo, 6,45 & constância, 30 \\
\hline componente conexa, 45, 69 & função de, 73 \\
\hline bordas, 14 & corpo \\
\hline candidata, 79 & rígido, 36 \\
\hline casamento, 10 & correlação, 81 \\
\hline casamento espacial, xix & alinhamento por, 82 \\
\hline detecção, xix, 76 & correspondência, 17, 19-32, 81 \\
\hline divisão de, 80 & cubo, 3 \\
\hline identificação, 12, 13 & \\
\hline intersecção, 78 & decodificação, 30 \\
\hline
\end{tabular}


deformável, xxiv

deformable, xxiv

dependência das descontinuidades, 30

dependência temporal, 29

descompressão, 2, 43

descontinuidade, 30

da profundidade, 30

descontinuidades, 30

detecção

de fronteira de faixas, 47

digital

formato, 1

vídeo, 1-3, 41

advento, 1

revolução, 1

distância

entre pontos, 9

quadrada média, 9

distância focal, 19-21, 74

dois $\mathrm{D}$, veja $2 \mathrm{D}$

dois e meio $\mathrm{D}$, veja $2 \frac{1}{2} \mathrm{D}$

domínio paramétrico, 73

efeitos especiais, 2, 4

eixo óptico, 21

espaço

$3 \mathrm{D}, 76$

da câmera, 76

discreto, 76

espaço do mundo, xix

espaço-temporal, 6

estéreo

ativo, $8,17,41,76$ passivo, 7, 17

passivo $\times$ ativo, 8

estereoscopia, 30

FEM, veja simulações de elemento finito

filtering, xxiv

filtração, xxiv

filtragem, xxiv, 19, 70

filtramento, xxiv

Finite Element Simulations, veja simulações de elemento finito

forma, 43,72

formas

reconstrução de, 19

formato

analógico, 1

de arquivo, 2

digital, 1

generator lock, 47

genlock, 47

geometria, xix, 13, 70, 81

alinhamento, xix, 75

aquisição, 7

captura, 47

casamento de, 11

construção incremental, 43

detecção, 48

dinâmica, 43

integração de, 10

interpolação, 12, 13

reconstrução, 47

resolução, xix, 11 


\begin{tabular}{|c|c|}
\hline suavização, 38 & registro, 7-9 \\
\hline grade, 28 & resolução, 2 \\
\hline de linhas, 24 & imagens range, 43 \\
\hline de pontos, 24 & IMPA, 14, 43, 45 \\
\hline projeção de, 24 & integração, 9 \\
\hline grafo & integração geométrica, xix \\
\hline de conexão de pontos, 76 & internet, 2 \\
\hline isolado, 76 & interpolação, 13, 64, 74 \\
\hline hexágono, 3 & $\begin{array}{l}\text { intersecção } \\
\text { mínima, } 79\end{array}$ \\
\hline $\mathrm{ICP}$, veja algoritmo ICP & Iterative Closest Point, veja algoritmo \\
\hline iluminação, 19 & $\mathrm{ICP}$ \\
\hline $\begin{array}{l}\text { sistema de, } 24 \\
\text { iluninação }\end{array}$ & jargão, xxiii \\
\hline de meio-plano, 24 & lente, 20 \\
\hline imagem & limiar, 76 \\
\hline alinhamento, 70 & de distância máximo, 79 \\
\hline aquisição, 19 & linha \\
\hline binária, 24 & reta, 28 \\
\hline captura, 7 & luminância, 6 \\
\hline combinação, 64 & luz \\
\hline consecutiva, 47 & ambiente, 8 \\
\hline correspondência, 8 & branca, 47 \\
\hline costura, 70 & de iluminação, 31 \\
\hline de alcance, xxiv & de projeção, 28 \\
\hline de intensidade, 24 & de referência, 29 \\
\hline de profundidade, xix, xxiv, $8,71,79$ & emitida, 31 \\
\hline deformações, 20 & estruturada, xix, xxiv, 9, 18, 19-32, \\
\hline diferença, 47 & 43,46 \\
\hline dinâmica, 19 & código, 20 \\
\hline integração, 7 & padrão de, 29 \\
\hline profundidade, 9 & fonte de, 23,31 \\
\hline projeção, 25 & intensidade, 29 \\
\hline
\end{tabular}


padrão de, 23

pontual, 32

projetada, 29

máscara de sombra, 47, 64

máximo local, 88

métodos probabilísticos, 43

mínimo

global, 9

local, 9

mínimo local, 88

maleável, xxiv

malha

4-K hierárquica, 38

dinâmica, 13, 36-39

genérica, 38

infraestrutura, 37

poligonal, 36

progressiva, 38

representação, 36

resolução, 38

semi-regular, 37

malleable, xxiv

mapeamento, 79

matiz, 30

MATLAB ${ }^{\circledR}, 89$

Matrix, 4

matrix

de rotação, 28

matriz

de blocos, 32

de microlaser, 32

de pontos, 28,31 ortonormal, 22

meia-aresta, 36, 37

modelagem

$3 \mathrm{D}, \mathbf{7}, \mathbf{9}, 45$

modelagem geométrica, 36

modelo

de superfície, 9

tridimensional, xix, 6, 15

alinhamento, 81

modelo pinhole, 20

movimento

detecção, 48

movimentos estelares, 38

multi-triangulação binária restrira, 38

multiescala progressiva, 36

multiresolução, 38

representação, 38

multiresolução semi-regular, 36, 37

nível de cinza, 70

NTSC, 45, 47

Nyquist, 72

objeto

$2 \mathrm{D}, 70$

$3 \mathrm{D}, 43$

colorido, 31

curvilíneo, 24

deformável, xix, 43

embutido em volume, 43

estático, xixn

móvel, xix, 14

maleável, 14

movimento, 64 


\begin{tabular}{|c|c|}
\hline não-rígido, 43 & parametrização, 74 \\
\hline poliédrico, 23 & período, 30 \\
\hline rígido, xixn & pixel, 4, veja sub-pixel, 74 \\
\hline tridimensional, 3,19 & plano, 3 \\
\hline oclusão, $7,23,28$ & ponto \\
\hline ondas do mar, 32 & único, 28 \\
\hline opacidade, 29 & conexo, 76 \\
\hline nível de, 29 & de referência, 30 \\
\hline OpenMesh, 39 & focal, 22 \\
\hline operadores de aresta, 38 & saliente, $75,81,86$ \\
\hline operadores estelares, $13, \mathbf{3 6}-\mathbf{3 9}$ & singular, 30 \\
\hline orientação, 28 & ponto focal, 19, 26 \\
\hline & ponto saliente \\
\hline padrão, 82 & identificação, 82 \\
\hline codificação, 28 & pontos \\
\hline complementar, 46 & correspondentes, $9,11-13$ \\
\hline de faixas, 46 & distância entre, 9 \\
\hline de luz & nuvem de, 13 \\
\hline absoluto, 30 & registro, 12,13 \\
\hline binário, 29, 31 & salientes, $11-14$ \\
\hline colorido, 29 & pontos de oclusão, xix \\
\hline dinâmico, 29 & predictive, xxiv \\
\hline em nível de cinza, 29 & preditivo, xxiv \\
\hline estático, 29 & preditor, xxiv \\
\hline periódico, 30, 31 & processamento de imagens, 2 \\
\hline de luz estruturada, 29 & profundidade, 3,6 \\
\hline de meio-plano, 24 & reconstrução, 45 \\
\hline padrões & projeção, 20, 21 \\
\hline análise de, 19 & codificada, 28 \\
\hline panoramas, 70 & de faixas ortogonais, 24 \\
\hline parâmetros & de grade, 24 \\
\hline extrínsecos, 74 & de linha estreita, 23 \\
\hline intrínsecos, 74 & de luz estruturada, 20 \\
\hline
\end{tabular}


de uma imagem, 25

projetor

parâmetros intrínsecos, 61

quatro D, veja 4-D

rótulo, 79

raio de visão, 74

range image, xxiv

range video, 43

razão de aspecto, 74

realçamento, 19

reconstrução 3D, 8

reconstrução de cenas, xix

reflexão, 28, 29, 31

aquisição, 7

aquisição de, 9

register, xxiv

registro, xix, xxiv, 8

inicial, 9

tridimensional, 11

renderização, 43

resolução, xix, 31, 32, 81, 82

restauração, 19

restrição epipolar, 23

restrição geométrica, 24

rotação, 22, 28, 74

ruído, 13,70

Scanalyze, 87

scanners laser, xxiv

segmentação, 19, 30, 32

sensor

óptico, 19-21 visual, 19

sensores

ópticos, 21

simulações de elemento finito, 36

sincronização, 45

sistema

estereoscópico, 20, 21

sistema estereoscópico, 25

som, 3

sub-pixel, 47

superfície

amostragem de, 36

com descontinuidade, 30

com textura, 30

contínua, 30

de forma fixa, 36

de Monge, 71

dinâmica, 32, 36

discretização de, 36

especular, 31

mensuração, 25, 26, 30

metálica, 31

oclusão, 28

profundidade, 30

refletora, 32

reflexão, 28, 29

representação, 36

triangulada, 36

taxa

de aquisição, 78

de vídeo, 89

taxa de aquisição, 72 


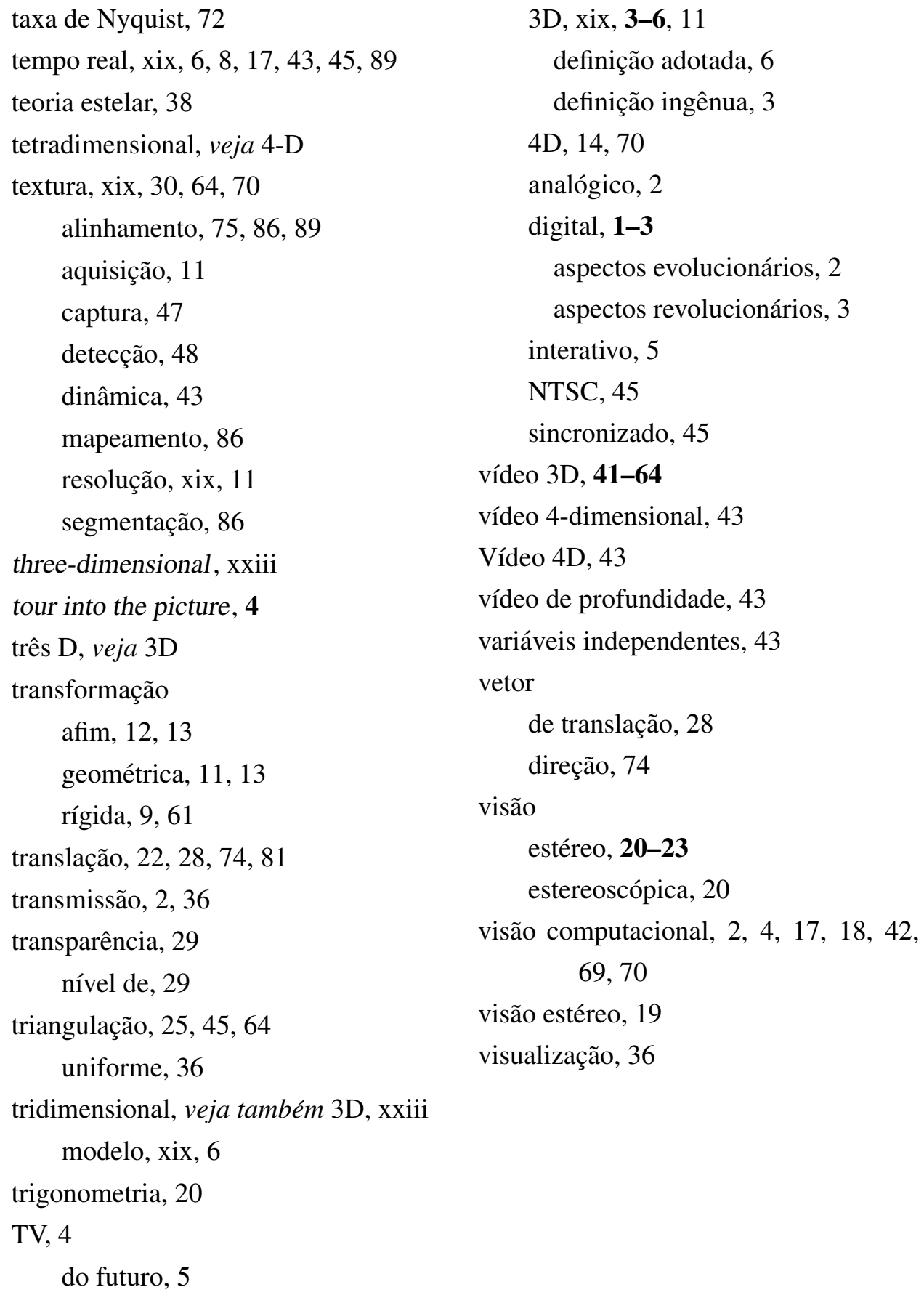




\section{Notas Finais}

Esta dissertação foi produzida usando-se a classe book do sistema de preparação de documentos LTEX (http: / / www. latex-project.org/) munida de diversos de seus pacotes, muitos baixados diretamente do CTAN (the Comprehensive TeX Archive Network-http://ctan.org/). A fonte é da família Times e possui corpo 11 com espaçamento um e meio. O estilo do leiaute é uma reunião desordenada de todas as coisas que fui aprendendo sobre tipografia e editoração.

O editor de texto usado sumariamente foi o GNU-Emacs (http://www . gnu.org/software/emacs/).

A maior parte das imagens foi manipulada por meio do programa GIMP (GNU Image Manipulation Program-http://www.gimp.org/). Também foram usados o Xfig, o gnuplot e o ambiente picture do $\mathrm{LTT}_{\mathrm{E} X}$. Para se retirar screenshots fez-se uso do programa ksnapshot.

Todas essas ferramentas foram usadas em uma rede turbinada com o sistema operacional Debian GNU/Linux (http: / www. debian.org/), atualmente na versão 3.1, codinome Sarge, com kernel versão 2.6.17.

A fase de escrita do texto foi muito prazerosa e divertida, repleta de aprendizados sobre redação, metodologia científica, programas para edição de imagens e processamento de texto, dentre outros. 